\title{
Conference presentations and academic publishing
}

Article

Accepted Version

Creative Commons: Attribution-Noncommercial-No Derivative Works 4.0

Gorodnichenko, Y., Pham, T. and Talavera, O. (2021)

Conference presentations and academic publishing. Economic Modelling, 95. pp. 228-254. ISSN 0264-9993 doi:

https://doi.org/10.1016/j.econmod.2020.12.017 Available at https://centaur.reading.ac.uk/97950/

It is advisable to refer to the publisher's version if you intend to cite from the work. See Guidance on citing.

To link to this article DOI: http://dx.doi.org/10.1016/j.econmod.2020.12.017

Publisher: Elsevier

All outputs in CentAUR are protected by Intellectual Property Rights law, including copyright law. Copyright and IPR is retained by the creators or other copyright holders. Terms and conditions for use of this material are defined in the End User Agreement.

\section{www.reading.ac.uk/centaur}

\section{CentAUR}

Central Archive at the University of Reading

Reading's research outputs online 


\title{
CONFERENCE PRESENTATIONS AND ACADEMIC PUBLISHING
}

\author{
Yuriy Gorodnichenko* $\quad$ Tho Pham** $\quad$ Oleksandr Talavera***
}

\begin{abstract}
This study contributes to the existing literature on the impact of conference presentations on career progression by quantifying the predictive power of conferences for publication success. Examining outcomes for more than 4,000 papers presented at three leading economics conferences over the 2006-2012 period, we find a positive link between conference presentations and the publishing probability in high-quality journals. This impact is most profound for prominent authors and male authors. In contrast, lesser known authors and female authors appear to gain less from conferences. Additionally, participating in major conferences is also associated with improved metrics for other measures of academic success such as the number of citations or abstract views. Further examination shows that annual meetings of the American Economic Association are particularly valuable in these dimensions.
\end{abstract}

Keywords: conferences, publishing outcomes, research visibility, professional development, gender effects

JEL codes: I23, O39

* Email: ygorodni@econ.berkeley.edu. Address: Department of Economics, University of California, Berkeley CA 94720-3880, US.

** Email: t.pham@reading.ac.uk. Address: Department of Economics, University of Reading, RG6 6UR, UK.

*** Email: o.talavera@bham.ac.uk. Address: Department of Economics, Birmingham Business School, University of Birmingham, Birmingham B15 2TT, UK.

Standard disclaimer applies. We are grateful to the Editor and two anonymous referees for valuable comments and suggestions. We also thank the seminar participants at Cardiff University, University of Reading, University of Birmingham, IÉSEG School of Management, and Kyiv School of Economics for comments and Ideas.repec.org for sharing data. 


\title{
CONFERENCE PRESENTATIONS AND ACADEMIC PUBLISHING
}

\begin{abstract}
:
This study contributes to the existing literature on the impact of conference presentations on career progression by quantifying the predictive power of conferences for publication success. Examining outcomes for more than 4,000 papers presented at three leading economics conferences over the 2006-2012 period, we find a positive link between conference presentations and the publishing probability in high-quality journals. This impact is most profound for prominent authors and male authors. In contrast, lesser known authors and female authors appear to gain less from conferences. Additionally, participating in major conferences is also associated with improved metrics for other measures of academic success such as the number of citations or abstract views. Further examination shows that annual meetings of the American Economic Association are particularly valuable in these dimensions.
\end{abstract}

Keywords: conferences, publishing outcomes, research visibility, professional development, gender effects, discrimination

JEL codes: I23, O39 
"ASSA is the premiere event to expose your work with colleagues and hear about the latest research emerging in the field. Economists from around the world take advantage of this unique opportunity to share, collaborate, and learn... all in one place." American Economic Association ${ }^{1}$

"The Annual Conference is our flagship event. It brings together hundreds of academic and professional economists to present the latest developments in economics and showcase their real-world application." Royal Economic Society ${ }^{2}$

"The EEA Annual Congress, which takes place at the end of August - early September, is a main event among the Association's activities." European Economic Association ${ }^{3}$

\section{Introduction}

Every year, thousands of economists flock to conferences organized by prominent professional societies such as the American Economic Association (AEA), the European Economic Association (EEA), and the Royal Economic Society (RES). While participating in these gatherings is undoubtedly valuable, what exactly participants and, perhaps more importantly, presenters get from these events remains unclear. A growing number of studies have investigated the benefits of conferences and found a positive link between conference attendance and research productivity (e.g., Blau et al., 2010). Conferences also provide researchers with opportunities to expand their collaboration (Campos et al., 2018) and advertise their works (Leon and McQuillin, 2020). However, the publish-or-perish imperative of academic life likely dictates participation in these highly prestigious conferences and yet to what extent these annual rituals advance researchers in their attempts to publish in scholarly journals is poorly measured and understood.

In this study, we attempt to quantify the contribution of conference participation to publication outcomes and other metrics of academic success. We also try to identify which types of authors benefit from participating in conference and specifically whether conferences have differential implications for male vs. female researchers. This is an important aspect of our analysis given that economics has an apparent lack of diversity and that disadvantageous treatment of female researchers in conference settings could propagate existing inequities. To this end, we assemble a

\footnotetext{
${ }^{1}$ https://www.aeaweb.org/conference/about (Accessed on 29 January 2019)

2 https://www.res.org.uk/event-listing/annual-conference.html (Accessed on 29 January 2019)

3 https://www.eeassoc.org/index.php?page $=12$ (Accessed on 29 January 2019)
} 
comprehensive dataset that contains information related to conference attendance, paper statistics, and author statistics of papers presented at the annual conferences organized by AEA, EEA, and RES during the 2006-2012 period.

The main analyses and results are as follows. After documenting some facts for papers presented in a major conference and non-presented papers, we examine how our results change after we control for a variety of author and paper characteristics. We show that publication in any journal is not positively associated with conference participation. At the same time, being presented at any of the considered conferences is positively related to an increased probability of being published in a high-quality journal [where the quality is measured with the rankings by the Association of Business Schools (ABS) or by the Scientific Journal Ranking (SJR)]. The predicted increase in the probability is large: participating in an AEA/EEA/RES conference is associated with an 1.3-1.4 percentage point increase in the probability of publication in an excellent or top-tier (ABS $4 *$ ) journal such as American Economic Review, Econometrica, Journal of Political Economy, Journal of Monetary Economics, Review of Economics and Statistics, and similar journals when the unconditional probability of publishing in these journals is $2.1-5.2 \%$ in our sample. Compared to the impact of presentations on the likelihood of publications in ABS-ranked journals, the effect is more pronounced when we use journal quality according to SJR: presentation in a major conference is related to an increase of 2.8 percentage points in the likelihood of publications in the most prestigious (first quartile, Q1) journals (the unconditional probability of publishing in such journals is $16.3 \%$ ).

We document considerable heterogeneity in the contribution of conferences to publication outcomes: participating in an AEA conference predicts a 5.2 percentage point (!) increase in the probability of publishing in a top-tier (ABS $4 *$ ) journal while the corresponding figures for EEA and RES conferences are close to zero. The increased probability of publishing in SJR Q1 journals for papers presented at AEA, EEA, and RES conferences is 2.9, 2.1, and 2.6 percentage points, respectively. Interestingly, participating in a major conference is associated with longer publication times (approximately six additional months) for mid-rank journals (ABS 3 or SJR Q2 journals) but there is no difference for publication in a top journal (an ABS $4 *$ journal) or a low-rank journal.

After establishing the "aggregate" results, we examine whether publication success rates after presenting in a major conference are similar for female and male authors. This part of our analysis is important given that economics is a male-dominated field and available evidence (AEA 2019) suggests that female economists can find the field rather hostile. We document that presenting a paper authored by a female author does not predict a higher probability of publication in a top economics journal. In contrast, the probability for male authors is statistically and economically 
large. While we cannot interpret this evidence as causally establishing discrimination, the difference in success rates is troubling given other facts on the academic environment in economics.

Despite differences in how various fields of economics operate, we do not observe much variation in how conferences contribute to publication outcomes in e.g. macroeconomics vs. applied microeconomics. Likewise, we find no discernable contribution from sharing a session with a prominent ("star") scholar, that is, a greater attendance from having a famous economist in a session does not spill over into a greater probability of publication in any journal. Furthermore, there is a "prime time" for presentation, that is, some times/days of a conference (e.g., the last session of the last day) predict lower publication probabilities. We also study how conferences contribute to citations and abstract views, proxies for impact and visibility, and we find that conference participation is associated with increased values for these two statistics.

This study contributes to emergent literature on the production and dissemination of research (e.g., Ductor et al., 2014; Iaria et al., 2018; Waldinger, 2016) ${ }^{4}$ and is particularly related to studies investigating the relationship between conference attendance and publication outcomes. A large number of studies in medical sciences have examined the publication rates of the abstracts presented at a conference and provided mixed results (e.g., von Elm et al., 2003; Galang et al., 2012; Winnik et al., 2012; Tzanetakis et al., 2018). Some studies find a publication rate of 45-50\% (e.g., von Elm et al., 2003; Livas et al., 2014) while some others acknowledge a significantly lower publication rate of around 20\% or less (e.g., Miguel-Dasit et al., 2003; Collier et al., 2010; Galang et al., 2012). Contributing to this literature, our analysis provides a more comprehensive coverage of economics conferences and compares the differences in publication outcomes of both presented and nonpresented works of the same authors. Furthermore, due to the difference in the nature/format of medical and economics conferences, the channels through which conference presentations could lead to publications can be narrowed in the context of this study. More specifically, submissions (and subsequently presentations) to a medical conference only require abstracts, it is not uncommon that the authorships of presentations and of publications are different (Tzanetakis et al., 2018). Thus, the positive impacts of conference presentations on publishing could take place through either the feedback channel or the co-authorship expansion channel. In contrast, since an economics conference typically requires a full-length research paper for submission and presentation, it is unlikely that the co-authorship of the presented research changes after the conference. Hence, one

\footnotetext{
${ }^{4}$ See also Boudreau et al. (2017), Belenzon and Schankerman (2013), Ding et al. (2016), McCabe and Snyder (2015), Levin and Stephan (1991), Pinkowitz (2002).
} 
can rule out the possibility of expanding author team as a positive contribution to the publication outcomes.

To a lesser extent, our study is also related to the literature for STEM sciences (engineering, computer science, etc.) which examines the relative value of conference papers and proceedings compared to full-length journal publications (e.g., Frohlich and Resier, 2001; Bar-Ilan, 2010; Freyne et al., 2010). For example, the number of citations received by leading conference papers is larger than that of journal articles, especially the articles in lower-rank journals (Rahm and Thor, 2005; Freyne et al., 2010; Vrettas and Sanderson, 2015). In a recent study, Reinartz and Urban (2017) examine the link between conference presentations and publications from a different perspective: sorting conference quality based on the publication success of presented papers. ${ }^{5}$ Our main contribution to these studies is in (1) examining the contribution of conferences to journal publications; (2) investigating the link between conference presentation and paper impact and visibility; and (3) exploring potential heterogeneity in outcomes along a range of dimensions (e.g., seniority, fields, conferences, etc.).

The analysis of gender differences in the effects of conference presentations contributes to the on-going concerns and debates about under-presentation of women in academia generally and economics particularly. According to the report on gender diversity and inclusion in events (Bizzabo, 2018), less than one third of 60,000 randomly chosen speakers at professional and corporate events are women. Similarly, Hospido and Sanz (2020) find that papers of which co-authors are all females are less likely to be accepted to economics conferences compared to papers with mix-gender or allmale co-authorship. In addition, there have been also discussions and concerns about the seminar culture, credit for co-authorship, as well as bias in publishing and tenure process (Goldin and Guerrieri, 2019). ${ }^{6}$ For example, compared to male speakers, female speakers tend to receive more patronizing and hostile questions from audience (Dupas et al., 2020). Moreover, female economists are less likely to receive credit for co-authored papers (Sarsons et al., 2020). Thus, the more female economists co-author, the less likely they get tenure. In contrast, male economists receive tenure regardless of whether their research is co-authored or sole-authored. Further, female-authored papers are held to higher standards compared to male-authored papers (Card et al., 2020; Hengel and Moon, 2020). In addition to these gender differences, in this study, we show that there is also a difference

\footnotetext{
${ }^{5}$ While not focusing on conference presentation, Blau et al. (2010) find that the workshop participation is positively related to subsequent publication rates and successful grant applications.

6 See https://www.youtube.com/watch?v=oJOEYPaqTII\&fbclid=IwAR2GTd20Jzykf_3czcTHbbiEV31L6SqRDUeX37RJL5eg68ilNLmgElhaWY\&ab_channel=BeckerFriedmanInstituteatUChicago-BFI for the video of the panel discussion on "Women in Economics: Progress and Challenges",
} 
in the impacts of conference presentations on publishing outcomes of female- versus male-authored papers.

The rest of the paper is organized as follows. In Section 2, we will describe the data collecting and assembling processes. We also discuss the summary statistics of our assembled samples in this section. Section 3 presents the empirical specifications and result discussions. Finally, conclusion is provided in Section 4.

\section{Data and sample}

\subsection{Data collection and construction}

This section describes the processes of collecting and assembling data used in the analysis. In particular, we explain how we collected and screened the conference program database. Next, we describe the process of collecting and assembling IDEAS/RePEc dataset which has information on citations $^{7}$ and publication outcomes. Finally, we discuss how we match these two databases.

\subsubsection{Conference program data}

The collection and construction of the conference program dataset are as follows. First, we used a Python script to extract information from available online programs of three leading economic conferences in the U.K., Europe, and the U.S. namely the Royal Economic Society Conference, the Annual Congress of the European Economic Association, and the American Economic Association Annual Meeting over the 2006-2012 period. We restrict our analysis to these seven years because of availability of conference programs online and long lags in the publication process. The returned information includes (1) presentation date and time, (2) assigned session of the presentation, (3) presentation title, and (4) information on authors or presenters.

Second, using title matching algorithm, we linked a given paper presented in a conference to one version of a paper listed in IDEAS/RePEc. If the paper was never listed in IDEAS/RePEc, then the search result returned an empty link. In some cases, there are variations between the papers' titles listed in the conference program and the ones available in IDEAS/RePEc, thus the algorithm was not able to match downloaded links with presented papers. We hand-checked all these cases to create

\footnotetext{
${ }^{7}$ In Appendix, we provide results based on citation counts provided by Scopus.
} 
the most complete list of IDEAS/RePEc links of presented papers. ${ }^{8}$ The matched links then allowed us to extract each paper's RePEc handle, which is an important field to match conference program data with the IDEAS/RePEc statistics later. ${ }^{9}$

Third, we kept only papers that were presented in the parallel/contributed/general sessions (e.g., this excludes presidential addresses). Due to missing data for papers presented in the European Meeting of the Econometric Society (ESEM) sessions in 2010, we excluded all papers presented in ESEM sessions in all years to ensure consistency. ${ }^{10} \mathrm{We}$ further cleaned the conference program data by excluding (1) papers that were presented several times in the same conference and (2) papers that were assigned in a session but titles were not confirmed. The details of the number of presented papers and matched links for each conference by year are given in Table 1. In total, we found matched IDEAS/RePEc links for approximately $70 \%$ of conference papers.

\subsubsection{IDEAS/RePEc statistics}

We assembled our IDEAS/RePEc statistics using different data sources. First, the related work information that links the different versions of the same work to each other was collected. Second, we extracted the monthly downloads and abstract views as well as the citation statistics for all available papers. Third, the authorship information which also contains publication-related information, i.e. published year or the journal where the work was published was obtained.

We then performed the following steps to merge these statistics. First, we merged downloads and abstract views of individual documents to obtain the monthly download and abstract view statistics for all RePEc handles (not just the papers in our conference program database). Second, using the related work information, we constructed a dataset of related works that contains all pairwise combination of different versions of the same work. This allows us to aggregate the monthly downloads, abstract views, and citations for each paper. Third, we assembled a data set of publication statistics including (1) name and RePEc handle of the journal where the paper was published in, (2) the journal ranking in the Association of Business Schools' Academic Journal Guide 2015 (ABS ranking), (3) the journal quartile in the Scientific Journal Ranking (SJR), and (4) year of

\footnotetext{
${ }^{8}$ We performed a wide spectrum of checks to ensure the papers listed in IDEAS/RePEc and the papers presented at the conference(s) are the same. For example, the checks include (1) checking the papers' acknowledgement and (2) comparing the abstracts of papers listed in IDEAS/RePEc with the ones from the conferences.

${ }^{9}$ A RePEc handle is a unique id assigned by RePEc to each listed paper based on the archive code, the series code, and the item code.

${ }^{10}$ Our results are quantitatively similar if we include these papers in the analysis.
} 
publication. ${ }^{11}$ Fourth, we created a monthly citation dataset based on the one provided by RePEc, which gives the citation analysis for IDEAS/RePEc distributed documents. ${ }^{12}$ Finally, we matched monthly download, abstract view, and citation statistics of each paper with the monthly ranking of each author of the paper.

\subsubsection{Conference-related samples}

After matching data from different sources as described in Section 2.1.2, a comprehensive panel dataset that contains information for both presented and non-presented works of all IDEAS/RePEc authors who have at least one work presented at any conference in the conference program sample is assembled. This restriction is to ensure that we have a homogenous sample and also for computational purposes. During the matching process, further screening is required to get the most complete dataset for analysis. In particular, we screen data and check by hand information on journal publications and co-authorship for (1) cases in which the number of authors is not consistent across versions of the same work or missing and (2) cases in which the published years for published works are missing. After screening, our data contains more than 13.6 million observations pertaining paper-author-month.

In the next step, we assemble two inter-related samples from this main dataset. The first sample is cross-sectional data at the paper-author level (sample of conference authors' works). Since our conference program data start in 2006, any publications prior to 2006 are not included. We also exclude (1) non-presented papers that were made available in IDEAS/RePEc after 2012 the last year in our conference program data and (2) presented papers that were posted on IDEAS/RePEc after being published in a journal. In addition, we exclude papers that were published in the American Economics Review Papers and Proceedings, the Journal of the European Economic Association Papers and Proceedings, and conference special issues of the Economic Journal as well as those only available in IDEAS/RePEc after being published. This sample consists of 90,854 paper-author pairs. ${ }^{13}$

The second sample is a panel dataset of conference papers (papers that were presented in (at least) one of the conferences), which will be analyzed in the examination of the channels through

\footnotetext{
${ }^{11}$ Details on the ABS ranking can be found at https://charteredabs.org/academic-journal-guide-2018/. A brief discussion of different journal quality rankings is presented in Appendix B.

${ }^{12}$ The citation statistics in our data only account for the citations made by other IDEAS/RePEc listed documents.

${ }^{13}$ Although we did our best to assemble the most complete data set for analysis, we cannot rule out the possibility that the non-conference papers are posted in IDEAS/RePEc later than the conference ones i.e. non-conference papers are posted at the stage closer to publications.
} 
which conference presentation can affect presented papers' impacts and visibility. In this analysis, any papers of which the earliest version was listed in IDEAS/RePEc after being presented are excluded. After this cleaning step, our sample contains information for 2,832 papers.

\subsection{Data description}

Table 2 presents summary statistics for the conference-, authorship-, and publishing-related attributes of conference authors' papers in our data. Columns 1 and 2 show statistics for 65,465 nonpresented and 4,043 presented works respectively. ${ }^{14}$ The majority (about 94\%) of presented works were presented only once at a major conference. However, 239 papers were presented at two conferences and 8 papers appeared in all three major conferences.

Given the benefits of collaboration in promoting research productivity, it is not surprising to observe the dominance of co-authored papers in the sample: most papers are co-authored by two authors $(\approx 45-48 \%$ of papers). Co-authored papers with three authors account for around $27 \%$ of presented works and $24 \%$ of non-presented works. The shares for single-author papers are $19 \%$ and $23 \%$ for presented and non-presented works, respectively.

There are tangible differences in the publishing outcomes between presented and nonpresented works. The proportion of presented papers that turn into publications is about 1.5 times higher than that of non-presented papers ( $43.4 \%$ versus $24 \%$ ). Comparing the shares of high-quality publications, we also observe the significantly higher share among presented papers. In particular, nearly $7 \%$ of the presented works were published in the ABS $4 *$-ranked journals, which is 2.5 times higher than that of non-presented works. At the same time, the proportion of the ABS 4 publications among presented papers is about 2 times higher than that of non-presented works. The gap in the proportion of the ABS 3-ranked publications is narrower: around 17.6\% for presented papers and 9.8\% for non-presented ones. There is no significant difference in the share of lower-ABS ranked or unranked publications: these types of publications account for around 2.4-3\% of works. A similar pattern is observed when we use SJR quartiles as the journal quality indicators: the share of SJR Q1 (i.e., the best quartile in SJR) publications is significantly higher for the presented works (36\% versus $16.3 \%$ ) while the difference in the publication rates for SJR Q2-Q4 is trivial.

The statistics by conference are shown in columns 3-5 of the same table. While authorshiprelated statistics are relatively similar across conferences, we observe some interesting publishing-

\footnotetext{
${ }^{14}$ Note that 4,043 papers account for papers that were listed first time in IDEAS/RePEc both before and after the conference.
} 
related statistics. First, we note the highest share of publications for AEA-presented papers, followed by EEA-presented papers and RES-presented papers (49.2\%, 41.9\%, and 39.8\%, respectively). Second, $15 \%$ of AEA-presented papers were published in the ABS $4 *$-ranked journals but this figure is only $3.6 \%$ for EEA-presented papers and $2.4 \%$ for RES-presented papers. ${ }^{15}$ Similarly, the share of papers presented at AEA, EEA, and RES which are published in SJR Q1 journals is $44.3 \%, 33.3 \%$, and $31.9 \%$, respectively. Third, there is a relatively small difference in the share of the ABS 4 publications across conferences (conditional on presenting at any of the conferences, there is $9-13 \%$ probability of publication in an ABS 4 journal). Given these shares for top-tier economics journals, we find that the proportions of ABS 3 and lower, SJR Q2 and lower, or unranked publications among AEA-presented works are significantly lower than that among EEA- and RES-presented works.

Table 2 also reports monthly statistics for downloads, abstract views, citations, and the number of versions. On average, a paper presented at a major conference has about two versions that are made available in IDEAS/RePEc, while a non-presented paper has 1.5 versions. This pattern is consistent with the view that authors of papers selected for a major professional conference have larger networks. The degree of "visibility" (downloads, abstract views) is, on average, higher for presented works than for non-presented works. For instance, a typically presented paper is downloaded about 2.1 times per month and its abstract is viewed about 7 times per month, while the corresponding figures for non-presented works are 1.5 and 5.6 respectively. The number of monthly citations for presented works is roughly double that of non-presented works. Consistent with our results above, AEA-presented papers have better statistics than EEA- or RES-presented papers. For example, the number of monthly citations for EEA- or RES-presented papers is approximately half that for AEA-presented papers.

\section{Empirical analysis}

Evidence presented in the previous section suggests that participating in a major conference has the potential to boost publication outcomes. In this section, we provide a regression-based analysis of whether and how conferences contribute to publications and other measures of academic success.

\footnotetext{
15 These figures do not account for conference papers and proceedings/special issues. There is also a possibility that a presented paper that was published in an ABS $4 *$ journal but not included because the paper's title has changed. However, this possibility is rather small, since we have already checked and validated cases when a found paper has a slightly different title with the presented one.
} 


\subsection{Publishing probability}

To investigate the link between conference presentation and research outcomes, we first examine the impact of conference presentation on the likelihood of being published. We employ the following linear probability model:

Publication $_{p, a}=\alpha+\beta_{1}$ Conference $_{p, \mathrm{a}, \mathrm{c}}+\boldsymbol{X}_{p, a} \boldsymbol{\gamma}+u_{a}+$ error $_{p, a}$

where $p$ and $a$ index papers and authors; Publication $_{p, a}$ is the dummy variable which takes value of 1 if paper $p$ of author $a$ is published, and 0 otherwise; Conference is a dummy variable which takes value of 1 if paper $p$ of author $a$ is presented at conference $c$, and 0 otherwise; $X$ is a vector of control variables; $u_{a}$ is author $a$ fixed effect. To account for possible correlation of the error term, we cluster standard errors by author and date of the first posting.

Clearly, selection of papers to a leading professional conference is not random. While we cannot isolate the causal effect of conference presentation on publication outcomes, we strive to control for characteristics that are likely central for the publication process and conference selection so that we can remove obvious sources of endogeneity. First, one might expect that the quality of authors is a strong predictor of whether a paper is selected for a conference. Because we have a history of conferences and a wide range of papers with overlapping research teams, we can control for author fixed effects thus mitigating a major endogeneity concern. Second, we control for the average number of (monthly) citations (as of March 2017), which proxies the quality of a given paper. While the number of citations might be influenced by publication status, we use citations to obtain a conservative estimate of the predictive power of conference participation for publication outcomes. ${ }^{16}$ Third, we use fixed effects for dates (month/year) when the first version of a paper appears. These fixed effects are important for non-parametrically controlling for trends in the publication process and conference selection as well as various age effects. Fourth, we control for the connectedness and breadth of a paper's team of authors by using the number of authors on the paper (e.g., Borijas and Doran, 2015) and the number of versions the paper has (typically, versions correspond to different working paper series). We add these controls progressively to illustrate the contribution of each block of variables.

\footnotetext{
${ }^{16} \mathrm{We}$ find that pre-conference citation count is not a significant predictor of selection into a major conference (Appendix Table 2).
} 
Table 3 reports results for the pooled sample and publication in any journal ranked by the ABS. When we use no controls [column (1)], participating in a major conference is associated with the probability of publication being higher by 19.2 percentage points, a large increase relative to the unconditional probability of $25 \%$. However, once we control for the connectedness and breadth of research teams [column (2)], the "conference effect" diminishes dramatically: conference presentation is associated with only a 3.4 percentage point increase in publication probability. Adding further controls such as author and post-date fixed effects [column (4)] reduces the estimate further and, in fact, the estimate is negative when the full list of control is included [column (5)]. These results suggest that selection into major conferences is evidently not random and that, after controlling for even imperfect measures of paper quality, participation in a conference has effectively no predictive power for publication in any academic journal. In other words, conferences appear to have little, if any, value added for generating publications.

Fortunately for conference organizers and participants, these striking results mask important heterogeneity in the quality of publication outcomes. Indeed, journals vary widely in prestige and impact so that measuring success with any publication might provide a misleading picture of how conferences contribute to academic achievements. To quantify variation in the quality of publication outcomes, we modify the baseline specification as follows:

Publication ABS rank $\boldsymbol{R}_{p, a}=\alpha+\beta_{1}$ Conference $_{p, \mathrm{a}, \mathrm{c}}+\boldsymbol{X}_{p, a} \boldsymbol{\gamma}+u_{a}+$ error

where Publication ABS rank $\boldsymbol{R}$ is a dummy variable equal to one if paper $p$ by author $a$ was published in a journal with ABS rank $\boldsymbol{R}$, and zero otherwise. Because the ABS ranking has five ranks $\left(1,2,3,4\right.$, and $\left.4^{*}\right)$, we estimate five separate regressions for specification (2). ${ }^{17} \mathrm{We}$ use the same set of controls as in specification (1).

Consistent with our conjecture, we find that participating in a major conference has different predictions for where a conference paper might be published (Table 4$)^{18}$. For example, when we have no controls for paper quality [column (1)], we observe that participating in a major conference does not predict a higher probability of publications in low-tier journals (unranked or ranked 1 by the ABS). At the same time, participation predicts higher probabilities of publication in high-quality journals (ranked 4 or $4 *$ by the ABS). We observe this pattern across all columns thus suggesting

\footnotetext{
${ }^{17}$ To increase the number of observations for the low-tier publications, we group un-ranked journals and ABS 1 journals. Our results are quantitatively similar without this bundling.

${ }^{18}$ Columns in Table 4 correspond to columns in Table 3, e.g., the list of controls in column (5) of Table 4 is identical to the list of controls in column (5) of Table 3.
} 
that irrespective of the set of controls used in estimation - participating in a major conference is associated with a higher probability of publication in a high-quality journal. For example, even after controlling for an extensive list of observable characteristics [column (5)], participating is associated with 1.4 percentage point higher probability of publication in the premier (ABS $4^{*}$ ) tier of journals. This is a large increase given that the unconditional probability of publication in a $4 *$ journal is only $2.5 \%$ in our sample. Also note that the distribution of coefficients across rows in a given column rationalizes the estimates in Table 3: for example, the small coefficients in column (3) of Table 3 stems from the fact that participating in a major conference is associated with a lower probability of publication in a low-rank journal and a higher probability of publication in a high-rank journal so that the probability of publication in any journal is approximately zero.

Interestingly, participation in conferences is associated with longer periods between when a paper is posted publicly for the first time and when this paper appears in a journal (Table 5). For any publication [column (1)], participating in a conference appears to delay publication by 5.92 months. However, there is heterogeneity in lags across journal ranks. For low-rank journals (un-ranked and ABS 1 rank) and top-tier journals (ABS $4 *$ rank), there is no statistical difference in publication times between papers presented in a major conference and papers not presented in such conferences. In contrast, it is publications in the middle of the ranks that appear to drive the coefficient for any publication: these journals appear to take about 5 to 6 months longer to publish papers presented in a major conference. Obviously, these delays are not necessarily causal. Instead, these estimates could indicate that authors of papers selected for an AEA/EEA/RES conference try their luck in a top-tier journal before sending their paper to a journal where the paper ends up. This conjecture appears to be roughly consistent with review times in top-tier journals (4 to 6 months). The no-difference result for low-rank journals (ABS 1 rank and un-ranked) is also arguably consistent with this conjecture: if authors understand that their paper is of poor quality and hence has a weak upside, they send the paper straight to a low-rank journal.

One may be concerned that the ABS ranking might not be a good indicator of journal quality as the selection and valuation of journals depend on a board of experts and thus, some influential journals might not be included in this ranking. To address this concern, we use the Scientific Journal Ranking (SJR) as the alternative indicator of journal quality: the prestige is highest for Q1 journals 
and lowest for Q4 journals. ${ }^{19},{ }^{20}$ The results presented in Appendix Tables A4-6 yield a similar picture. That is, conference presentation is related to an increase of 2.8 percentage points in the likelihood of publishing in the most impactful journals, i.e., SJR Q1 journals (column (5) of Panel I in Appendix Table A4). In contrast, conference papers are less likely to be published in SJR Q4 journals, i.e., the least prestigious journals. Moreover, it takes more than 10 months longer to publish a conference paper in a SJR Q2 journal and around 5 months longer to publish in a SJR Q1 journal. Again, there is no difference in publication times in lower-ranked journals between presented and non-presented papers.

One concern related to the linear probability model is its predictive power. Thus, as a robustness check, we implement a machine learning technique, namely the Least Absolute Shrinkage and Selection Operator (LASSO), to re-estimate models (1) and (2). The aim of using this method is to minimize the residual sum of squares subject to a penalty $(\lambda)$ on the absolute size of coefficient estimates (Ahrens et al., 2018). More coefficients are set to zero then dropped with increasing $\lambda$. Thus, the variance will decrease at the expense of increasing bias, but this trade-off will help improve the degree of prediction accuracy of the model.

Results from our analysis using LASSO are presented in Appendix Table A13. Missing coefficient means the coefficient estimate is dropped from the final model. In general, the findings from LASSO approach are similar to the ones obtained from the linear probability model and the estimated coefficients are comparable. In particular, we find that conference presentation does not play an important role in determining the likelihood of publication in any journal, which is corresponding to the close-to-zero estimated coefficient in the previous analysis. Similarly, Conference is dropped from the estimation with publication in ABS 2 journals while its contribution to publications in ABS 1 and 3 journals is minimal (i.e., close to zero). In contrast, conference presentation will help increase the likelihood of being published in high-quality journals (ABS 4 and $4^{*}$ ) by 1.1-1.4 percentage points. Similar results are obtained when we use SJR quartile as the indicator of journal quality: the coefficient on Conference is dropped from the estimations with SJR Q2-Q3 journals, negative (-2.5 percentage points) in the estimation with SJR Q4 journals, and positive (4.1 percentage points) in the estimation with SJR Q1 journals.

\footnotetext{
19 Detailed explanation of the calculation of a journal's prestige is documented at https://www.scimagojr.com/SCImagoJournalRank.pdf.

${ }^{20} \mathrm{We}$ also used the journal quartiles from the Journal Citation Reports (JCR) as an alternative journal quality indicator. The results using this measure are similar to those using SJR ranking and available upon request.
} 


\subsection{Variation across conferences}

Similar to journals, conferences vary dramatically in selectivity, prestige, and attendance. For example, 13,450 people registered to attend AEA in 2019 while 1,283 and 526 people registered for EEA in 2018 and RES in 2018. Thus, one might expect variation in how successful conferences are in "placing" papers in journals. To investigate this potential heterogeneity, we modify our specifications (1) and (2) to include a separate dummy variable for each conference.

Consistent with our earlier results, we find (Table 6) that when no control variables are added [column (1)], conference participation is associated with a higher probability of publication in any journal. The magnitude of the estimated coefficients then diminishes when we control for various characteristics. While the patterns are qualitatively similar to the pooled results, there is a quantitative difference in outcomes across conferences. Specifically, participating in AEA conferences seems to be most beneficial: the estimated coefficients are systematically larger for AEA conferences than for EEA conferences and RES conferences and, in turn, EEA conferences have larger coefficients than RES conferences. For example, when no controls are added [column (1)], AEA participation is related to an increase of 23.5 percentage points in the likelihood of being published while the corresponding figures for EEA and RES participation are 16.1 percentage points and 11.7 percentage points, respectively. The absolute difference in estimated coefficients across conferences shrinks as we include greater number of controls, to the point where we cannot reject the null of equal coefficients on conference dummy variables.

However, similar to the pooled results, there is considerable variation in the estimated coefficients across conferences and journals (Table 7). For example, participating in AEA conference has zero predictive power for publication in a low-rank journal (ABS 1 rank and unranked) while presenting at EEA and RES conferences is related to a reduction of 1.6-2.6 percentage points in the likelihood of publishing in a low-rank journal. For top-tier (ABS $4 *$ rank) journals, coefficient on EEA dummy variable is effectively zero and coefficient on RES dummy variable is 0.01. In contrast, the coefficient on AEA dummy variable remains large even after controlling for a number of paper characteristics: participating in an AEA conference is associated with 5.2 percentage higher probability of publication in a $4 *$ journal, which is approximately double (!) of the 2.5 percent unconditional probability of publishing in a $4^{*}$ journal. Furthermore, the estimated coefficients for $4 *$ journals suggest that the pooled " $4 *$ effects" reported in Table 4 are entirely driven by AEA. Interestingly, the differences across conferences are much more muted for excellent journals (4 in ABS ranking) than for top-tier (4*) journals. The similar results are found when we use the SJR quartile as the indicator of journal quality (Appendix Table A7). Although presentation 
in AEA, EEA, and RES conferences is positively related to the probability of publishing in SJR Q1 journals, the effect is most profound for the papers presented at AEA. More specifically, AEA presentations lead to nearly 3 percentage point increase in the likelihood of SJR Q1 publications while this increase is between 2.1-2.6 percentage points for EEA and RES presentations.

So far, we have shown that conference presentation (especially at AEA conferences) is positively related to the likelihood of publishing in a high-rank journal and negatively related to the likelihood of publishing in a low-rank journal. There are two potential explanations for these. First, authors can choose to submit (and subsequently present) their best papers to those leading conferences. Thus, eventually, presented works are more likely to be published in prestigious journals. In this sense, conference presentation can merely signal high quality (signaling effect). Second, the quality of conference papers might not necessarily be higher than the quality of nonpresented ones. However, conferences provide authors with valuable feedback which otherwise the authors would not get. As a result, conference help improve quality (Campos et al., 2018; Freyne et al., 2010; Leon and McQuillin, 2020) which is beneficial to publishing prospects (maturation effect).

Although we are not able to disentangle these two channels, we can show (Appendix Table A3) that pre-conference quality (indicated by pre-conference citations) is not a significant predictor of conference presentation probability, i.e., the signaling effect is not immediately apparent. To some extent, the insignificant link between conferences' selectivity measured by acceptance rates or reviewers' scores and citations of the conference papers (Freyne et al., 2010; Bartneck et al., 2017) suggests that conferences acceptance (rejection) might not always reflect the quality of the presented (non-presented) works. Thus, the maturation effect is more likely than the signaling effect.

Moreover, the stronger impact of AEA presentations is consistent with the maturation effect, which could be attributed to the differences in the structures of three conferences. More specifically, a session at AEA conferences often comprises an assigned chair and discussants who are not necessarily presenters (or authors) of papers in that session. The situation is different for EEA and RES conferences: the last presenter is assigned as the session chair and no discussants are assigned. Hence, the size of audience in a typical AEA session is arguably larger than that in EEA and RES sessions. Consequently, papers presented at AEA conferences are likely to receive more feedbacks, comments, and suggestions, resulting in higher chances to improve the papers' quality.

\subsection{Variation across fields}

In this section, we examine whether conference participation has differential predictive power for publication outcomes across fields of economics. Indeed, economics is a heterogeneous 
social science with fields operating in different publication regimes and methodological standards. With a risk of oversimplification, we consider the following major fields of economics: microeconomic theory, macroeconomics (which includes international economics and financial economics), applied microeconomics (which includes labor economics, public finances, industrial organization, health economics, law and economics), development and environment (which also includes agricultural economics, comparative economics, and urban economics), and econometrics (which also includes mathematical economics and other quantitative subfields). While this classification is obviously crude, it provides an approximation for differences across fields. Whenever a paper falls into multiple fields, we classify the paper as being in field $\mathrm{X}$ if one of its Journal of Economic Literature (JEL) codes is in field X. In other words, our classification is not mutually exclusive.

We estimate specifications (1) and (2) by each major field separately and report the results in Table 8. Because we can recover JEL codes for about $70 \%$ of the papers registered in the IDEAS/RePEc database, we also report results for papers in any field with a non-missing JEL code [column (1)] as well as results for papers with missing JEL codes [column (7)]. We find that results for papers with JEL codes are broadly similar to the results for all papers (Tables 3 and 4) and, thus, we conjecture weak (if any) selection effects from using only papers with non-missing JEL codes. The general patterns regarding any publication and publications in lower-rank journals are similar across fields: after controlling for paper characteristics, participating in a major conference is associated with a lower probability of such publications (rows 1-5 of Table 8). However, we observe some differences when we examine publication in top-tier journals i.e. while all coefficients on Conference are positive, only coefficients for econometrics and development/environment field are statistically significant (the last row of Table 8). At the same time, the magnitudes of estimated coefficients do vary. Specifically, presenting a paper in the development/environment field is associated with a 2.5 percentage point increase in the probability of publication in a top-tier journal while the corresponding figure for macroeconomics is only 0.9 percentage point. $^{21}$

\subsection{Prime time}

What is the best time to present a paper? In an ideal world, researchers should discover the true value of a presented study irrespective of whether they are tired after a long day, sleepy in the morning after a jet lag, or fresh and bright after a large cup of coffee. However, casual observations

\footnotetext{
${ }^{21}$ There is little variation across fields when we use the SJR quartile as the indicator of journal quality (Appendix Table 8).
} 
of many conferences suggest that, for example, presenting in the last slot of the last day of a conference typically entails a smaller audience and, thus, presumably a lower impact. As a result, one might conjecture that there exists a "prime time" for presenting a paper that maximizes its chances of publication. To learn if certain conference slots have predictive power for future publication outcomes, we modify our baseline specification as follows:

$$
\text { Publication }_{p, a}=\alpha+\sum_{c} \sum_{\tau} \beta_{c, \tau} \text { TimeDayConference } e_{p, a, c, \tau}+\boldsymbol{X}_{p, a} \boldsymbol{\gamma}+u_{a}+\text { error }
$$

where TimeDayConference $e_{p, a, c, \tau}$ is a dummy variable which equals to one if paper $p$ with authors $a$ was presented in conference $c$ at time slot $\tau$. To ensure we have enough observations per slot, we create morning and afternoon slots for each day of a conference. For example, AEA conferences last three days and so we have six slots: morning of day \#1, afternoon of day \#1, morning of day \#2, afternoon of day \#2, morning of day \#3, and afternoon of day \#3. RES also runs 3-day conferences but the morning of the first day does not have plenary sessions and, hence, we have five time slots. EEA has 5-day conferences but the morning of the first day has no sessions. As a result, EEA conferences have nine slots.

We find that AEA and RES indeed have the lowest probability of publication in any journal presented in the last slot of a conference (column (1) in Figure 1). There is generally an inverted-U profile for estimated coefficients with the highest probability being the morning of the second day. EEA does not exhibit this pattern for the probability of publication in any journal: the estimated profile is generally flat. For publications in the most prestigious (ABS 4* rank or SJR Q1 quartile) journals (columns (2) and (4) of Figure 1), AEA shows a downward-sloping profile with the highest probability estimated for the morning of the first day (5-7.8\%!) and the lowest probability for the afternoon of the last day (approximately zero percent). RES has a qualitatively similar profile but there is no clear monotonicity. While we do not observe any statistically significant coefficients in the EEA profile for publications in top-tier journals, we see that mornings of the first three days of the conference tend to have positive point estimates. Finally, the probability of publication in a lowrank (ABS 1 rank, SJR Q1, and un-ranked) journal shows the greatest variation across conferences: AEA has an inverted-U profile, RES has an upward-sloping profile, and EEA has a downwardsloping profile. This evidence appears to suggest that, indeed, the time/day when a paper is presented predicts how well the paper will fare in journals.

One might argue that our results do not necessarily reflect the "prime time" effect, and thus conference effect, but rather other unobserved factors. For example, conference organizers could have incentives to allocate better presentation slots to papers authored by prominent scholars. Hence, 
the positive effects of prime time on publication outcomes could be driven by the prominent authors' presumably higher-quality papers rather than the benefits of conference presentation. To check this possibility, we compare the time slots assigned to papers authored by well-known vs. less-known authors for each conference in our sample. Appendix Table A14 documents similar distributions of presentation slots over conference days and time for two groups of papers. In other words, the allocation of presentation time is fairly "random" and conference organizers seem not to favor a particular group of authors when assigning sections, which strengthens our findings of the benefits of conference presentation (and prime time) on publishing outcomes.

\subsection{Who benefits?}

\subsubsection{Prominent author effect}

Azoulay et al. (2010), Borjas and Dojan (2015), Oettl (2012), and others emphasize the importance of star scholars in generating academic output and impact. Whether a star scholar's ability to draw attention spills over to others is an open question. For example, it is not clear if being in the same conference session with a prominent scientist increases chances of publication in a scholarly journal. To shed some light on the matter, we augment the baseline specification with the indicators of whether a prominent scholar is (1) in the paper's author team (Paper with Top 1\%) and (2) in the author team of other papers in the same session (Session with Top 1\%). Paper with Top $1 \%$ equals to one if at least one of the authors of the paper is in the top $1 \%$ of IDEAS/RePEc Top Economist ranking. Similarly, Session with Top 1\% equals to one if at least one of the authors of another paper in the session where paper $p$ is presented is in the top $1 \%$ of the Top Economist ranking. ${ }^{22}$

Publication $_{p, a}=\alpha+\beta_{1}$ Conference $_{p, a, c}+\beta_{2}$ Conference $_{p, a, c} \times$ Session with Top $1 \%_{p, a, c}$

$$
+\boldsymbol{X}_{p, a} \boldsymbol{\gamma}+u_{a}+\text { error }_{p, a}
$$

Publication $_{p, a}=\alpha+\beta_{1}$ Conference $_{p, a, c}+\beta_{2}$ Paper with Top $1 \%_{p, a}$

$$
\begin{aligned}
& +\beta_{3} \text { Conference }_{p, a, c} \times \text { Paper with Top } 1 \%_{p, a} \\
& +\boldsymbol{X}_{p, a} \boldsymbol{\gamma}+u_{a}+\text { error }_{p, a}
\end{aligned}
$$

where the rest of the specifications is identical to specification (1).

\footnotetext{
${ }^{22}$ We also experimented with top ten percent of the IDEAS/RePEc Top Economist Ranking and got quantitatively similar results.
} 
We find that presenting in a session with eminent scholars generally has statistically insignificant predictive power for publication outcomes for other papers in a conference session (Table 9). For example, when we pool data across conferences (Panel A), the incremental increase in the probability of any publication [column (1)] in a session with a star academic is only 0.7 percentage points (standard error 2.3\%). The corresponding increase for a top-tier publication is 2.4 percentage points (standard error 1.5\%). From previous results, we know that differences for toptier publications are almost entirely driven by AEA conferences. When we focus on these conferences (Panel B), we find that there is a small, insignificant association between top-tier publications and sharing a session with a prominent academic. Thus, although stars can attract crowds, a large attendance does not seem to translate into high chances of publication in scholarly journals. The good news for lesser-known scholars is that sharing a session with a star does not crowd-out publication chances (that is, estimated $\beta_{2}$ is not negative).

Although there is no significant benefit from sharing a session with a star scholar, having a prominent author in the author team can be beneficial (Table 10). There is a predicted 5.3 percentage point increase in the probability of being published in any journal for presented papers which have star author(s). This increase for top authors is smaller (2.6 percentage points) when we consider the likelihood of lower-tier publications (ABS 1 journals) while the predicted increase in the likelihood of $\mathrm{ABS} 4 *$ publications is 5.3 percentage points. However, the effect varies across conferences and publication outcomes. For example, papers that have top authors and were presented at AEA conferences experience a higher probability of publications in lower-rank journals only with the increased probability of between 1.5 percentage points (SJR Q4 publications) and 3 percentage points (ABS 1 and 2 publications). EEA-presented papers authored by a star scientist are more likely to be published in a scholarly journal with an increase of 8.1 percentage points in the likelihood of publishing in SJR Q1 journals (column (4) in Appendix Table A10). Finally, outcomes for RESpresented papers do not seem to differ across authors with different statuses in the profession.

\subsubsection{Gender effect}

It has been widely recognized that women are often disadvantaged compared to men in labor market regarding wage or promotion. In recent years, gender gap in academia generally and in economics profession particularly has got greater attention with some evidence suggesting that female economists face more obstacles in career advancement compared to the male peers. In fact, as reported in the climate survey conducted by the American Economic Association (2019), a significant proportion of female respondents have experienced discrimination or unfair treatment in 
various aspects e.g. promotion, compensation, job market, or publishing decisions. Male economists, however, are less likely to report such negative experience.

The evidence of gender gap in economics profession has been also provided in a growing number of studies. Examining the number of citations received by papers published in the "top 5" economics journals, Hengel and Moon (2020) find that female-authored articles are cited more than male-authored ones. Similarly, examining referee reports and citations of submissions to four leading journals, Card et al. (2020) acknowledge that all female papers get more citations than all male counterparts. In both papers, female-authored papers being held to higher standards is suggested as a possible explanation of such results. In addition to the bias in citations, all-femaleauthor papers are also less likely to be accepted to conferences (Hospido and Sanz, 2020). In this section, we aim to provide new evidence regarding gender gaps in the economics profession by examining the extent to which the benefit of conference presentation on publishing for female authors is different from that for male authors.

To answer this question, we use webtools gemderize.io and namsor.com to classify authors' gender based on their first names (the former service) and their full names (the latter service). Out of 5,170 authors in our sample, the gender classifications obtained from these tools return the similarity of $95 \%$. For the remaining authors whose names are either unisex or the gender classifications provided by two services are different, we manually establish gender of authors by going through their photos or biographies in the institutional and personal webpages. Consistent with economics being a male-dominated field, we indeed observe the prevalence of male economists in our sample: the ratio of female to male authors is about 1:4.

The results obtained from re-estimating models (1) and (2) on the female and male subsamples are presented in columns (1)-(2) of Table 11 (the ABS ranking is the journal quality indicator) and Appendix Table A11 (the SJR quartile is the journal quality). We find that participation in a major conference reduces the probability of publications any academic journal or in low-tier journals for both female and male authors. The effect on publications in top journals, however, is different for female and male authors. On the one hand, presented papers by male authors experience a 1.6 percentage points higher likelihood of being published in ABS 4/4* journals and 3.3 percentage points higher likelihood of being published in SJR Q1 journals. On the other hand, the probability of being published in the high-quality journals for female authors' presented papers is next to zero. 
One might argue that this result does not necessarily reflect the different effects of conference presentation for female and male economists but is rather driven by the difference in their research productivity that has been documented in the literature (see, e.g., Albert et al., 2016; Ginther and Hayes, 2003; Ginther and Kahn, 2004; Kahn, 1993; Maske et al., 2002). To partially address this concern, we adopt the Coarsened Exact Matching technique to match female authors with their male counterparts based on various productivity-related metrics. The matching process is done as follows. In the first step, we match female authors whose works were presented in one of the conferences in 2006 with male authors whose works were also presented in 2006 based on (1) the number of downloads the author received in 2006; (2) the number of co-authors (registered in IDEAS/RePEc) by 2006; and (3) the number of distinct works the author had by 2006. Next, in any given year starting from 2007, we perform matching for female authors whose works were presented in that year but not in previous years with male authors whose works were presented in the same year but not in previous years. After matching, we get a sample of 2,293 authors with the female/male ratio of $1: 3$.

The estimated results for the matched samples are reported in columns (3)-(4) of Table 11 and Appendix Table A11. Again, we observe that conference participation only helps male researchers in placing their works in the high-quality journals. Female researchers, although are not disadvantaged (i.e., the effect of conference presentation is not negative), do not benefit (at least in terms of publishing attempt) from participating in a major conference neither. This finding, to some extent, supports our argument above that the maturation effect is more likely to take place and could be possibly explained by the aggressive seminar culture towards female speakers documented by Dupas et al. (2020). More specifically, it has been suggested that during economics seminars and job market talks, female presenters tend to receive more unfair/clarifying questions. If this culture also exists during conference presentations and female authors are also presenters, one would expect that female authors are less likely to benefit from questions asked during the conferences since such questions do not add value to the papers.

Obviously, these estimates are not causal, and we cannot unambiguously attribute the differences in outcomes for female and male authors to discrimination. However, our statistics paint a potentially troubling picture: female authors appear to gain less at the top end of journal hierarchy after presenting their work in major conferences. Even after controlling for basic heterogeneity in research profiles of authors, we find that, after presenting a paper at a major conference, male authors have higher probabilities of publication in top academic outlets than their female counterparts. 


\subsection{Other outcomes}

So far, we have found evidence for the positive impact of conference presentation on the probability of publishing (in the high-rank journals). Of course, conference participation can contribute to other measures of success such the quality and impact of the papers (Leon and McQuillin, 2020). We use the number of citations as a proxy for impact and the number of abstract views as a proxy for visibility. ${ }^{23}$ To quantify the predictive power of conference participation, we employ the following specification:

$$
\operatorname{Ln}\left(1+\text { Outcome }_{p, a}=\alpha+\beta_{1} \text { Conference }_{p, \mathrm{a}, \mathrm{c}}+\boldsymbol{X}_{p, a} \boldsymbol{\gamma}+u_{a}+\text { error }_{p, a}\right.
$$

where Outcome is either (1) Citations which is the average number of a paper's monthly citations or (2) Abstract views which is the average number of monthly abstract views. ${ }^{24}$ The results in Table 12 show a consistent pattern: presented papers are likely to be cited and viewed more often, regardless of whether or not we use controls in specification (5). In particular, the abstracts of presented papers are viewed more often than that of non-presented papers by at least $9 \%$. Similarly, conference presentation is associated with an increase of about $4 \%$ in the number of citations received monthly.

To assess the timing of the estimated boost in abstract views and citations, we consider the following panel regression:

$$
\operatorname{Ln}(1+\text { Outcome })_{p, c, m}=\alpha+\sum_{s=-\underline{s}}^{\bar{S}} \beta_{\mathrm{s}} \text { Conference }_{p, c, m-\tau}+\boldsymbol{X}_{p, c, m} \boldsymbol{\gamma}+\lambda_{m}+\eta_{p}+
$$
error $_{p, c, m}$

(6)

where $\tau$ is the time of conference, $m$ is calendar month, $\lambda_{m}$ is time fixed effect, and $\eta_{p}$ is paper fixed effect. Outcome $e_{p, c, m}$ is either monthly abstract views (Abstract views) or monthly citations (Citations) of paper $p$ presented at conference $c$. As before, we control for various characteristics $\boldsymbol{X}$ that can also affect the visibility and impact level of a paper. This includes (1) Age which is the natural log of the paper's age; (2) New version which equals to one if a new version of the paper is made available and zero otherwise; (3) and Share of influential authors which is the ratio of the number of the authors in the top ten percent of the Top Economist ranking in a given

\footnotetext{
${ }^{23}$ Results are similar if we use the number of downloads as the indicator of visibility.

${ }^{24}$ We use $\log (1+Y)$ as the dependent variable rather than $\log (Y)$ because many papers have no citations (about $21 \%)$.
} 
month to the total number of authors. This model is estimated on the panel data sample of conference papers.

The results presented in Figure 2 confirm the positive effect of conference participation on paper visibility and impact. In the conference month, a paper would receive a 6 percentage points boost in the number of abstract views compared to the number of monthly abstract views received before. The increase in the following month is about 4 percentage points. There is also a difference in the average level of monthly abstract views between pre- and post-conference period. These findings suggest the important role of conferences in promoting research. However, in this analysis, we do not observe any significant boost in the number of monthly citations after the conference. This is rather expected since the research impact through citations requires a considerable time to be reflected.

\section{Conclusion}

In this study, we quantify the role of conferences on improving the publishing prospects of presented works. We use a comprehensive dataset containing information on research portfolios of scholars whose works were presented at three leading economic conferences in the US, the UK, and Europe. More specifically, our data is assembled from multiple sources including (1) official programs of the AEA Meetings, the EEA Annual Conferences, and the RES Annual Conferences over the 2006-2012 period; and (2) IDEAS/RePEc statistics on the conference papers, conference authors as well as statistics on other works (but not presented at conferences) of those authors.

Our results show a significantly positive association between conference presentation (especially at AEA conferences) and the probability of being published in a high-quality journal. We also find a strong correlation between conference presentation and research visibility: the number of average monthly abstract views and citations of a presented paper is at least 4-9 percentage points higher than that of non-presented ones. These findings underscore the importance of conference presentations for research productivity and promotion. While our focus on narrow outcomes (is a paper published in a scholarly journal or not?) does not necessarily provide a complete picture of the conferences' value, our results clearly indicate that academic institutions should have effective mechanisms to encourage and support researchers to present in the high-quality conferences. By doing so, both researchers and universities can benefit from improved research performance (more publications in high-quality journals) and increased research dissemination (higher visibility). 
Our analysis and subsequent work should also help design better professional conferences in the future. For example, one of the striking results is that AEA conferences tend to be much more successful in predicting top-tier publications than other major conferences. Whether this difference is due to the much greater attendance of AEA meetings or some other forces is an open question. In any case, other conferences can presumably emulate the design of AEA conferences to achieve better outcomes. We also observe potential frictions: spillovers from star scholars to other papers in a session appear rather limited (if present at all); gains for lesser-known authors might be smaller than for well-known authors; and where a paper is placed in a conference schedule seems to have predictive power for publication outcomes. Perhaps, the most disturbing finding is that female authors seem to gain from conference presentations less than male authors. Rationalizing these facts as well as establishing causal effects of conference presentations requires conscious efforts from conference organizers to implement randomized control trials or perhaps provide more information for other research designs (e.g., regression discontinuity) to develop a better understanding of what exactly conferences deliver to participating scholars.

Nevertheless, some changes can be readily made to improve the contribution of conferences to career progression of "disadvantaged" groups (e.g., early career or female economists). For instance, prime times could be reserved for authors/presenters belonging to such groups. Additionally, more conferences/workshops which provide "disadvantaged" groups with a forum to present their works and receive feedbacks and mentorship (and potentially collaboration) could be organized. Some instances of such events include the CSWEP CeMENT workshops (organized by the American Economic Association), the WinE Retreat (organized by the European Economic Association and the Econometric Society), and the RES Mentoring Retreat (organized by the Royal Economic Society). Given the convenience brought by advanced technology and the Internet (i.e., virtual conferences), similar events could be expanded to a larger scale at relatively low costs.

\section{References}

Albert, C., Davia, M.A. and Legazpe, N., 2016. Determinants of research productivity in Spanish Academia. European Journal of Education, 51(4), pp.535-549.

American Economic Association (AEA), 2019. AEA Professional Climate Survey: Main Findings. March 19, 2019. Available at https://www.aeaweb.org/resources/member-docs/climatesurvey-results-mar-18-2019. 
Azoulay, P., Graff Zivin, J.S. and Wang, J., 2010. Superstar extinction. The Quarterly Journal of Economics, 125(2), pp.549-589.

Bar-Ilan, J., 2010. Web of Science with the Conference Proceedings Citation Indexes: The case of computer science. Scientometrics, 83(3), pp.809-824.

Bartneck, C., 2017. Reviewers' scores do not predict impact: bibliometric analysis of the proceedings of the human-robot interaction conference. Scientometrics, 110(1), pp.179-194.

Belenzon, S. and Schankerman, M., 2013. Spreading the word: Geography, policy, and knowledge spillovers. Review of Economics and Statistics, 95(3), pp.884-903.

Bizzabo, 2018. [Blog] Available at: <https://blog.bizzabo.com/event-gender-diversitystudy> [Accessed 10 November 2020].

Blau, F.D., Currie, J.M., Croson, R.T. and Ginther, D.K., 2010. Can mentoring help female assistant professors? Interim results from a randomized trial. American Economic Review, 100(2), pp.348-52.

Borjas, G.J. and Doran, K.B., 2015. Which peers matter? The relative impacts of collaborators, colleagues, and competitors. Review of Economics and Statistics, 97(5), pp.11041117.

Boudreau, K.J., Brady, T., Ganguli, I., Gaule, P., Guinan, E., Hollenberg, A. and Lakhani, K.R., 2017. A field experiment on search costs and the formation of scientific collaborations. Review of Economics and Statistics, 99(4), pp.565-576.

Brown, T. and Gutman, S.A., 2019. A comparison of bibliometric indicators in occupational therapy journals published in English. Canadian Journal of Occupational Therapy, 86(2), pp.125135.

Campos, R., Leon, F. and McQuillin, B., 2018. Lost in the Storm: The Academic Collaborations That Went Missing in Hurricane ISSAC. The Economic Journal, 128(610), pp.9951018.

Card, D., DellaVigna, S., Funk, P. and Iriberri, N., 2020. Are Referees and Editors in Economics Gender Neutral? The Quarterly Journal of Economics, 135(1), pp.269-327.

Collier, J.M., Vig, N. and Hammond, D., 2010. Publish or perish? A survey of abstracts accepted for meetings of the British Association of Oral and Maxillofacial Surgeons, and subsequently published. British Journal of Oral and Maxillofacial Surgery, 48(7), pp.540-543. 
Ding, W.W., Levin, S.G., Stephan, P.E. and Winkler, A.E., 2010. The impact of information technology on academic scientists' productivity and collaboration patterns. Management Science, 56(9), pp.1439-1461.

Ductor, L., Fafchamps, M., Goyal, S. and van der Leij, M.J., 2014. Social networks and research output. Review of Economics and Statistics, 96(5), pp.936-948.

Dupas, P., Modestino, A., Niederle, M. and Wolfers, J., 2020. Gender and the Dynamics of Economics Seminars. Discussion paper, Stanford University.

Freyne, J., Coyle, L., Smyth, B. and Cunningham, P., 2010. Relative status of journal and conference publications in computer science. Communications of the ACM, 53(11), pp.124-132.

Frohlich, C. and Resler, L., 2001. Analysis of publications and citations from a geophysics research institute. Journal of the American Society for Information Science and Technology, 52(9), pp.701-713.

Galang, M.T., Yuan, J.C.C., Lee, D.J., Barao, V.A., Shyamsunder, N. and Sukotjo, C., 2011. Factors influencing publication rates of abstracts presented at the ADEA annual session \& exhibition. Journal of Dental Education, 75(4), pp.549-556.

Ginther, D.K. and Hayes, K.J., 2003. Gender differences in salary and promotion for faculty in the humanities 1977-95. Journal of Human Resources, 38(1), pp.34-73.

Ginther, D.K. and Kahn, S., 2004. Women in economics: moving up or falling off the academic career ladder?. Journal of Economic Perspectives, 18(3), pp.193-214.

Hengel, E. and Moon, E., 2019. Gender and Quality at Top Economic Journals. Unpublished paper.

Hospido, L. and Sanz, C., 2020. Gender Gaps in the Evaluation of Research: Evidence from Submissions to Economics Conferences. Oxford Bulletin of Economics and Statistics, In Press.

Iaria, A., Schwarz, C. and Waldinger, F., 2018. Frontier knowledge and scientific production: evidence from the collapse of international science. The Quarterly Journal of Economics, 133(2), pp.927-991.

Kahn, S., 1993. Gender differences in academic career paths of economists. American Economic Review, 83(2), pp.52-56. 
Leon, F. L. L. and McQuillin, B., 2020. The Role of Conferences on the Pathway to Academic Impact Evidence from a Natural Experiment. Journal of Human Resources, 55(1), pp.164-193.

Levin, S.G. and Stephan, P.E., 1991. Research productivity over the life cycle: Evidence for academic scientists. The American Economic Review, 81(1), pp.114-132.

Livas, C., Pandis, N. and Ren, Y., 2014. Full-text publication of abstracts presented at European Orthodontic Society congresses. European Journal of Orthodontics, 36(5), pp.569-575.

Maske, K.L., Durden, G.C. and Gaynor, P.E., 2003. Determinants of scholarly productivity among male and female economists. Economic Inquiry, 41(4), pp.555-564.

McCabe, M.J. and Snyder, C.M., 2015. Does online availability increase citations? Theory and evidence from a panel of economics and business journals. Review of Economics and Statistics, 97(1), pp.144-165.

Miguel-Dasit, A., Martí-Bonmatí, L., Aleixandre, R., Sanfeliu, P. and Valderrama, J.C., 2006. Publications resulting from Spanish radiology meeting abstracts: Which, Where and Who. Scientometrics, 66(3), pp.467-480.

Oettl, A., 2012. Reconceptualizing stars: Scientist helpfulness and peer performance. Management Science, 58(6), pp.1122-1140.

Pinkowitz, L., 2002. Research dissemination and impact: Evidence from web site downloads. The Journal of Finance, 57(1), pp.485-499.

Rahm, E. and Thor, A., 2005. Citation analysis of database publications. ACM Sigmod Record, 34(4), pp.48-53.

Reinartz, S.J. and Urban, D., 2017. Finance conference quality and publication success: A conference ranking. Journal of Empirical Finance, 42, pp.155-174.

Sarsons, H., Gërxhani, K., Reuben, E. and Schram, A., 2015. Gender differences in recognition for group work. Journal of Political Economy, In Press.

Sicilia, M.A., Sánchez-Alonso, S. and García-Barriocanal, E., 2011. Comparing impact factors from two different citation databases: The case of computer science. Journal of Informetrics, 5(4), pp.698-704.

Tzanetakis, G.N., Tzimpoulas, N., Floratos, S., Agrafioti, A., Kontakiotis, E.G. and Shemesh, H., 2018. Full-text publication rates of research abstracts presented at the European 
Society of Endodontology congresses in the last 20 years. International Endodontic Journal, 51(2), pp.215-222.

Von Elm, E., Costanza, M.C., Walder, B. and Tramèr, M.R., 2003. More insight into the fate of biomedical meeting abstracts: a systematic review. BMC Medical Research Methodology, 3(1), p.12.

Vrettas, G. and Sanderson, M., 2015. Conferences versus journals in computer science. Journal of the Association for Information Science and Technology, 66(12), pp.2674-2684.

Waldinger, F., 2016. Bombs, brains, and science: The role of human and physical capital for the creation of scientific knowledge. Review of Economics and Statistics, 98(5), pp.811-831.

Winnik, S., Raptis, D.A., Walker, J.H., Hasun, M., Speer, T., Clavien, P.A., Komajda, M., Bax, J.J., Tendera, M., Fox, K. and Van de Werf, F., 2012. From abstract to impact in cardiovascular research: factors predicting publication and citation. European Heart Journal, 33(24), pp.30343045. 


\section{Tables}

Table 1. Conference program statistics

\begin{tabular}{|c|c|c|c|c|c|c|}
\hline \multirow{3}{*}{ Year } & \multicolumn{2}{|c|}{$\begin{array}{c}\text { American Economic } \\
\text { Association }\end{array}$} & \multicolumn{2}{|c|}{$\begin{array}{c}\text { European Economic } \\
\text { Association }\end{array}$} & \multicolumn{2}{|c|}{ Royal Economic Society } \\
\hline & Papers & $\begin{array}{l}\text { Matched } \\
\text { Links }\end{array}$ & Papers & $\begin{array}{l}\text { Matched } \\
\text { Links }\end{array}$ & Papers & $\begin{array}{l}\text { Matched } \\
\text { Links }\end{array}$ \\
\hline & $(1)$ & $(2)$ & (3) & (4) & $(5)$ & $(6)$ \\
\hline 2006 & 2451 & 240 & 675 & 4451 & 191 & 126 \\
\hline 2007 & 584 & 298 & 674 & 403 & 231 & 159 \\
\hline 2008 & 590 & 284 & 812 & 502 & 267 & 175 \\
\hline 2009 & 659 & 367 & 761 & 438 & 188 & 121 \\
\hline 2010 & 662 & 355 & 756 & 483 & 254 & 190 \\
\hline 2011 & 722 & 409 & 679 & 364 & 496 & 325 \\
\hline 2012 & 730 & 411 & 780 & 419 & 461 & 321 \\
\hline
\end{tabular}

Notes: This table shows the number of papers presented in each conference - year and the number of IDEAS/RePEc links that are collected. 
Table 2. Summary statistics

\begin{tabular}{|c|c|c|c|c|c|}
\hline & \multirow{2}{*}{$\begin{array}{c}\text { Non-presented } \\
\text { papers }\end{array}$} & \multicolumn{4}{|c|}{ Paper presented at a conference } \\
\hline & & Any & AEA & EEA & RES \\
\hline & $(1)$ & $(2)$ & $(3)$ & $(4)$ & $(5)$ \\
\hline No. of papers & 665,465 & 44,043 & 1,252 & 2,091 & 955 \\
\hline \multicolumn{6}{|c|}{ No. of conference presentations } \\
\hline 1 conference & & 3,796 & & & \\
\hline 2 conferences & & 239 & & & \\
\hline 3 conferences & & 8 & & & \\
\hline \multicolumn{6}{|l|}{ No. of authors } \\
\hline Single author & 15,212 & 776 & 208 & 430 & 189 \\
\hline 2 authors & 29,515 & 1,923 & 579 & 1,001 & 459 \\
\hline 3 authors & 15,605 & 1,077 & 356 & 542 & 249 \\
\hline 4 authors & 3,684 & 229 & 86 & 108 & 51 \\
\hline 5 authors & 810 & 29 & 18 & 7 & 6 \\
\hline More than 5 authors & 639 & 9 & 5 & 3 & 1 \\
\hline Publications & 15,723 & 1,754 & 616 & 876 & 380 \\
\hline \multicolumn{6}{|l|}{ Journal rankings } \\
\hline \multicolumn{6}{|l|}{ ABS } \\
\hline $\operatorname{ABS} 4 *$ & 1,389 & 272 & 190 & 75 & 23 \\
\hline ABS 4 & 2,677 & 402 & 163 & 182 & 92 \\
\hline ABS 3 & 6,386 & 710 & 193 & 391 & 175 \\
\hline ABS 2 & 3,260 & 270 & 40 & 170 & 71 \\
\hline ABS 1 or Un-ranked & 2,011 & 100 & 30 & 58 & 19 \\
\hline \multicolumn{6}{|l|}{ SJR } \\
\hline SJR Q1 & 10,679 & 1,456 & 555 & 696 & 305 \\
\hline SJR Q2 & 2,168 & 193 & 31 & 123 & 53 \\
\hline SJR Q3 & 371 & 29 & 5 & 20 & 5 \\
\hline SJR Q4 & 2,505 & 76 & 25 & 37 & 17 \\
\hline \multicolumn{6}{|l|}{ Monthly statistics } \\
\hline \multicolumn{6}{|l|}{ No. of version } \\
\hline Mean & 1.478 & 1.972 & 2.110 & 1.954 & 1.863 \\
\hline St.Dev. & 0.864 & 1.199 & 1.276 & 1.199 & 1.100 \\
\hline \multicolumn{6}{|l|}{ Downloads } \\
\hline Mean & 1.495 & 2.133 & 2.695 & 1.912 & 1.934 \\
\hline St.Dev. & 3.884 & 5.128 & 6.751 & 4.290 & 3.995 \\
\hline \multicolumn{6}{|l|}{ Abstract views } \\
\hline Mean & 5.579 & 6.911 & 8.806 & 6.182 & 6.137 \\
\hline St.Dev. & 11.304 & 11.308 & 14.336 & 9.849 & 9.735 \\
\hline \multicolumn{6}{|l|}{ Citations } \\
\hline Mean & 0.138 & 0.305 & 0.528 & 0.217 & 0.206 \\
\hline St.Dev. & 1.370 & 1.823 & 2.433 & 1.481 & 1.353 \\
\hline
\end{tabular}

Notes: This table summarizes statistics of conference authors' works. Columns 1-2 show statistics for all (distinct) presented and non-presented works, respectively. Columns 3-5 show statistics for papers presented at American Economic Association (AEA), European Economic Association (EEA), and Royal Economic Society (RES) conferences, respectively. No. of papers is the number of distinct presented and non-presented works. No. of conferences is the number of conferences where a given paper was presented at. No. of authors is the number of authors for a given paper. Publications is the number of works that were published in a journal. Journal rankings is the journal rank in the Association of Business Schools' Academic Journal Guide 2015 (ABS 2015 ranking). Number of versions is the monthly statistics of versions of each paper available in IDEAS/RePEc. Downloads, Abstract views, and Citations are the monthly downloads, abstract views, and new citations that a paper gets, respectively. 
Table 3. Conference participation and publication outcomes

\begin{tabular}{|c|c|c|c|c|c|}
\hline & $(1)$ & $(2)$ & (3) & (4) & $(5)$ \\
\hline Conference & $\begin{array}{l}0.192 * * * \\
(0.014)\end{array}$ & $\begin{array}{l}0.034 * * * \\
(0.011)\end{array}$ & $\begin{array}{l}0.006 \\
(0.009)\end{array}$ & $\begin{array}{c}-0.016^{*} \\
(0.008)\end{array}$ & $\begin{array}{l}-0.026 * * * \\
(0.008)\end{array}$ \\
\hline Log(1+Citations $)$ & & & & & $\begin{array}{l}0.268 * * * \\
(0.015)\end{array}$ \\
\hline \multicolumn{6}{|c|}{ No. of versions $($ Base $=1$ ) } \\
\hline 2 & & $\begin{array}{l}0.446 * * * \\
(0.014)\end{array}$ & $\begin{array}{l}0.432 * * * \\
(0.013)\end{array}$ & $\begin{array}{l}0.419 * * * \\
(0.014)\end{array}$ & $\begin{array}{l}0.394 * * * \\
(0.013)\end{array}$ \\
\hline 3 & & $\begin{array}{l}0.617 * * * \\
(0.013)\end{array}$ & $\begin{array}{l}0.617 * * * \\
(0.014)\end{array}$ & $\begin{array}{l}0.599 * * * \\
(0.015)\end{array}$ & $\begin{array}{l}0.548 * * * \\
(0.014)\end{array}$ \\
\hline 4 & & $\begin{array}{l}0.700 * * * \\
(0.013)\end{array}$ & $\begin{array}{l}0.717 * * * \\
(0.014)\end{array}$ & $\begin{array}{l}0.696 \text { *** } \\
(0.015)\end{array}$ & $\begin{array}{l}0.627 * * * \\
(0.015)\end{array}$ \\
\hline 5 & & $\begin{array}{l}0.795 * * * \\
(0.015)\end{array}$ & $\begin{array}{l}0.832 * * * \\
(0.016)\end{array}$ & $\begin{array}{l}0.807 * * * \\
(0.017)\end{array}$ & $\begin{array}{l}0.707 * * * \\
(0.017)\end{array}$ \\
\hline$\geq 6$ & & $\begin{array}{l}0.822 * * * \\
(0.015)\end{array}$ & $\begin{array}{l}0.877 * * * \\
(0.016)\end{array}$ & $\begin{array}{l}0.857 * * * \\
(0.017)\end{array}$ & $\begin{array}{l}0.730 * * * \\
(0.018)\end{array}$ \\
\hline \multicolumn{6}{|c|}{ No. of authors $($ Base $=1)$} \\
\hline 2 & & $\begin{array}{c}0.005 \\
(0.004)\end{array}$ & $\begin{array}{c}0.001 \\
(0.004)\end{array}$ & $\begin{array}{l}-0.011 * * * \\
(0.003)\end{array}$ & $\begin{array}{l}-0.016 * * * \\
(0.003)\end{array}$ \\
\hline 3 & & $\begin{array}{l}0.015^{* *} \\
(0.006)\end{array}$ & $\begin{array}{c}0.007 \\
(0.005)\end{array}$ & $\begin{array}{l}-0.018 * * * \\
(0.004)\end{array}$ & $\begin{array}{l}-0.027 * * * \\
(0.004)\end{array}$ \\
\hline 4 & & $\begin{array}{c}0.005 \\
(0.010)\end{array}$ & $\begin{array}{l}-0.002 \\
(0.008)\end{array}$ & $\begin{array}{l}-0.032 * * * \\
(0.007)\end{array}$ & $\begin{array}{l}-0.047 * * * \\
(0.007)\end{array}$ \\
\hline 5 & & $\begin{array}{c}0.019 \\
(0.017)\end{array}$ & $\begin{array}{c}0.012 \\
(0.015)\end{array}$ & $\begin{array}{l}-0.026^{*} \\
(0.014)\end{array}$ & $\begin{array}{l}-0.046 * * * \\
(0.014)\end{array}$ \\
\hline$\geq 6$ & & $\begin{array}{l}-0.043^{* *} \\
(0.021)\end{array}$ & $\begin{array}{l}-0.039 * \\
(0.020)\end{array}$ & $\begin{array}{l}-0.070 * * * \\
(0.020)\end{array}$ & $\begin{array}{l}-0.096^{* * * *} \\
(0.020)\end{array}$ \\
\hline Author FE & No & No & Yes & Yes & Yes \\
\hline Post Date FE & No & No & No & Yes & Yes \\
\hline Observations & 90,854 & 90,854 & 90,732 & 90,727 & 90,727 \\
\hline R-squared & 0.013 & 0.423 & 0.495 & 0.516 & 0.528 \\
\hline
\end{tabular}

Notes: This table presents results for the link between conference presentation and the probability of being published in any journal. Conference equals to one if the paper is presented in one of the conferences and zero otherwise. Citations is the average number of citations that the paper received monthly. No. of versions is the number of versions of the paper. No. of authors is the number of the paper's authors. Column 1 reports results for the estimation without control variables. Columns (2)-(5) report results when control variables are added. Standard errors are clustered by author and date of the first posting. *, **, and *** denote $10 \%, 5 \%$, and $1 \%$ significance level, respectively. 
Table 4. Conference participation and publication outcomes by journal quality (ABS ranking)

\begin{tabular}{|c|c|c|c|c|c|}
\hline Journal quality & $(1)$ & $(2)$ & (3) & (4) & (5) \\
\hline 1 & $\begin{array}{l}-0.004 \\
(0.003)\end{array}$ & $\begin{array}{l}-0.017 * * * \\
(0.003)\end{array}$ & $\begin{array}{l}-0.017 * * * \\
(0.003)\end{array}$ & $\begin{array}{l}-0.021 * * * \\
(0.003)\end{array}$ & $\begin{array}{l}-0.019 * * * \\
(0.003)\end{array}$ \\
\hline 2 & $\begin{array}{l}0.013 * * \\
(0.005)\end{array}$ & $\begin{array}{l}-0.011^{* *} \\
(0.005)\end{array}$ & $\begin{array}{l}-0.017 * * * \\
(0.005)\end{array}$ & $\begin{array}{l}-0.022 * * * \\
(0.005)\end{array}$ & $\begin{array}{l}-0.020 * * * \\
(0.005)\end{array}$ \\
\hline 3 & $\begin{array}{l}0.075^{* * * *} \\
(0.008)\end{array}$ & $\begin{array}{l}0.014 * \\
(0.008)\end{array}$ & $\begin{array}{l}0.000 \\
(0.007)\end{array}$ & $\begin{array}{l}-0.010 \\
(0.007)\end{array}$ & $\begin{array}{l}-0.012 * \\
(0.007)\end{array}$ \\
\hline 4 & $\begin{array}{l}0.059 * * * \\
(0.006)\end{array}$ & $\begin{array}{l}0.024 * * * \\
(0.006)\end{array}$ & $\begin{array}{l}0.019 * * * \\
(0.005)\end{array}$ & $\begin{array}{l}0.017 * * * \\
(0.005)\end{array}$ & $\begin{array}{l}0.013 * * \\
(0.005)\end{array}$ \\
\hline $4 *$ & $\begin{array}{l}0.050 * * * \\
(0.006)\end{array}$ & $\begin{array}{l}0.027 * * * \\
(0.005)\end{array}$ & $\begin{array}{l}0.024 * * * \\
(0.005)\end{array}$ & $\begin{array}{l}0.022 * * * \\
(0.005)\end{array}$ & $\begin{array}{l}0.014 * * * \\
(0.005)\end{array}$ \\
\hline Author FE & No & No & Yes & Yes & Yes \\
\hline Post Date FE & No & No & No & Yes & Yes \\
\hline Controls & No & Yes & Yes & Yes & Yes \\
\hline Control for citations & No & No & No & No & Yes \\
\hline Observations & 90,854 & 90,854 & 90,732 & 90,727 & 90,727 \\
\hline
\end{tabular}

Notes: This table presents results for the link between conference presentation and the probability of being published in the ABS 1-4* journals. The reported coefficients are for Conference variable which equals to one if the paper is presented in one of the conferences and zero otherwise. Full table of results is reported in Appendix Table A4. Column 1 reports results for the estimation without control variables. Columns (2)-(5) report results when control variables are added. Standard errors are clustered by author and date of the first posting. *,**, and $* * *$ denote $10 \%, 5 \%$, and $1 \%$ significance level, respectively. 
Table 5. Publication time

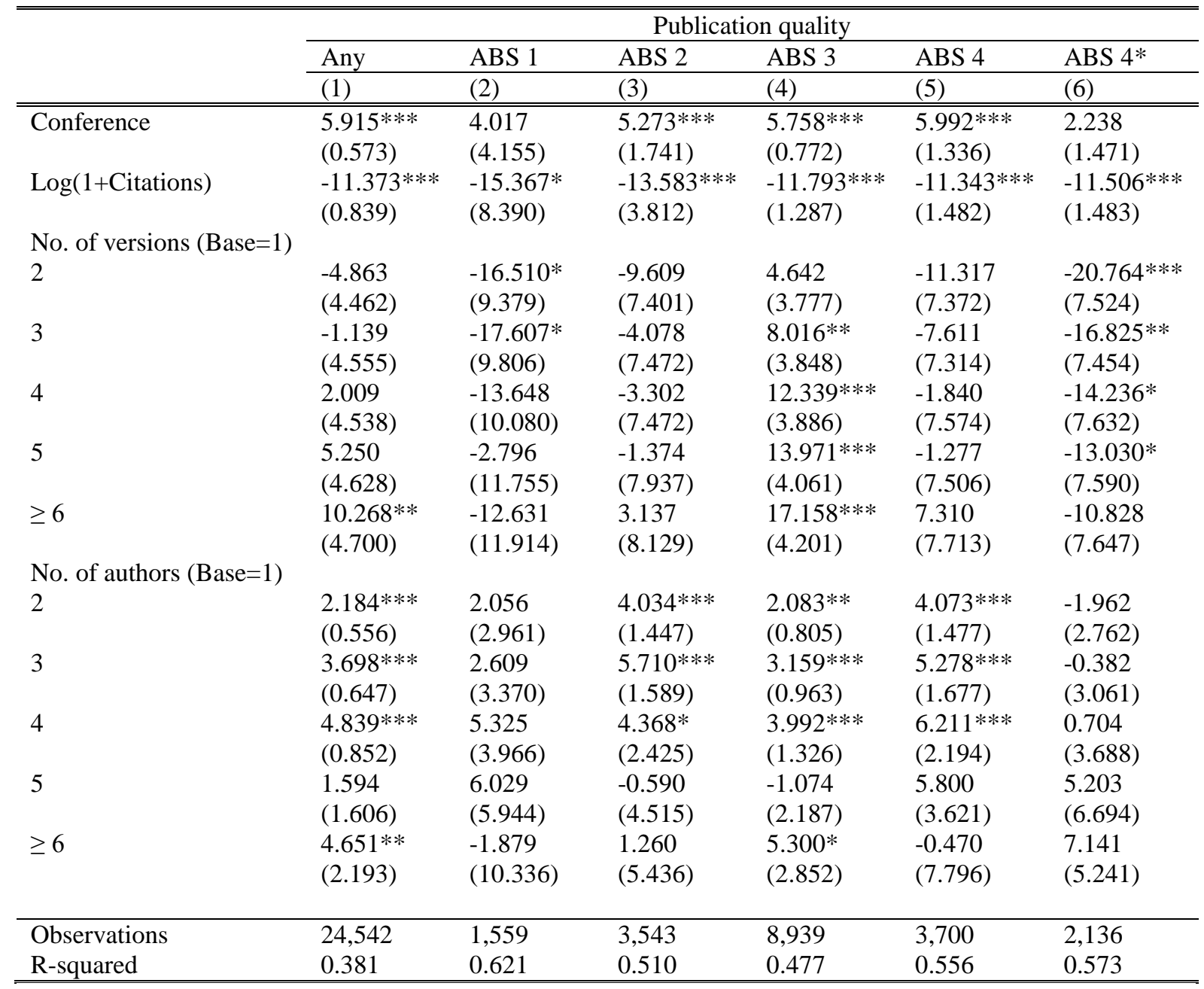

Notes: This table presents results for the link between conference presentation and the publication time which is duration (in months) between the first posting date and the date the paper appears in the journal. Column 1 reports results for publications in any journal. Columns (2)-(6) report results for publications in ABS1-4* journals, respectively. Conference equals to one if the paper is presented in one of the conferences and zero otherwise. Citations is the average number of citations that the paper received monthly. No. of versions is the number of versions of the paper. No. of authors is the number of the paper's authors. Standard errors are clustered by author and date of the first posting. *, **, and $* * *$ denote $10 \%, 5 \%$, and $1 \%$ significance level, respectively. 
Table 6. Conference participation (by conference) and publication outcomes

\begin{tabular}{|c|c|c|c|c|c|}
\hline & $(1)$ & $(2)$ & (3) & (4) & $(5)$ \\
\hline \multirow[t]{2}{*}{ AEA conference } & $0.235 * * *$ & (0.054*** & "0.036*** & 0.010 & -0.017 \\
\hline & $(0.021)$ & $(0.014)$ & $(0.013)$ & $(0.012)$ & $(0.012)$ \\
\hline \multirow[t]{2}{*}{ EEA conference } & $0.161 * * *$ & $0.021 *$ & -0.007 & $-0.023 * *$ & $-0.024 * *$ \\
\hline & $(0.015)$ & $(0.013)$ & $(0.011)$ & $(0.010)$ & $(0.010)$ \\
\hline \multirow[t]{2}{*}{ RES conference } & $0.117 * * *$ & 0.017 & -0.009 & $-0.025^{*}$ & $-0.029 *$ \\
\hline & $(0.021)$ & $(0.016)$ & $(0.015)$ & $(0.015)$ & $(0.015)$ \\
\hline $\log (1+$ Citations $)$ & & & & & $0.268 * * *$ \\
\hline \multicolumn{6}{|c|}{ No. of versions $($ Base $=1)$} \\
\hline \multirow{3}{*}{2} & & & & & $(0.015)$ \\
\hline & & $0.446 * * *$ & $0.432 * * *$ & $0.419 * * *$ & $0.394 * * *$ \\
\hline & & $(0.014)$ & $(0.013)$ & $(0.014)$ & $(0.013)$ \\
\hline \multirow[t]{2}{*}{3} & & $0.617 * * *$ & $0.617 * * *$ & $0.598 * * *$ & $0.548 * * *$ \\
\hline & & $(0.013)$ & $(0.014)$ & $(0.014)$ & $(0.014)$ \\
\hline \multirow[t]{2}{*}{4} & & $0.700 * * *$ & $0.717 * * *$ & $0.696 * * *$ & $0.627 * * *$ \\
\hline & & $(0.013)$ & $(0.014)$ & $(0.015)$ & $(0.015)$ \\
\hline \multirow[t]{2}{*}{5} & & $0.794 * * *$ & $0.831 * * *$ & $0.806^{* * *}$ & $0.707 * * *$ \\
\hline & & $(0.015)$ & $(0.016)$ & $(0.017)$ & $(0.017)$ \\
\hline \multirow[t]{2}{*}{$\geq 6$} & & $0.821 * * *$ & $0.876^{* * *}$ & $0.856 * * *$ & $0.730 * * *$ \\
\hline & & $(0.015)$ & $(0.016)$ & $(0.017)$ & $(0.018)$ \\
\hline \multicolumn{6}{|c|}{ No. of authors $($ Base $=1)$} \\
\hline \multirow[t]{2}{*}{2} & & 0.005 & 0.001 & $-0.011 * * *$ & $-0.016 * * *$ \\
\hline & & $(0.004)$ & $(0.004)$ & $(0.003)$ & $(0.003)$ \\
\hline \multirow[t]{2}{*}{3} & & $0.015 * *$ & 0.007 & $-0.018 * * *$ & $-0.027 * * *$ \\
\hline & & $(0.006)$ & $(0.005)$ & $(0.004)$ & $(0.004)$ \\
\hline \multirow[t]{2}{*}{4} & & 0.005 & -0.002 & $-0.032 * * *$ & $-0.047 * * *$ \\
\hline & & $(0.010)$ & $(0.008)$ & $(0.007)$ & $(0.007)$ \\
\hline \multirow[t]{2}{*}{5} & & 0.018 & 0.011 & $-0.026^{*}$ & $-0.046 * * *$ \\
\hline & & $(0.017)$ & $(0.015)$ & $(0.014)$ & $(0.014)$ \\
\hline \multirow[t]{2}{*}{$\geq 6$} & & $-0.043 * *$ & $-0.039 * *$ & $-0.070 * * *$ & $-0.096 * * *$ \\
\hline & & $(0.021)$ & $(0.020)$ & $(0.020)$ & $(0.020)$ \\
\hline Author FE & No & No & Yes & Yes & Yes \\
\hline Post Date FE & No & No & No & Yes & Yes \\
\hline Observations & 90,854 & 90,854 & 90,732 & 90,727 & 90,727 \\
\hline R-squared & 0.014 & 0.423 & 0.496 & 0.516 & 0.528 \\
\hline
\end{tabular}

Notes: This table presents results for the link between conference presentation by conference and the probability of being published in any journal. AEA conference, EEA conference, and RES conference equal to one if the paper is presented in the AEA, EEA, and RES conferences, respectively; and zero otherwise. Citations is the average number of new citations that the received monthly. No. of versions is the number of versions of the paper. No. of authors is the number of the paper's authors. Column 1 reports results for the estimation without control variables. Columns (2)-(5) report results when control variables are added. Standard errors are clustered by author and date of the first posting. *,**, and $* * *$ denote $10 \%, 5 \%$, and $1 \%$ significance level, respectively. 
Table 7. Conference participation (by conference) and publication outcomes (by quality)

\begin{tabular}{|c|c|c|c|c|c|c|}
\hline Journal quality & Conference & (1) & (2) & (3) & (4) & (5) \\
\hline ABS 1 & $\begin{array}{l}\text { AEA } \\
\text { EEA } \\
\text { RES }\end{array}$ & $\begin{array}{l}-0.005 \\
(0.005) \\
0.002 \\
(0.005) \\
-0.011 * * \\
(0.005)\end{array}$ & $\begin{array}{l}-0.019 * * * \\
(0.005) \\
-0.009 * * \\
(0.004) \\
-0.019 * * * \\
(0.005)\end{array}$ & $\begin{array}{l}-0.009 * \\
(0.005) \\
-0.013 * * * \\
(0.004) \\
-0.024 * * * \\
(0.006)\end{array}$ & $\begin{array}{l}-0.013 * * * \\
(0.005) \\
-0.016^{* * *} \\
(0.005) \\
-0.027 * * * \\
(0.006)\end{array}$ & $\begin{array}{l}-0.007 \\
(0.005) \\
-0.016 * * * \\
(0.005) \\
-0.026 * * * \\
(0.006)\end{array}$ \\
\hline ABS 2 & $\begin{array}{l}\text { AEA } \\
\text { EEA } \\
\text { RES }\end{array}$ & $\begin{array}{l}-0.025 * * * \\
(0.006) \\
0.029 * * * \\
(0.008) \\
0.017 * \\
(0.010)\end{array}$ & $\begin{array}{l}-0.052 * * * \\
(0.006) \\
0.006 \\
(0.007) \\
0.001 \\
(0.010)\end{array}$ & $\begin{array}{l}-0.029 * * * \\
(0.006) \\
-0.011 \\
(0.007) \\
-0.014 \\
(0.010)\end{array}$ & $\begin{array}{l}-0.034 * * * \\
(0.006) \\
-0.016 * * \\
(0.007) \\
-0.017 * \\
(0.010)\end{array}$ & $\begin{array}{l}-0.028 * * * \\
(0.006) \\
-0.015 * * \\
(0.007) \\
-0.016 \\
(0.010)\end{array}$ \\
\hline ABS 3 & $\begin{array}{l}\text { AEA } \\
\text { EEA } \\
\text { RES }\end{array}$ & $\begin{array}{l}0.044 * * * \\
(0.012) \\
0.080 * * * \\
(0.011) \\
0.067 * * * \\
(0.016)\end{array}$ & $\begin{array}{l}-0.026^{* *} \\
(0.012) \\
0.026^{* *} \\
(0.010) \\
0.027^{*} \\
(0.015)\end{array}$ & $\begin{array}{l}-0.022 * \\
(0.012) \\
0.008 \\
(0.010) \\
0.006 \\
(0.014)\end{array}$ & $\begin{array}{l}-0.033 * * * \\
(0.011) \\
0.001 \\
(0.010) \\
-0.003 \\
(0.014)\end{array}$ & $\begin{array}{l}-0.040 * * * \\
(0.012) \\
0.001 \\
(0.010) \\
-0.004 \\
(0.014)\end{array}$ \\
\hline ABS 4 & $\begin{array}{l}\text { AEA } \\
\text { EEA } \\
\text { RES }\end{array}$ & $\begin{array}{l}0.081 * * * \\
(0.011) \\
0.042 * * * \\
(0.007) \\
0.053 * * * \\
(0.013)\end{array}$ & $\begin{array}{l}0.040 * * * \\
(0.010) \\
0.011 \\
(0.007) \\
0.032 * * * \\
(0.011)\end{array}$ & $\begin{array}{l}0.022 * * \\
(0.009) \\
0.012 * \\
(0.007) \\
0.032 * * * \\
(0.011)\end{array}$ & $\begin{array}{l}0.020 * * \\
(0.009) \\
0.012 * \\
(0.007) \\
0.030 * * * \\
(0.012)\end{array}$ & $\begin{array}{l}0.009 \\
(0.009) \\
0.011 \\
(0.007) \\
0.029 * * \\
(0.011)\end{array}$ \\
\hline $\operatorname{ABS} 4 *$ & $\begin{array}{l}\text { AEA } \\
\text { EEA } \\
\text { RES }\end{array}$ & $\begin{array}{l}0.142 * * * \\
(0.013) \\
0.009 * \\
(0.005) \\
-0.009 \\
(0.006)\end{array}$ & $\begin{array}{l}0.114 * * * \\
(0.012) \\
-0.011 * * \\
(0.005) \\
-0.022 * * * \\
(0.006)\end{array}$ & $\begin{array}{l}0.076 * * * \\
(0.012) \\
-0.001 \\
(0.005) \\
-0.008 \\
(0.005)\end{array}$ & $\begin{array}{l}0.073 * * * \\
(0.013) \\
-0.002 \\
(0.005) \\
-0.008 \\
(0.006)\end{array}$ & $\begin{array}{l}0.052 * * * \\
(0.011) \\
-0.003 \\
(0.005) \\
-0.010 * * \\
(0.005)\end{array}$ \\
\hline $\begin{array}{l}\text { Author FE } \\
\text { Post Date FE } \\
\text { Controls } \\
\text { Control for citations } \\
\text { Observations }\end{array}$ & & $\begin{array}{l}\text { No } \\
\text { No } \\
\text { No } \\
\text { No } \\
90,854\end{array}$ & $\begin{array}{l}\text { No } \\
\text { No } \\
\text { Yes } \\
\text { No } \\
90,854\end{array}$ & $\begin{array}{l}\text { Yes } \\
\text { No } \\
\text { Yes } \\
\text { No } \\
90,732\end{array}$ & $\begin{array}{l}\text { Yes } \\
\text { Yes } \\
\text { Yes } \\
\text { No } \\
90,727\end{array}$ & $\begin{array}{l}\text { Yes } \\
\text { Yes } \\
\text { Yes } \\
\text { Yes } \\
90,727\end{array}$ \\
\hline
\end{tabular}

Notes: This table presents results for the link between conference presentation by conference and the probability of being published in the ABS 1-4* journals. The reported coefficients are for AEA conference, EEA conference, and RES conference which equal to one if the paper is presented in the AEA, EEA, and RES conferences, respectively; and zero otherwise. Column 1 reports results for the estimation without control variables. Columns (2)-(5) report results when control variables are added. Standard errors are clustered by author and date of the first posting. $* * *$, and $* * *$ denote $10 \%, 5 \%$, and $1 \%$ significance level, respectively. 
Table 8. Conference participation and publication outcomes by journal quality and field

\begin{tabular}{|c|c|c|c|c|c|c|c|}
\hline & Any JEL & Micro Theory & Econometrics & Macro & Applied Micro & $\begin{array}{l}\text { Development } \\
\text { Environment } \\
\end{array}$ & Missing JEL \\
\hline Journal quality & $(1)$ & $(2)$ & (3) & (4) & $(5)$ & $(6)$ & (7) \\
\hline Any & $\begin{array}{l}-0.036 * * * \\
(0.008)\end{array}$ & $\begin{array}{l}-0.061 * * * \\
(0.018)\end{array}$ & $\begin{array}{l}-0.050 * * * \\
(0.015)\end{array}$ & $\begin{array}{l}-0.046 * * * \\
(0.013)\end{array}$ & $\begin{array}{l}-0.035^{* * *} \\
(0.011)\end{array}$ & $\begin{array}{l}-0.032 * \\
(0.016)\end{array}$ & $\begin{array}{c}0.001 \\
(0.016)\end{array}$ \\
\hline ABS 1 & $\begin{array}{l}-0.022^{* * *} \\
(0.004)\end{array}$ & $\begin{array}{l}-0.025^{* * * *} \\
(0.007)\end{array}$ & $\begin{array}{l}-0.013 * \\
(0.007)\end{array}$ & $\begin{array}{l}-0.027 * * * \\
(0.005)\end{array}$ & $\begin{array}{l}-0.017 * * * \\
(0.005)\end{array}$ & $\begin{array}{l}-0.008 \\
(0.008)\end{array}$ & $\begin{array}{l}-0.001 \\
(0.008)\end{array}$ \\
\hline ABS 2 & $\begin{array}{l}-0.022 * * * \\
(0.006)\end{array}$ & $\begin{array}{l}-0.018 * \\
(0.011)\end{array}$ & $\begin{array}{l}-0.018 * * \\
(0.009)\end{array}$ & $\begin{array}{l}-0.028 * * * \\
(0.008)\end{array}$ & $\begin{array}{l}-0.021 * * * \\
(0.007)\end{array}$ & $\begin{array}{l}-0.031 * * * \\
(0.011)\end{array}$ & $\begin{array}{l}-0.008 \\
(0.008)\end{array}$ \\
\hline ABS 3 & $\begin{array}{l}-0.016 * \\
(0.008)\end{array}$ & $\begin{array}{l}-0.034 * * \\
(0.016)\end{array}$ & $\begin{array}{l}-0.032 * * \\
(0.014)\end{array}$ & $\begin{array}{l}-0.022 * \\
(0.012)\end{array}$ & $\begin{array}{l}-0.010 \\
(0.011)\end{array}$ & $\begin{array}{l}-0.033^{* *} \\
(0.017)\end{array}$ & $\begin{array}{l}-0.011 \\
(0.012)\end{array}$ \\
\hline ABS 4 & $\begin{array}{l}0.012^{* *} \\
(0.006)\end{array}$ & $\begin{array}{c}0.011 \\
(0.011)\end{array}$ & $\begin{array}{l}-0.004 \\
(0.010)\end{array}$ & $\begin{array}{l}0.024 * * \\
(0.010)\end{array}$ & $\begin{array}{c}0.004 \\
(0.008)\end{array}$ & $\begin{array}{c}0.016 \\
(0.012)\end{array}$ & $\begin{array}{l}0.023 * * \\
(0.010)\end{array}$ \\
\hline ABS $4 *$ & $\begin{array}{l}0.014 * * \\
(0.005)\end{array}$ & $\begin{array}{c}0.007 \\
(0.008)\end{array}$ & $\begin{array}{c}0.017 * \\
(0.010)\end{array}$ & $\begin{array}{c}0.009 \\
(0.008)\end{array}$ & $\begin{array}{c}0.010 \\
(0.007)\end{array}$ & $\begin{array}{l}0.025^{* *} \\
(0.010)\end{array}$ & $\begin{array}{c}0.001 \\
(0.006)\end{array}$ \\
\hline $\begin{array}{l}\text { Author FE } \\
\text { Post Date FE } \\
\text { Controls } \\
\text { Control for citations } \\
\text { Observations } \\
\end{array}$ & $\begin{array}{c}\text { Yes } \\
\text { Yes } \\
\text { Yes } \\
\text { Yes } \\
59,980 \\
\end{array}$ & $\begin{array}{c}\text { Yes } \\
\text { Yes } \\
\text { Yes } \\
\text { Yes } \\
15,559 \\
\end{array}$ & $\begin{array}{c}\text { Yes } \\
\text { Yes } \\
\text { Yes } \\
\text { Yes } \\
16,124 \\
\end{array}$ & $\begin{array}{c}\text { Yes } \\
\text { Yes } \\
\text { Yes } \\
\text { Yes } \\
26,766 \\
\end{array}$ & $\begin{array}{c}\text { Yes } \\
\text { Yes } \\
\text { Yes } \\
\text { Yes } \\
28,863 \\
\end{array}$ & $\begin{array}{c}\text { Yes } \\
\text { Yes } \\
\text { Yes } \\
\text { Yes } \\
12,825 \\
\end{array}$ & $\begin{array}{c}\text { Yes } \\
\text { Yes } \\
\text { Yes } \\
\text { Yes } \\
29,801 \\
\end{array}$ \\
\hline
\end{tabular}

Notes: This table presents results for the link between conference presentation and the probability of being published by ABS ranking and field. The reported coefficients are for Conference variable which equals to one if the paper is presented in one of the conferences and zero otherwise. Columns (1)-(7) reports results for the estimations for papers in any field, in the field of Micro Theory, Econometrics, Macroeconomics, Applied Microeconomics, Development and Environment Economics, and papers whose JEL codes are missing, respectively. Standard errors are clustered by author and date of the first posting. *, **, and *** denote $10 \%, 5 \%$, and $1 \%$ significance level, respectively. 
Table 9. Spill-over effect

\begin{tabular}{|c|c|c|c|c|c|c|}
\hline \multirow{8}{*}{$\begin{array}{l}\text { Author FE } \\
\text { Post Date FE } \\
\text { Controls } \\
\text { Control for citations } \\
\text { Observations }\end{array}$} & \multicolumn{6}{|c|}{ Publication quality } \\
\hline & Any & ABS 1 & ABS 2 & ABS 3 & ABS 4 & $\mathrm{ABS} 4 *$ \\
\hline & Yes & Yes & Yes & Yes & Yes & Yes \\
\hline & Yes & Yes & Yes & Yes & Yes & Yes \\
\hline & Yes & Yes & Yes & Yes & Yes & Yes \\
\hline & Yes & Yes & Yes & Yes & Yes & Yes \\
\hline & 90,727 & 90,727 & 90,727 & 90,727 & 90,727 & 90,727 \\
\hline & (1) & (2) & (3) & (4) & $(5)$ & (6) \\
\hline \multicolumn{7}{|l|}{ Panel A: Any conference } \\
\hline Conference & $\begin{array}{l}-0.027 * * * \\
(0.008)\end{array}$ & $\begin{array}{l}-0.020 * * * \\
(0.004)\end{array}$ & $\begin{array}{l}-0.020 * * * \\
(0.005)\end{array}$ & $\begin{array}{l}-0.011 \\
(0.007)\end{array}$ & $\begin{array}{l}0.015 * * \\
(0.006)\end{array}$ & $\begin{array}{l}0.011 * * \\
(0.005)\end{array}$ \\
\hline Conf. $\times$ Session with Top $1 \%$ & $\begin{array}{l}0.007 \\
(0.023)\end{array}$ & $\begin{array}{l}0.010 \\
(0.010)\end{array}$ & $\begin{array}{l}-0.002 \\
(0.012)\end{array}$ & $\begin{array}{l}-0.012 \\
(0.020)\end{array}$ & $\begin{array}{l}-0.013 \\
(0.018)\end{array}$ & $\begin{array}{l}0.024 \\
(0.015)\end{array}$ \\
\hline R-squared & 0.528 & 0.121 & 0.170 & 0.234 & 0.187 & 0.271 \\
\hline \multicolumn{7}{|l|}{ Panel B. AEA } \\
\hline Conference & $\begin{array}{l}-0.019 \\
(0.013)\end{array}$ & $\begin{array}{l}-0.014 * * * \\
(0.005)\end{array}$ & $\begin{array}{l}-0.033 * * * \\
(0.007)\end{array}$ & $\begin{array}{l}-0.035 * * \\
(0.014)\end{array}$ & $\begin{array}{l}0.018 \\
(0.012)\end{array}$ & $\begin{array}{l}0.048 * * * \\
(0.014)\end{array}$ \\
\hline Conf. $\times$ Session with Top $1 \%$ & $\begin{array}{l}0.006 \\
(0.029)\end{array}$ & $\begin{array}{l}0.029 * \\
(0.015)\end{array}$ & $\begin{array}{l}0.021 \\
(0.015)\end{array}$ & $\begin{array}{l}-0.021 \\
(0.025)\end{array}$ & $\begin{array}{l}-0.036 \\
(0.025)\end{array}$ & $\begin{array}{l}0.014 \\
(0.026)\end{array}$ \\
\hline R-squared & 0.528 & 0.121 & 0.170 & 0.234 & 0.187 & 0.272 \\
\hline \multicolumn{7}{|l|}{ Panel C. EEA } \\
\hline Conference & $\begin{array}{l}-0.027 * * \\
(0.010)\end{array}$ & $\begin{array}{l}-0.015^{* * *} \\
(0.005)\end{array}$ & $\begin{array}{l}-0.015 * * \\
(0.008)\end{array}$ & $\begin{array}{l}-0.002 \\
(0.010)\end{array}$ & $\begin{array}{l}0.011 \\
(0.007)\end{array}$ & $\begin{array}{l}-0.004 \\
(0.005)\end{array}$ \\
\hline Conf. $\times$ Session with Top $1 \%$ & $\begin{array}{l}0.016 \\
(0.041)\end{array}$ & $\begin{array}{l}-0.036^{* * *} \\
(0.007)\end{array}$ & $\begin{array}{l}-0.017 \\
(0.026)\end{array}$ & $\begin{array}{l}0.034 \\
(0.040)\end{array}$ & $\begin{array}{l}0.026 \\
(0.032)\end{array}$ & $\begin{array}{l}0.003 \\
(0.019)\end{array}$ \\
\hline R-squared & 0.528 & 0.121 & 0.169 & 0.234 & 0.187 & 0.270 \\
\hline \multicolumn{7}{|l|}{ Panel D. RES } \\
\hline Conference & $\begin{array}{l}-0.030 * \\
(0.015)\end{array}$ & $\begin{array}{l}-0.027 * * * \\
(0.006)\end{array}$ & $\begin{array}{l}-0.016 \\
(0.010)\end{array}$ & $\begin{array}{l}-0.006 \\
(0.014)\end{array}$ & $\begin{array}{l}0.030 * * * \\
(0.012)\end{array}$ & $\begin{array}{l}-0.010 * \\
(0.005)\end{array}$ \\
\hline Conf. $\times$ Session with Top $1 \%$ & $\begin{array}{l}-0.025 \\
(0.061)\end{array}$ & $\begin{array}{l}-0.008 \\
(0.011)\end{array}$ & $\begin{array}{l}-0.026 \\
(0.021)\end{array}$ & $\begin{array}{l}0.034 \\
(0.062)\end{array}$ & $\begin{array}{l}-0.006 \\
(0.041)\end{array}$ & $\begin{array}{l}-0.018 \\
(0.020)\end{array}$ \\
\hline R-squared & 0.528 & 0.121 & 0.169 & 0.234 & 0.187 & 0.270 \\
\hline
\end{tabular}

Notes: This table presents results for the link between conference presentation and the probability of being published, controlling for the spill-over effect of having a star scholar in the session (specification 4.1). Columns (1)-(10) report results for publications in any journal and in ABS 1-4*, respectively. Conference equals to one if the paper is presented and zero otherwise. Session with Top 1\% equals to one if the paper is presented in the session of which any author of other papers has been in top one percent of the IDEAS/RePEc Top Economist ranking and zero otherwise. Standard errors are clustered by author and date of the first posting. *, **, and *** denote $10 \%, 5 \%$, and $1 \%$ significance level, respectively. 
Table 10. Prominent author effect

\begin{tabular}{|c|c|c|c|c|c|c|}
\hline \multirow{9}{*}{$\begin{array}{l}\text { Author FE } \\
\text { Post Date FE } \\
\text { Controls } \\
\text { Control for citations } \\
\text { Control for author ranking } \\
\text { Observations }\end{array}$} & \multicolumn{6}{|c|}{ Publication quality } \\
\hline & \multicolumn{2}{|c|}{ Any $\quad$ ABS 1} & \multirow{2}{*}{$\begin{array}{l}\text { ABS } 2 \\
\text { Yes }\end{array}$} & \multirow{2}{*}{$\begin{array}{l}\text { ABS } 3 \\
\text { Yes }\end{array}$} & \multirow{2}{*}{$\begin{array}{l}\text { ABS } 4 \\
\text { Yes }\end{array}$} & \multirow{2}{*}{$\begin{array}{l}\text { ABS 4* } \\
\text { Yes } \\
\end{array}$} \\
\hline & Yes & Yes & & & & \\
\hline & Yes & Yes & Yes & Yes & Yes & Yes \\
\hline & Yes & Yes & Yes & Yes & Yes & Yes \\
\hline & Yes & Yes & Yes & Yes & Yes & Yes \\
\hline & Yes & Yes & Yes & Yes & Yes & Yes \\
\hline & 90,727 & 90,727 & 90,727 & 90,727 & 90,727 & 90,727 \\
\hline & $(1)$ & $(2)$ & (3) & (4) & $(5)$ & (6) \\
\hline \multicolumn{7}{|l|}{ Panel A. Any conference } \\
\hline Conference & $\begin{array}{l}-0.033 * * * \\
(0.008)\end{array}$ & $\begin{array}{l}-0.022 * * * \\
(0.003)\end{array}$ & $\begin{array}{l}-0.020 * * * \\
(0.005)\end{array}$ & $\begin{array}{l}-0.012 \\
(0.007)\end{array}$ & $\begin{array}{l}0.014 * * * \\
(0.005)\end{array}$ & $\begin{array}{l}0.007 \\
(0.004)\end{array}$ \\
\hline Conf.xPaper with Top $1 \%$ & $\begin{array}{l}0.053 * * \\
(0.023)\end{array}$ & $\begin{array}{l}0.026^{* * *} \\
(0.011)\end{array}$ & $\begin{array}{l}-0.004 \\
(0.010)\end{array}$ & $\begin{array}{l}-0.005 \\
(0.020) \\
\end{array}$ & $\begin{array}{l}-0.010 \\
(0.020)\end{array}$ & $\begin{array}{l}0.053 * * * \\
(0.017)\end{array}$ \\
\hline R-squared & 0.528 & 0.121 & 0.170 & 0.234 & 0.187 & 0.271 \\
\hline \multicolumn{7}{|l|}{ Panel B. AEA } \\
\hline Conference & $\begin{array}{l}-0.027 * * \\
(0.013)\end{array}$ & $\begin{array}{l}-0.015 * * * \\
(0.005)\end{array}$ & $\begin{array}{l}-0.035^{* * *} \\
(0.006)\end{array}$ & $\begin{array}{l}-0.036^{* * * *} \\
(0.013)\end{array}$ & $\begin{array}{l}0.017 * \\
(0.009)\end{array}$ & $\begin{array}{l}0.043 * * * \\
(0.011)\end{array}$ \\
\hline Conf.xPaper with Top $1 \%$ & $\begin{array}{l}0.047 \\
(0.030)\end{array}$ & $\begin{array}{l}0.032 * * \\
(0.014) \\
\end{array}$ & $\begin{array}{l}0.030 * * \\
(0.012) \\
\end{array}$ & $\begin{array}{l}-0.015 \\
(0.025) \\
\end{array}$ & $\begin{array}{l}-0.032 \\
(0.024) \\
\end{array}$ & $\begin{array}{l}0.037 \\
(0.025) \\
\end{array}$ \\
\hline R-squared & 0.528 & 0.121 & 0.170 & 0.235 & 0.187 & 0.272 \\
\hline \multicolumn{7}{|l|}{ Panel C. EEA } \\
\hline Conference & $\begin{array}{l}-0.031 * * * \\
(0.010)\end{array}$ & $\begin{array}{l}-0.019 * * * \\
(0.005)\end{array}$ & $\begin{array}{l}-0.014 * \\
(0.007)\end{array}$ & $\begin{array}{l}-0.003 \\
(0.010)\end{array}$ & $\begin{array}{l}0.011 \\
(0.007)\end{array}$ & $\begin{array}{l}-0.005 \\
(0.004)\end{array}$ \\
\hline Conf. $\times$ Paper with Top $1 \%$ & $\begin{array}{l}0.066^{* * *} \\
(0.032) \\
\end{array}$ & $\begin{array}{l}0.020 \\
(0.024) \\
\end{array}$ & $\begin{array}{l}-0.027 \\
(0.019) \\
\end{array}$ & $\begin{array}{l}0.037 \\
(0.041) \\
\end{array}$ & $\begin{array}{l}0.021 \\
(0.036) \\
\end{array}$ & $\begin{array}{l}0.024 \\
(0.025) \\
\end{array}$ \\
\hline R-squared & 0.528 & 0.121 & 0.170 & 0.234 & 0.187 & 0.270 \\
\hline \multicolumn{7}{|l|}{ Panel D. RES } \\
\hline Conference & $\begin{array}{l}-0.031^{*} \\
(0.016)\end{array}$ & $\begin{array}{l}-0.026 * * * \\
(0.006)\end{array}$ & $\begin{array}{l}-0.014 \\
(0.010)\end{array}$ & $\begin{array}{l}-0.003 \\
(0.015)\end{array}$ & $\begin{array}{l}0.027 * * \\
(0.011)\end{array}$ & $\begin{array}{l}-0.013 * * * \\
(0.005)\end{array}$ \\
\hline Conf. $\times$ Paper with Top $1 \%$ & $\begin{array}{l}-0.013 \\
(0.065) \\
\end{array}$ & $\begin{array}{l}-0.024 * * \\
(0.010)\end{array}$ & $\begin{array}{l}-0.049 * * \\
(0.020)\end{array}$ & $\begin{array}{l}-0.018 \\
(0.056)\end{array}$ & $\begin{array}{l}0.049 \\
(0.058)\end{array}$ & $\begin{array}{l}0.033 \\
(0.031)\end{array}$ \\
\hline R-squared & 0.528 & 0.121 & 0.170 & 0.234 & 0.187 & 0.270 \\
\hline \multicolumn{7}{|c|}{$\begin{array}{l}\text { Notes: This table presents results for the link between conference presentation and the probability of being } \\
\text { published, controlling for the effect of having a star scholar in the author team (specification 4.2). Columns (1)- } \\
\text { (6) report results for publications in any journal and in ABS } 1-4^{*} \text {, respectively. Panels A-D report results for } \\
\text { presentation in any conference, in AEA, EEA, and RES conferences, respectively. Conference equals to one if } \\
\text { the paper is presented and zero otherwise. Paper with Top 1\% equals to one if at least one of the authors of the } \\
\text { paper has been in top one percent of the IDEAS/RePEc Top Economist ranking and zero otherwise. Standard } \\
\text { errors are clustered by author and date of the first posting. *, **, and } * * * \text { denote } 10 \%, 5 \% \text {, and } 1 \% \text { significance } \\
\text { level, respectively. }\end{array}$} \\
\hline
\end{tabular}


Table 11. Gender effect

\begin{tabular}{|c|c|c|c|c|}
\hline \multirow[b]{3}{*}{ Journal quality } & \multicolumn{2}{|c|}{ Unmatched sample } & \multicolumn{2}{|c|}{ Matched sample } \\
\hline & Female & Male & Female & Male \\
\hline & $(1)$ & $(2)$ & (3) & $(4)$ \\
\hline \multirow[t]{2}{*}{ Any } & $-0.052 * * *$ & $-0.022 * * *$ & $-0.055 * * *$ & $-0.028 * * *$ \\
\hline & $(0.014)$ & $(0.008)$ & $(0.016)$ & $(0.010)$ \\
\hline \multirow[t]{2}{*}{ ABS 1} & $-0.021 * * *$ & $-0.018 * * *$ & $-0.017 * *$ & $-0.020 * * *$ \\
\hline & $(0.006)$ & $(0.004)$ & $(0.007)$ & $(0.005)$ \\
\hline \multirow[t]{2}{*}{ ABS 2} & $-0.017 *$ & $-0.021 * * *$ & -0.017 & $-0.021 * * *$ \\
\hline & $(0.009)$ & $(0.005)$ & $(0.012)$ & $(0.007)$ \\
\hline \multirow[t]{2}{*}{ ABS 3} & -0.016 & -0.011 & $-0.033 * *$ & $-0.022 * *$ \\
\hline & $(0.013)$ & $(0.008)$ & $(0.015)$ & $(0.009)$ \\
\hline \multirow[t]{2}{*}{ ABS 4} & -0.001 & $0.016 * * *$ & 0.005 & $0.019 * *$ \\
\hline & $(0.009)$ & $(0.006)$ & $(0.010)$ & $(0.007)$ \\
\hline \multirow[t]{2}{*}{ ABS 4* } & 0.003 & $0.016 * * *$ & 0.008 & $0.017 * * *$ \\
\hline & $(0.007)$ & $(0.005)$ & $(0.008)$ & $(0.006)$ \\
\hline Author FE & Yes & Yes & Yes & Yes \\
\hline Post Date FE & Yes & Yes & Yes & Yes \\
\hline Controls & Yes & Yes & Yes & Yes \\
\hline Control for citations & Yes & Yes & Yes & Yes \\
\hline Observations & 11,448 & 79,263 & 7,220 & 28,830 \\
\hline
\end{tabular}

Notes: This table presents the comparison of the link between conference presentation and the probability of being published between female (Columns (1) and (3)) and male authors (Columns (2) and (4)). Columns (1)-(2) report results for unmatched samples. Columns (3)-(4) report results for matched samples. The reported coefficients are for Conference variable which equals to one if the paper is presented in one of the conferences and zero otherwise. $*$, **, and $* * *$ denote $10 \%, 5 \%$, and $1 \%$ significance level, respectively. 
Table 12. Conference participation and paper visibility and impact

\begin{tabular}{|c|c|c|c|c|c|c|c|c|}
\hline & \multicolumn{4}{|c|}{ Abstract views } & \multicolumn{4}{|c|}{ Citations } \\
\hline & (1) & (2) & (3) & (4) & (5) & (6) & (7) & $(8)$ \\
\hline \multirow[t]{2}{*}{ Conference } & $0.239 * * *$ & 0.016 & $0.028 * *$ & $0.095 * * *$ & $0.110 * * *$ & $0.042 * * *$ & $0.043 * * *$ & $0.039 * * *$ \\
\hline & $(0.023)$ & $(0.016)$ & $(0.012)$ & $(0.010)$ & $(0.008)$ & $(0.006)$ & $(0.005)$ & $(0.005)$ \\
\hline \multicolumn{9}{|c|}{ No. of versions $($ Base $=1)$} \\
\hline \multirow[t]{2}{*}{2} & & $0.483 * * *$ & $0.462 * * *$ & $0.463 * * *$ & & $0.104 * * *$ & $0.098 * * *$ & $0.094 * * *$ \\
\hline & & $(0.013)$ & $(0.012)$ & $(0.008)$ & & $(0.003)$ & $(0.003)$ & $(0.003)$ \\
\hline \multirow[t]{2}{*}{3} & & $0.774 * * *$ & $0.751 * * *$ & $0.758 * * *$ & & $0.205 * * *$ & $0.195 * * *$ & $0.189 * * *$ \\
\hline & & $(0.017)$ & $(0.017)$ & $(0.011)$ & & $(0.005)$ & $(0.005)$ & $(0.005)$ \\
\hline \multirow[t]{2}{*}{4} & & $0.984 * * *$ & $0.968 * * *$ & $0.973 * * *$ & & $0.283 * * *$ & $0.266^{* * *}$ & $0.259 * * *$ \\
\hline & & $(0.020)$ & $(0.018)$ & $(0.013)$ & & $(0.008)$ & $(0.007)$ & $(0.007)$ \\
\hline \multirow[t]{2}{*}{5} & & $1.161 * * *$ & $1.140 * * *$ & $1.148 * * *$ & & $0.404 * * *$ & $0.380 * * *$ & $0.372 * * *$ \\
\hline & & $(0.025)$ & $(0.023)$ & $(0.018)$ & & $(0.015)$ & $(0.013)$ & $(0.013)$ \\
\hline \multirow[t]{2}{*}{$\geq 6$} & & $1.368 * * *$ & $1.336 * * *$ & $1.338 * * *$ & & $0.509 * * *$ & $0.477 * * *$ & $0.473 * * *$ \\
\hline & & $(0.033)$ & $(0.031)$ & $(0.025)$ & & $(0.022)$ & $(0.019)$ & $(0.019)$ \\
\hline \multicolumn{9}{|c|}{ No. of authors $($ Base $=1)$} \\
\hline \multirow[t]{2}{*}{2} & & $0.064 * * *$ & $0.064 * * *$ & $0.095 * * *$ & & $0.018 * * *$ & $0.021 * * *$ & $0.019 * * *$ \\
\hline & & $(0.014)$ & $(0.010)$ & $(0.008)$ & & $(0.002)$ & $(0.002)$ & $(0.002)$ \\
\hline \multirow[t]{2}{*}{3} & & $0.089 * * *$ & $0.090 * * *$ & $0.156 * * *$ & & $0.036 * * *$ & $0.039 * * *$ & $0.036 * * *$ \\
\hline & & $(0.016)$ & $(0.012)$ & $(0.010)$ & & $(0.003)$ & $(0.003)$ & $(0.003)$ \\
\hline \multirow[t]{2}{*}{4} & & $0.105^{* * *}$ & $0.095 * * *$ & $0.192 * * *$ & & $0.061 * * *$ & $0.058 * * *$ & $0.054 * * *$ \\
\hline & & $(0.020)$ & $(0.016)$ & $(0.013)$ & & $(0.006)$ & $(0.005)$ & $(0.005)$ \\
\hline \multirow[t]{2}{*}{5} & & 0.047 & $0.073 * *$ & $0.174 * * *$ & & $0.088 * * *$ & $0.082 * * *$ & $0.076 * * *$ \\
\hline & & $(0.035)$ & $(0.028)$ & $(0.026)$ & & $(0.013)$ & $(0.012)$ & $(0.012)$ \\
\hline \multirow[t]{2}{*}{$\geq 6$} & & 0.001 & 0.066 & $0.188 * * *$ & & $0.095 * * *$ & $0.101 * * *$ & $0.098 * * *$ \\
\hline & & $(0.071)$ & $(0.046)$ & $(0.040)$ & & $(0.024)$ & $(0.021)$ & $(0.020)$ \\
\hline Author FE & No & No & Yes & Yes & No & No & Yes & Yes \\
\hline Post Date FE & No & No & No & Yes & No & No & No & Yes \\
\hline Observations & 90,854 & 90,854 & 90,732 & 90,727 & 90,854 & 90,854 & 90,732 & 90,727 \\
\hline R-squared & 0.008 & 0.289 & 0.450 & 0.500 & 0.015 & 0.266 & 0.411 & 0.419 \\
\hline
\end{tabular}

Notes: This table presents results for the link between conference presentation and the average abstract views and citations received by a paper (specification (5)). Conference equals to one if the paper is presented in one of the conferences and zero otherwise. Abstract views is the average number of abstract views that the paper received monthly. Citations is the average number of citations that the paper received monthly. No. of versions is the number of versions of the paper. No. of authors is the number of the paper's authors. Columns (1)-(4) report results for the estimations with average abstract views. Columns (5)-(8) report results for the estimations with average citations. Standard errors are clustered by author and date of the first posting. *,**, and *** denote $10 \%$, $5 \%$, and $1 \%$ significance level, respectively. 


\section{Figures}

\section{Figure 1. Publication outcomes and time/day of presentation}
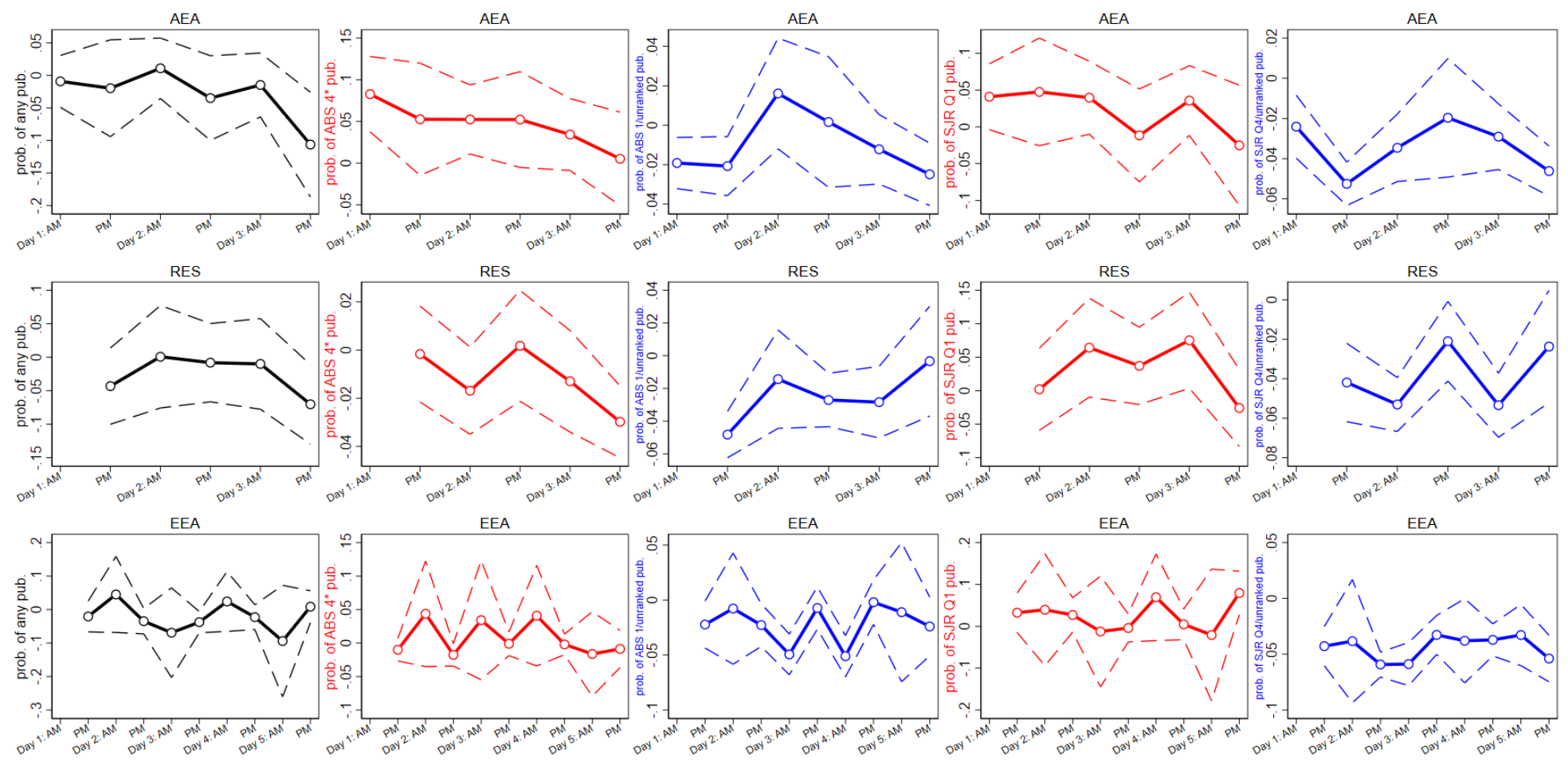

Notes: This figure presents results for the link between conference presentation by conference time and the probability of being published. The employed specification is:

$$
\text { Publication }_{p, a}=\alpha+\sum_{c} \sum_{\tau} \beta_{c, \tau} \text { TimeDayConference }_{p, a, c, \tau}+\boldsymbol{X}_{p, a} \boldsymbol{\gamma}+u_{a}+\text { error }
$$

where TimeDayConference $e_{p, a, c, \tau}$ equals to one if paper $\mathrm{p}$ with authors a was presented in conference $\mathrm{c}$ at time slot $\tau$ (presented in the horizontal lines). The list of control variables includes (1) $\log (1+$ Citations) of which Citations is the average number of citations that the received monthly; (2) No. of versions is the number of versions of the paper; and (3) No. of authors is the number of the paper's authors. The solid black, red, and blue lines show the estimated coefficients on TimeDayConference ${ }_{p, a, c, \tau}$ in the estimations with publications in any journal (column 1), in ABS 4* journals (column 2), in ABS 1 journals (column 3), in SJR Q1 journals (column 4), and in SJR Q4 journals (column 5) as the outcome, respectively. The dashed lines indicate 1.96 standard error confidence intervals. 
Figure 2. Dynamics of citations and abstract views before and after a major conference.

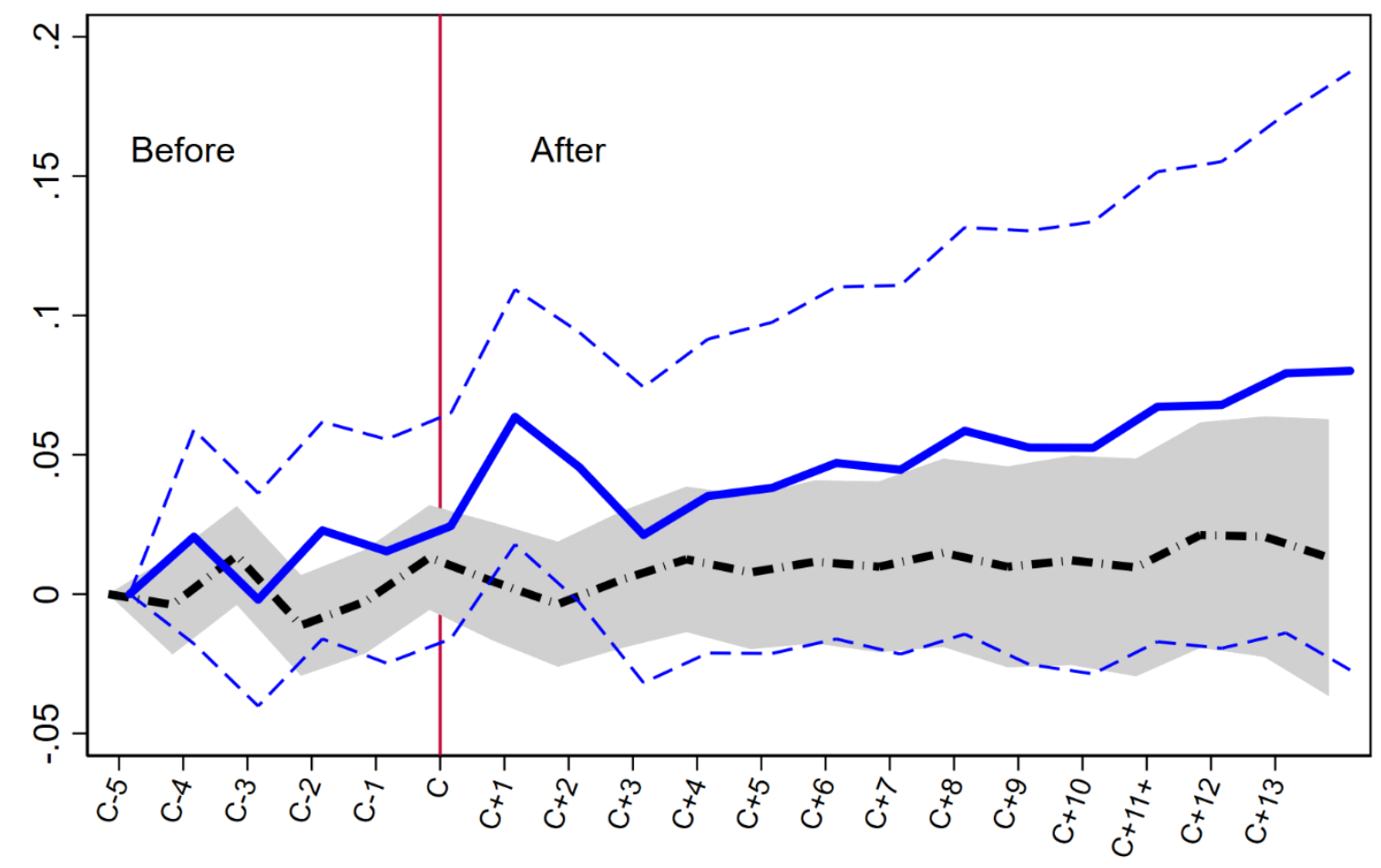

\section{- - - Citations $\longrightarrow$ Abstract views}

Notes: This figure presents results for the following specification:

$$
\operatorname{Ln}(1+\text { Outcome })_{p, c, m}=\alpha+\sum_{s=-\underline{S}}^{\bar{s}} \beta_{\mathrm{s}} \text { Conference }_{p, c, m-\tau}+\boldsymbol{X}_{p, c, m} \boldsymbol{\gamma}+\lambda_{m}+\eta_{p}+\text { error }
$$

where $\tau$ is the time of conference $\mathrm{c}$ where paper $\mathrm{p}$ was presented at, $m$ is calendar month. The list of control variable includes (1) Age which is the natural log of the paper's age; (2) New version which equals to one if a new version of the paper is made available and zero otherwise; (3) and Share of influential authors which is the ratio of the number of the authors in the top ten percent of the Top Economist ranking in a given month to the total number of authors. Outcome is the number of either monthly abstract views or citations.

The estimated coefficients on Conference ${ }_{p, c, m-\tau}$ are represented by the solid blue line and the solid black line for estimations with the number of abstract views and citations respectively. The dashed lines indicate confidence intervals at 5\% significant level. In the horizontal axis, $\mathrm{C}$ refers to conference. The red vertical line represents the conference month. 


\section{Appendix A}

Appendix Table A1. Papers' monthly statistics

\begin{tabular}{|c|c|c|c|c|c|c|c|c|c|c|}
\hline & \multicolumn{5}{|c|}{ Presented papers } & \multicolumn{5}{|c|}{ Non-presented papers } \\
\hline & Min & Mean & Max & SD & $\mathrm{N}$ & Min & Mean & Max & SD & $\mathrm{N}$ \\
\hline & (1) & (2) & (3) & (4) & (5) & (6) & (7) & (8) & (9) & (10) \\
\hline No. of version & 1 & 1.972 & 18 & 1.199 & 373,375 & 1 & 1.478 & 15 & 0.864 & $8,239,070$ \\
\hline Downloads & 0 & 2.133 & 1,340 & 5.128 & 373,375 & 0 & 1.495 & 841 & 3.884 & $8,239,070$ \\
\hline Abstract views & 0 & 6.911 & 1,473 & 11.308 & 373,375 & 0 & 5.579 & 2,412 & 11.304 & $8,239,070$ \\
\hline Citations & 0 & 0.305 & 402 & 1.823 & 373,375 & 0 & 0.138 & 971 & 1.370 & $8,239,070$ \\
\hline
\end{tabular}

Notes: This table presents statistics for the monthly statistics of the paper in our sample. Number of versions is the monthly statistics of versions of each paper available in IDEAS/RePEc. Downloads, Abstract views, and Citations are the monthly downloads, abstract views, and new citations that a paper gets, respectively. 
Appendix Table A2. Summary statistics for conference paper sample

\begin{tabular}{|c|c|c|}
\hline & $\begin{array}{l}\text { Papers posted before } \\
\text { conference }\end{array}$ & $\begin{array}{l}\text { Papers posted } \\
\text { after conference }\end{array}$ \\
\hline & $(1)$ & $(2)$ \\
\hline \multicolumn{3}{|l|}{ No. of papers } \\
\hline \multicolumn{3}{|c|}{ No. of conference presentations } \\
\hline 1 conference & 2,641 & 3,219 \\
\hline 2 conferences & 185 & 85 \\
\hline 3 conferences & 6 & 3 \\
\hline \multicolumn{3}{|l|}{ No. of authors } \\
\hline Single author & 615 & 963 \\
\hline 2 authors & 1,320 & 1,324 \\
\hline 3 authors & 713 & 696 \\
\hline 4 authors & 148 & 163 \\
\hline 5 authors & 20 & 41 \\
\hline More than 5 authors & 16 & 120 \\
\hline Publications & 1,259 & 1,669 \\
\hline \multicolumn{3}{|l|}{ Journal rankings } \\
\hline \multicolumn{3}{|l|}{ ABS } \\
\hline ABS 4* & 218 & 488 \\
\hline ABS 4 & 307 & 310 \\
\hline ABS 3 & 468 & 540 \\
\hline ABS 2 & 185 & 233 \\
\hline ABS 1 or Un-ranked & 81 & 98 \\
\hline \multicolumn{3}{|l|}{ SJR } \\
\hline SJR Q1 & 1,040 & 1,377 \\
\hline SJR Q2 & 139 & 150 \\
\hline SJR Q3 & 27 & 18 \\
\hline SJR Q4 & 53 & 124 \\
\hline \multicolumn{3}{|l|}{ Monthly statistics } \\
\hline \multicolumn{3}{|l|}{ No. of version } \\
\hline Mean & 1.978 & 1.555 \\
\hline St.Dev. & 1.216 & 0.957 \\
\hline \multicolumn{3}{|l|}{ Downloads } \\
\hline Mean & 2.204 & 1.518 \\
\hline St.Dev. & 5.193 & 3.979 \\
\hline \multicolumn{3}{|l|}{ Abstract views } \\
\hline Mean & 7.276 & 4.662 \\
\hline St.Dev. & 11.442 & 7.786 \\
\hline \multicolumn{3}{|l|}{ Citations } \\
\hline Mean & 0.327 & 0.282 \\
\hline St.Dev. & 2.258 & 1.574 \\
\hline
\end{tabular}

Notes: This table summarizes statistics of conference papers. Columns 1-2 show statistics for papers that were posted on IDEAS/RePEc before and after the conference, respectively. No. of papers is the number of distinct presented and non-presented works. No. of conferences is the number of conferences where a given paper was presented at. No. of authors is the number of authors for a given paper. Publications is the number of works that were published in a journal. Journal rankings is the journal rank in the Association of Business Schools' Academic Journal Guide 2015 (ABS 2015 ranking) or the Scientific Journal Rankings (SJR). Number of versions is the monthly statistics of versions of each paper available in IDEAS/RePEc. Downloads, Abstract views, and Citations are the monthly downloads, abstract views, and new citations that a paper gets, respectively. 
Appendix Table A3. Probability of presentation

\begin{tabular}{|c|c|c|c|c|c|c|}
\hline & 2007 & 2008 & 2009 & 2010 & 2011 & 2012 \\
\hline Author FE & Yes & Yes & Yes & Yes & Yes & Yes \\
\hline \multirow[t]{2}{*}{ Age FE } & Yes & Yes & Yes & Yes & Yes & Yes \\
\hline & $(1)$ & $(2)$ & (3) & $(4)$ & $(5)$ & $(6)$ \\
\hline \multicolumn{7}{|l|}{ Panel A. AEA } \\
\hline \multicolumn{3}{|l|}{$\log (1+$ Citations $)$} & $\begin{array}{l}-0.010 \\
(0.011)\end{array}$ & $\begin{array}{l}-0.012 \\
(0.008)\end{array}$ & $\begin{array}{l}0.004 \\
(0.006)\end{array}$ & $\begin{array}{l}-0.006 \\
(0.006)\end{array}$ \\
\hline Version & $\begin{array}{l}0.055 \\
(0.034)\end{array}$ & $\begin{array}{l}0.024 \\
(0.017)\end{array}$ & $\begin{array}{l}0.035^{* *} * \\
(0.013)\end{array}$ & $\begin{array}{l}0.016 \\
(0.011)\end{array}$ & $\begin{array}{l}0.013 * * \\
(0.006)\end{array}$ & $\begin{array}{l}0.022 * \\
(0.012)\end{array}$ \\
\hline \multicolumn{7}{|l|}{ No. of authors } \\
\hline 2 & $\begin{array}{l}0.107 * \\
(0.056)\end{array}$ & $\begin{array}{l}0.080 * * * \\
(0.028)\end{array}$ & $\begin{array}{l}0.098 * * * \\
(0.031)\end{array}$ & $\begin{array}{l}0.077 * * * \\
(0.023)\end{array}$ & $\begin{array}{l}0.037 * * * \\
(0.013)\end{array}$ & $\begin{array}{l}0.018 \\
(0.013)\end{array}$ \\
\hline 3 & $\begin{array}{l}0.145 \\
(0.106)\end{array}$ & $\begin{array}{l}0.082 * \\
(0.046)\end{array}$ & $\begin{array}{l}0.080 * * \\
(0.038)\end{array}$ & $\begin{array}{l}0.092 * * * \\
(0.030)\end{array}$ & $\begin{array}{l}0.091 * * * \\
(0.023)\end{array}$ & $\begin{array}{l}0.034 * \\
(0.018)\end{array}$ \\
\hline 4 & $\begin{array}{l}0.022 \\
(0.191)\end{array}$ & $\begin{array}{l}0.018 \\
(0.076)\end{array}$ & $\begin{array}{l}-0.033 \\
(0.042)\end{array}$ & $\begin{array}{l}0.033 \\
(0.032)\end{array}$ & $\begin{array}{l}0.077 \\
(0.053)\end{array}$ & $\begin{array}{l}0.039 \\
(0.042)\end{array}$ \\
\hline 5 & $\begin{array}{l}-0.389 * * * \\
(0.069)\end{array}$ & $\begin{array}{l}-0.072 \\
(0.046)\end{array}$ & $\begin{array}{l}-0.027 \\
(0.026)\end{array}$ & $\begin{array}{l}0.205^{* *} \\
(0.082)\end{array}$ & $\begin{array}{l}-0.005 \\
(0.030)\end{array}$ & $\begin{array}{l}-0.014 \\
(0.028)\end{array}$ \\
\hline$\geq 6$ & $\begin{array}{l}-0.223^{*} \\
(0.127)\end{array}$ & $\begin{array}{l}0.031 \\
(0.036)\end{array}$ & $\begin{array}{l}-0.125 \\
(0.132)\end{array}$ & $\begin{array}{l}0.025 \\
(0.043)\end{array}$ & $\begin{array}{l}-0.065 \\
(0.055)\end{array}$ & $\begin{array}{l}-0.058 * * \\
(0.024)\end{array}$ \\
\hline Observations & 404 & 966 & 1,007 & 1,310 & 2,197 & 2,234 \\
\hline R-squared & 0.288 & 0.173 & 0.261 & 0.247 & 0.237 & 0.220 \\
\hline \multicolumn{7}{|l|}{ Panel B. EEA } \\
\hline $\log (1+$ Citations $)$ & & $\begin{array}{l}-0.028 * * \\
(0.014)\end{array}$ & $\begin{array}{l}-0.014 \\
(0.009)\end{array}$ & $\begin{array}{l}-0.006 \\
(0.007)\end{array}$ & $\begin{array}{l}-0.014 * \\
(0.008)\end{array}$ & $\begin{array}{l}-0.004 \\
(0.007)\end{array}$ \\
\hline Version & $\begin{array}{l}0.068 * \\
(0.035)\end{array}$ & $\begin{array}{l}0.030 \\
(0.019)\end{array}$ & $\begin{array}{l}0.011 \\
(0.009)\end{array}$ & $\begin{array}{l}0.033 * * \\
(0.016)\end{array}$ & $\begin{array}{l}0.016 * \\
(0.009)\end{array}$ & $\begin{array}{l}0.034 * * * \\
(0.013)\end{array}$ \\
\hline \multicolumn{7}{|l|}{ No. of authors } \\
\hline 2 & $\begin{array}{l}0.152 * * * \\
(0.043)\end{array}$ & $\begin{array}{l}0.066 * * \\
(0.027)\end{array}$ & $\begin{array}{l}0.064 * * * \\
(0.015)\end{array}$ & $\begin{array}{l}0.046^{* * *} \\
(0.018)\end{array}$ & $\begin{array}{l}0.057 * * * \\
(0.015)\end{array}$ & $\begin{array}{l}0.021 * \\
(0.012)\end{array}$ \\
\hline 3 & $\begin{array}{l}0.146 * * * \\
(0.043)\end{array}$ & $\begin{array}{l}0.097 * * \\
(0.036)\end{array}$ & $\begin{array}{l}0.085 * * * \\
(0.027)\end{array}$ & $\begin{array}{l}0.072 * * * \\
(0.023)\end{array}$ & $\begin{array}{l}0.070 * * * \\
(0.021)\end{array}$ & $\begin{array}{l}0.016 \\
(0.017)\end{array}$ \\
\hline 4 & $\begin{array}{l}0.105 \\
(0.089)\end{array}$ & $\begin{array}{l}0.115 \\
(0.073)\end{array}$ & $\begin{array}{l}0.052 * \\
(0.030)\end{array}$ & $\begin{array}{l}0.033 \\
(0.025)\end{array}$ & $\begin{array}{l}0.086 * * \\
(0.035)\end{array}$ & $\begin{array}{l}0.041 * \\
(0.024)\end{array}$ \\
\hline 5 & $\begin{array}{l}0.023 \\
(0.110)\end{array}$ & $\begin{array}{l}-0.027 \\
(0.045)\end{array}$ & $\begin{array}{l}-0.022 \\
(0.052)\end{array}$ & $\begin{array}{l}0.039 \\
(0.065)\end{array}$ & $\begin{array}{l}-0.049 \\
(0.041)\end{array}$ & $\begin{array}{l}-0.050^{* *} \\
(0.024)\end{array}$ \\
\hline$\geq 6$ & $\begin{array}{l}0.014 \\
(0.092)\end{array}$ & $\begin{array}{l}-0.069 \\
(0.087)\end{array}$ & $\begin{array}{l}-0.017 \\
(0.029)\end{array}$ & $\begin{array}{l}-0.051 * * \\
(0.023)\end{array}$ & $\begin{array}{l}-0.008 \\
(0.024)\end{array}$ & $\begin{array}{l}-0.021 \\
(0.015)\end{array}$ \\
\hline Observations & 805 & 1,116 & 1,951 & 2,380 & 2,956 & 2,609 \\
\hline R-squared & 0.253 & 0.269 & 0.266 & 0.261 & 0.279 & 0.251 \\
\hline
\end{tabular}

(continued on the next page) 


\begin{tabular}{|c|c|c|c|c|c|c|}
\hline \multicolumn{7}{|l|}{ "Panel C. RES } \\
\hline $\log (1+$ Citations $)$ & & $\begin{array}{l}0.036 \\
(0.023)\end{array}$ & $\begin{array}{l}-0.011 \\
(0.011)\end{array}$ & $\begin{array}{l}-0.016 \\
(0.012)\end{array}$ & $\begin{array}{l}-0.000 \\
(0.005)\end{array}$ & $\begin{array}{l}0.011^{*} \\
(0.007)\end{array}$ \\
\hline Version & $\begin{array}{l}0.042 \\
(0.115)\end{array}$ & $\begin{array}{l}-0.019 \\
(0.037)\end{array}$ & $\begin{array}{l}-0.009 \\
(0.009)\end{array}$ & $\begin{array}{l}0.020 \\
(0.012)\end{array}$ & $\begin{array}{l}0.001 \\
(0.008)\end{array}$ & $\begin{array}{l}0.004 \\
(0.005)\end{array}$ \\
\hline \multicolumn{7}{|l|}{ No. of authors } \\
\hline 2 & $\begin{array}{l}0.075 \\
(0.126)\end{array}$ & $\begin{array}{l}0.107 * * \\
(0.044)\end{array}$ & $\begin{array}{l}0.118 * * \\
(0.045)\end{array}$ & $\begin{array}{l}0.066^{* * * *} \\
(0.022)\end{array}$ & $\begin{array}{l}0.056^{* * * *} \\
(0.019)\end{array}$ & $\begin{array}{l}0.040 * * * \\
(0.013)\end{array}$ \\
\hline 3 & $\begin{array}{l}0.280 * * \\
(0.125)\end{array}$ & $\begin{array}{l}0.074 \\
(0.046)\end{array}$ & $\begin{array}{l}0.167 * * \\
(0.067)\end{array}$ & $\begin{array}{l}0.071 * * \\
(0.030)\end{array}$ & $\begin{array}{l}0.060 * * * \\
(0.019)\end{array}$ & $\begin{array}{l}0.054 * * \\
(0.021)\end{array}$ \\
\hline 4 & $\begin{array}{l}-0.040 \\
(0.103)\end{array}$ & $\begin{array}{l}0.190 \\
(0.160)\end{array}$ & $\begin{array}{l}0.084 * * \\
(0.041)\end{array}$ & $\begin{array}{l}0.081 * * \\
(0.038)\end{array}$ & $\begin{array}{l}0.155 * * * \\
(0.044)\end{array}$ & $\begin{array}{l}0.015 \\
(0.024)\end{array}$ \\
\hline 5 & $\begin{array}{l}0.262 * * \\
(0.113)\end{array}$ & $\begin{array}{l}0.192 * * * \\
(0.070)\end{array}$ & $\begin{array}{l}0.163 * * * \\
(0.055)\end{array}$ & $\begin{array}{l}-0.069 \\
(0.055)\end{array}$ & $\begin{array}{l}-0.046 \\
(0.032)\end{array}$ & $\begin{array}{l}0.013 \\
(0.018)\end{array}$ \\
\hline$\geq 6$ & & $\begin{array}{l}0.304 * * \\
(0.149)\end{array}$ & $\begin{array}{l}0.090 * \\
(0.051)\end{array}$ & $\begin{array}{l}-0.009 \\
(0.051)\end{array}$ & $\begin{array}{l}-0.059 * \\
(0.030)\end{array}$ & $\begin{array}{l}0.101 \\
(0.068)\end{array}$ \\
\hline Observations & 151 & 473 & 536 & 980 & 2,193 & 3,094 \\
\hline R-squared & 0.371 & 0.303 & 0.297 & 0.295 & 0.263 & 0.216 \\
\hline
\end{tabular}

Notes: This table reports results for the link between pre-conference quality and probability of being accepted to a conference. Samples for estimation are assembled as follows. For each conference - year, a paper is considered as "potentially accepted" for presentation if it satisfies all criteria: (1) was listed in IDEAS/RePEc prior the submission deadline of this year's conference, (2) was listed after the 2005 conference's submission deadline, and (3) was not presented in the past conferences. Columns (1)-(6) show results for the samples of "potentially accepted" papers to conferences in 2007-2012, respectively. Panels A-C show results for the samples of "potentially accepted" papers to AEA, EEA, and RES conferences, respectively. Citations is the natural log of one plus number of total citations received by the paper over 12 months prior to the submission deadline. Version is the number of versions that a paper has prior to the submission deadline. No. of authors is the number of authors of the paper. $* * *$, and $* * *$ denote $10 \%, 5 \%$, and $1 \%$ significance level, respectively. 
Appendix Table A4. Conference participation and publication outcomes (by quality)

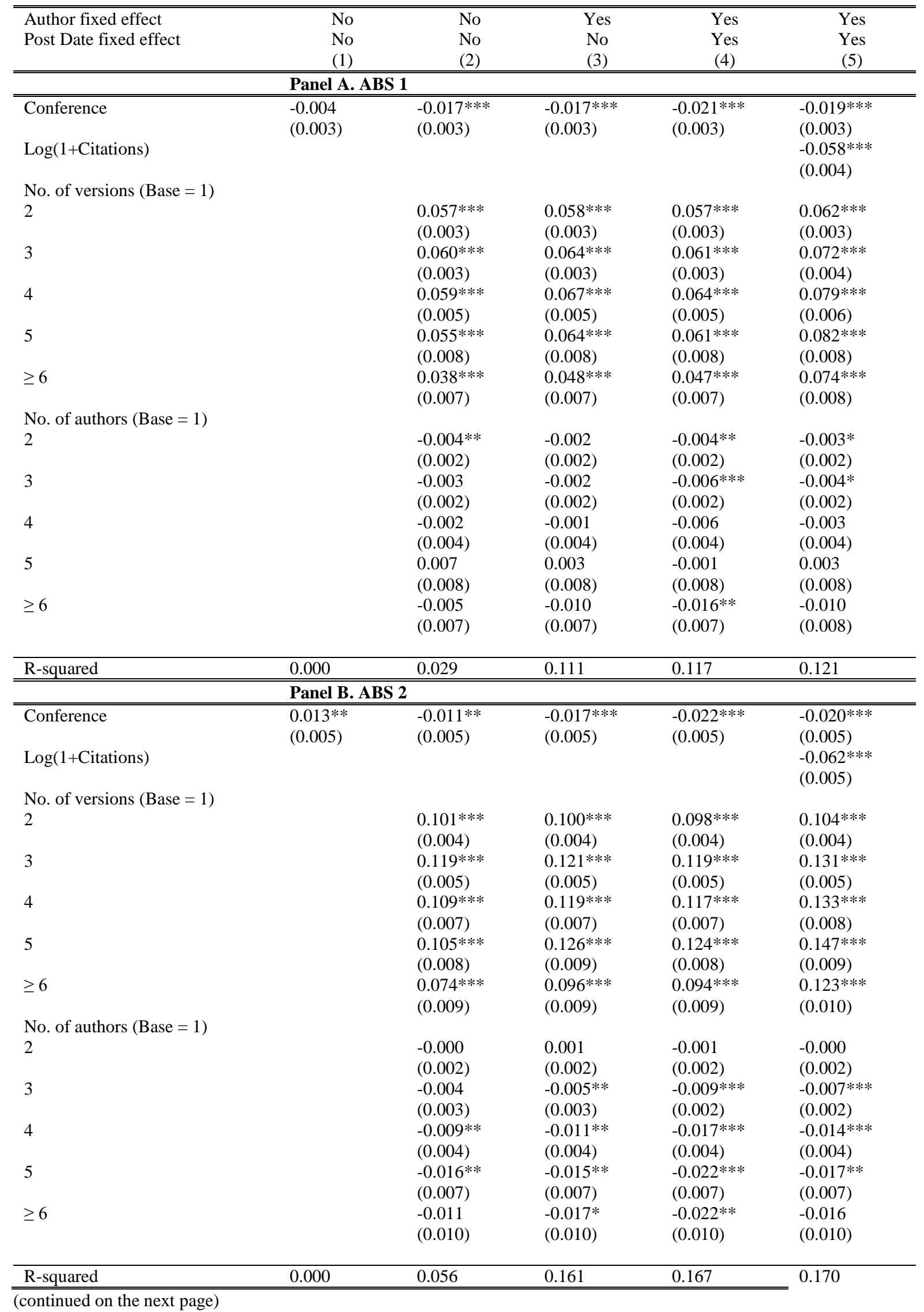




\begin{tabular}{|c|c|c|c|c|c|}
\hline \multirow[b]{2}{*}{ Conference } & \multicolumn{5}{|c|}{ Panel C. ABS 3} \\
\hline & $\begin{array}{l}0.075 * * * \\
(0.008)\end{array}$ & $\begin{array}{l}0.014^{*} \\
(0.008)\end{array}$ & $\begin{array}{l}0.000 \\
(0.007)\end{array}$ & $\begin{array}{l}-0.010 \\
(0.007)\end{array}$ & $\begin{array}{l}-0.012 * \\
(0.007)\end{array}$ \\
\hline $\log (1+$ Citations $)$ & & & & & $\begin{array}{l}0.066^{* * * *} \\
(0.011)\end{array}$ \\
\hline \multicolumn{6}{|c|}{ No. of versions $($ Base $=1)$} \\
\hline 2 & & $\begin{array}{l}0.182 * * * \\
(0.006)\end{array}$ & $\begin{array}{l}0.175 * * * \\
(0.006)\end{array}$ & $\begin{array}{l}0.170 * * * \\
(0.006)\end{array}$ & $\begin{array}{l}0.164 * * * \\
(0.006)\end{array}$ \\
\hline 3 & & $\begin{array}{l}0.253 * * * \\
(0.008)\end{array}$ & $\begin{array}{l}0.252 * * * \\
(0.008)\end{array}$ & $\begin{array}{l}0.245 * * * \\
(0.008)\end{array}$ & $\begin{array}{l}0.233 * * * \\
(0.008)\end{array}$ \\
\hline 4 & & $\begin{array}{l}0.275^{* * *} \\
(0.011)\end{array}$ & $\begin{array}{l}0.282 * * * \\
(0.011)\end{array}$ & $\begin{array}{l}0.276^{* * * *} \\
(0.011)\end{array}$ & $\begin{array}{l}0.259 * * * \\
(0.012)\end{array}$ \\
\hline 5 & & $\begin{array}{l}0.288 * * * \\
(0.015)\end{array}$ & $\begin{array}{l}0.306 * * * \\
(0.014)\end{array}$ & $\begin{array}{l}0.297 * * * \\
(0.014)\end{array}$ & $\begin{array}{l}0.273 * * * \\
(0.014)\end{array}$ \\
\hline$\geq 6$ & & $\begin{array}{l}0.277 * * * \\
(0.019)\end{array}$ & $\begin{array}{l}0.303 * * * \\
(0.018)\end{array}$ & $\begin{array}{l}0.297 * * * \\
(0.018)\end{array}$ & $\begin{array}{l}0.266 * * * \\
(0.019)\end{array}$ \\
\hline \multicolumn{6}{|c|}{ No. of authors $($ Base $=1)$} \\
\hline 2 & & $\begin{array}{l}0.001 \\
(0.003)\end{array}$ & $\begin{array}{l}0.002 \\
(0.003)\end{array}$ & $\begin{array}{l}-0.003 \\
(0.003)\end{array}$ & $\begin{array}{l}-0.005^{*} \\
(0.003)\end{array}$ \\
\hline 3 & & $\begin{array}{l}0.011 * * * \\
(0.004)\end{array}$ & $\begin{array}{l}0.009 * * \\
(0.004)\end{array}$ & $\begin{array}{l}-0.002 \\
(0.004)\end{array}$ & $\begin{array}{l}-0.004 \\
(0.004)\end{array}$ \\
\hline 4 & & $\begin{array}{l}0.012 * \\
(0.006)\end{array}$ & $\begin{array}{l}0.008 \\
(0.006)\end{array}$ & $\begin{array}{l}-0.006 \\
(0.006)\end{array}$ & $\begin{array}{l}-0.010 \\
(0.006)\end{array}$ \\
\hline 5 & & $\begin{array}{l}0.004 \\
(0.013)\end{array}$ & $\begin{array}{l}0.001 \\
(0.013)\end{array}$ & $\begin{array}{l}-0.017 \\
(0.013)\end{array}$ & $\begin{array}{l}-0.022 * \\
(0.013)\end{array}$ \\
\hline$\geq 6$ & & $\begin{array}{l}-0.007 \\
(0.015)\end{array}$ & $\begin{array}{l}-0.003 \\
(0.014)\end{array}$ & $\begin{array}{l}-0.019 \\
(0.014)\end{array}$ & $\begin{array}{l}-0.025^{*} \\
(0.014)\end{array}$ \\
\hline \multirow[t]{2}{*}{ R-squared } & 0.004 & 0.133 & 0.223 & 0.232 & 0.234 \\
\hline & \multicolumn{5}{|c|}{ Panel D. ABS 4} \\
\hline Conference & $\begin{array}{l}0.059 * * * \\
(0.006)\end{array}$ & $\begin{array}{l}0.024 * * * \\
(0.006)\end{array}$ & $\begin{array}{l}0.019 * * * \\
(0.005)\end{array}$ & $\begin{array}{l}0.017 * * * \\
(0.005)\end{array}$ & $\begin{array}{l}0.013 * * \\
(0.005)\end{array}$ \\
\hline \multicolumn{2}{|l|}{$\log (1+$ Citations $)$} & & & & $\begin{array}{l}0.104 * * * \\
(0.010)\end{array}$ \\
\hline \multicolumn{6}{|c|}{ No. of versions $($ Base $=1)$} \\
\hline 2 & & $\begin{array}{l}0.068 * * * \\
(0.003)\end{array}$ & $\begin{array}{l}0.065^{* * *} * \\
(0.003)\end{array}$ & $\begin{array}{l}0.062 * * * \\
(0.003)\end{array}$ & $\begin{array}{l}0.053 * * * \\
(0.003)\end{array}$ \\
\hline 3 & & $\begin{array}{l}0.119 * * * \\
(0.005)\end{array}$ & $\begin{array}{l}0.118 * * * \\
(0.005)\end{array}$ & $\begin{array}{l}0.113 * * * \\
(0.005)\end{array}$ & $\begin{array}{l}0.094 * * * \\
(0.005)\end{array}$ \\
\hline 4 & & $\begin{array}{l}0.158 * * * \\
(0.008)\end{array}$ & $\begin{array}{l}0.155 * * * \\
(0.008)\end{array}$ & $\begin{array}{l}0.150 * * * \\
(0.008)\end{array}$ & $\begin{array}{l}0.123 * * * \\
(0.008)\end{array}$ \\
\hline 5 & & $\begin{array}{l}0.204 * * * \\
(0.012)\end{array}$ & $\begin{array}{l}0.200 * * * \\
(0.012)\end{array}$ & $\begin{array}{l}0.194 * * * \\
(0.011)\end{array}$ & $\begin{array}{l}0.155^{* * *} * \\
(0.011)\end{array}$ \\
\hline$\geq 6$ & & $\begin{array}{l}0.227 * * * \\
(0.017)\end{array}$ & $\begin{array}{l}0.228 * * * \\
(0.016)\end{array}$ & $\begin{array}{l}0.223 * * * \\
(0.016)\end{array}$ & $\begin{array}{l}0.174 * * * \\
(0.017)\end{array}$ \\
\hline \multicolumn{6}{|c|}{ No. of authors $($ Base $=1)$} \\
\hline 2 & & $\begin{array}{l}0.005 * * * \\
(0.002)\end{array}$ & $\begin{array}{l}0.002 \\
(0.002)\end{array}$ & $\begin{array}{l}0.001 \\
(0.002)\end{array}$ & $\begin{array}{l}-0.001 \\
(0.002)\end{array}$ \\
\hline 3 & & $\begin{array}{l}0.001 \\
(0.003)\end{array}$ & $\begin{array}{l}0.000 \\
(0.003)\end{array}$ & $\begin{array}{l}-0.003 \\
(0.002)\end{array}$ & $\begin{array}{l}-0.007 * * * \\
(0.002)\end{array}$ \\
\hline 4 & & $\begin{array}{l}-0.005 \\
(0.004)\end{array}$ & $\begin{array}{l}-0.003 \\
(0.004)\end{array}$ & $\begin{array}{l}-0.007 \\
(0.004)\end{array}$ & $\begin{array}{l}-0.012 * * * \\
(0.004)\end{array}$ \\
\hline 5 & & $\begin{array}{l}-0.001 \\
(0.010)\end{array}$ & $\begin{array}{l}0.001 \\
(0.009)\end{array}$ & $\begin{array}{l}-0.003 \\
(0.009)\end{array}$ & $\begin{array}{l}-0.011 \\
(0.010)\end{array}$ \\
\hline$\geq 6$ & & $\begin{array}{l}-0.023 * * \\
(0.009)\end{array}$ & $\begin{array}{l}-0.017 * \\
(0.010)\end{array}$ & $\begin{array}{l}-0.019 * * \\
(0.010)\end{array}$ & $\begin{array}{l}-0.029 * * * \\
(0.009)\end{array}$ \\
\hline R-squared & 0.005 & 0.080 & 0.173 & 0.180 & 0.187 \\
\hline
\end{tabular}




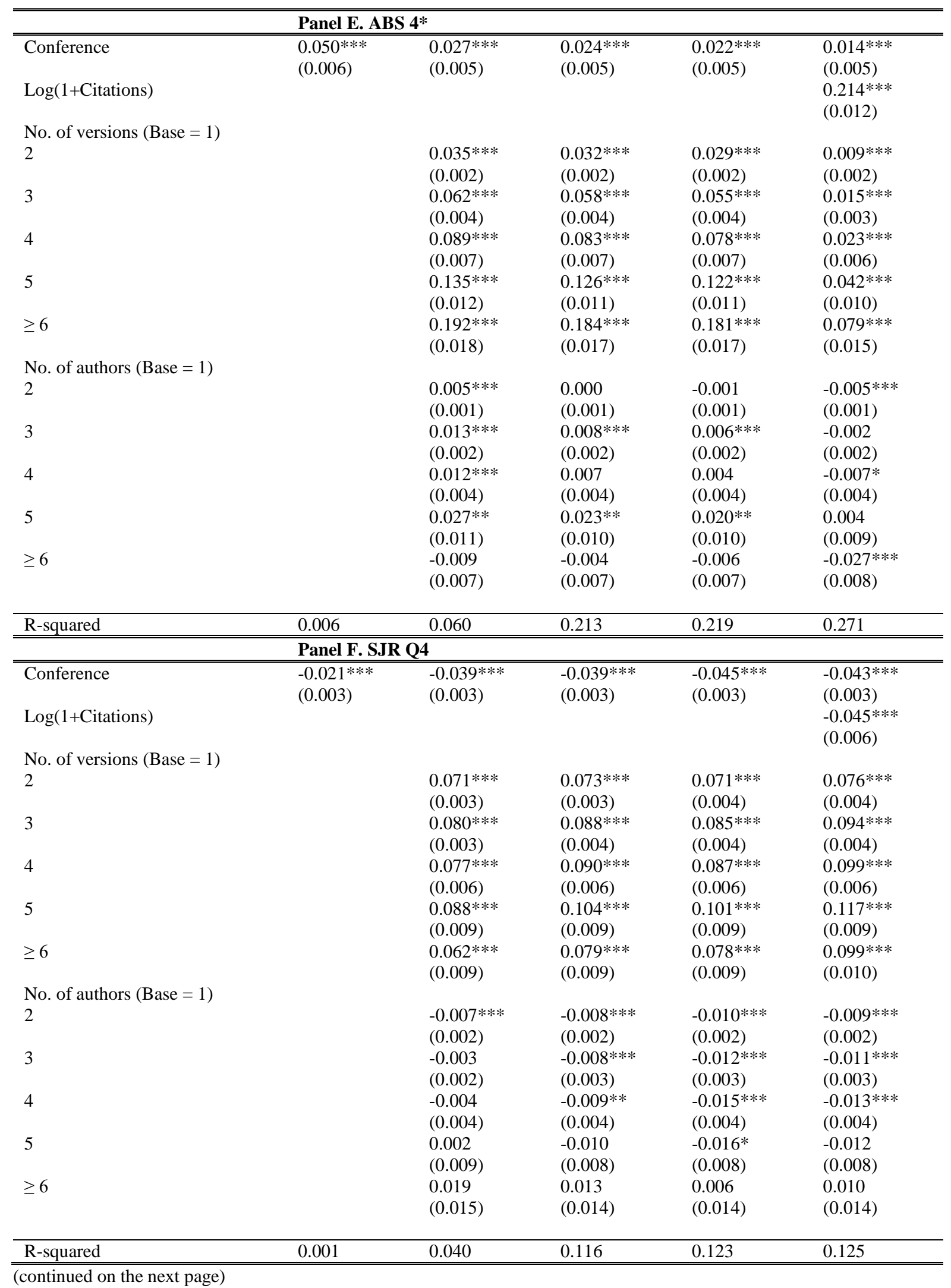




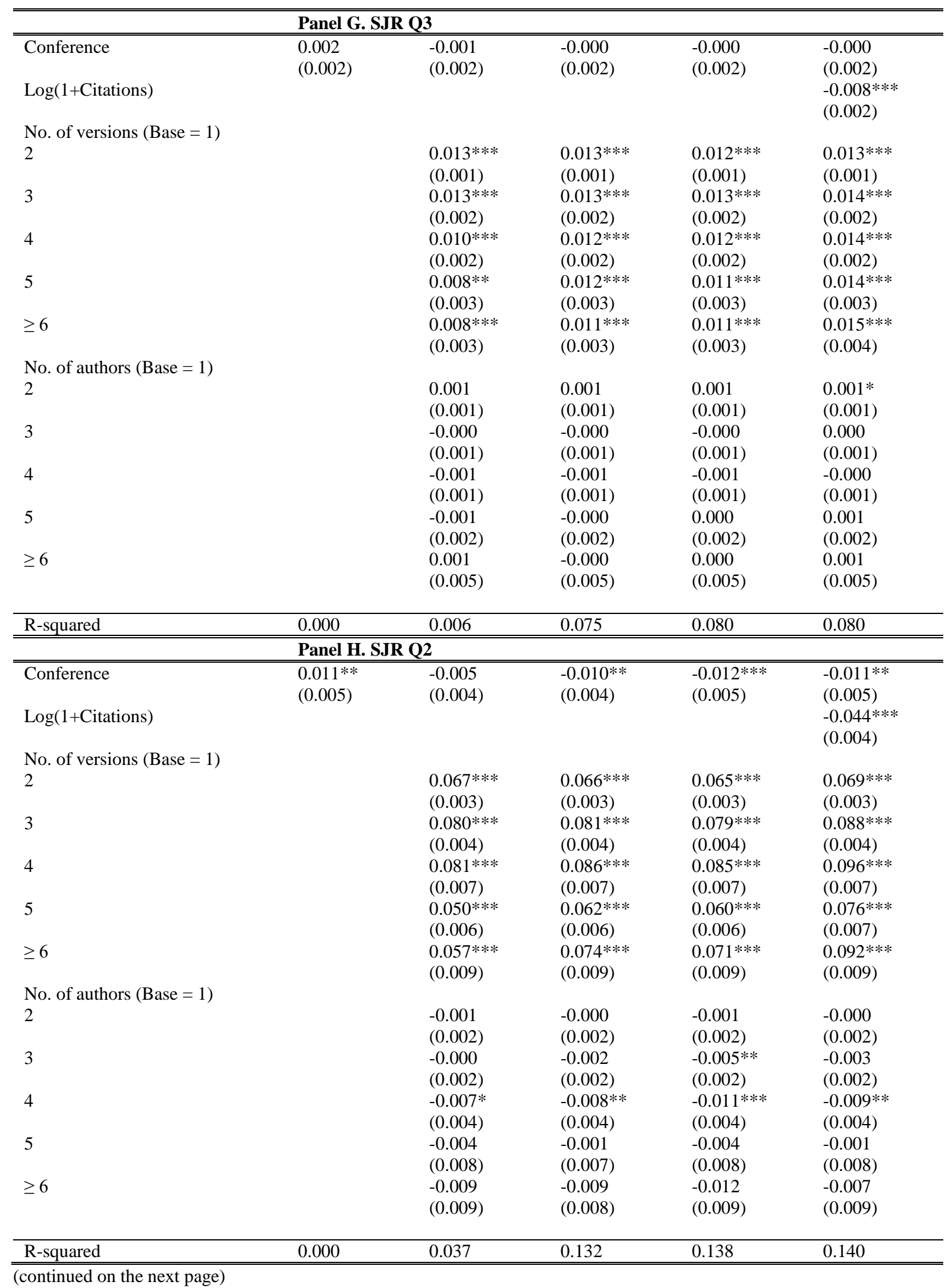




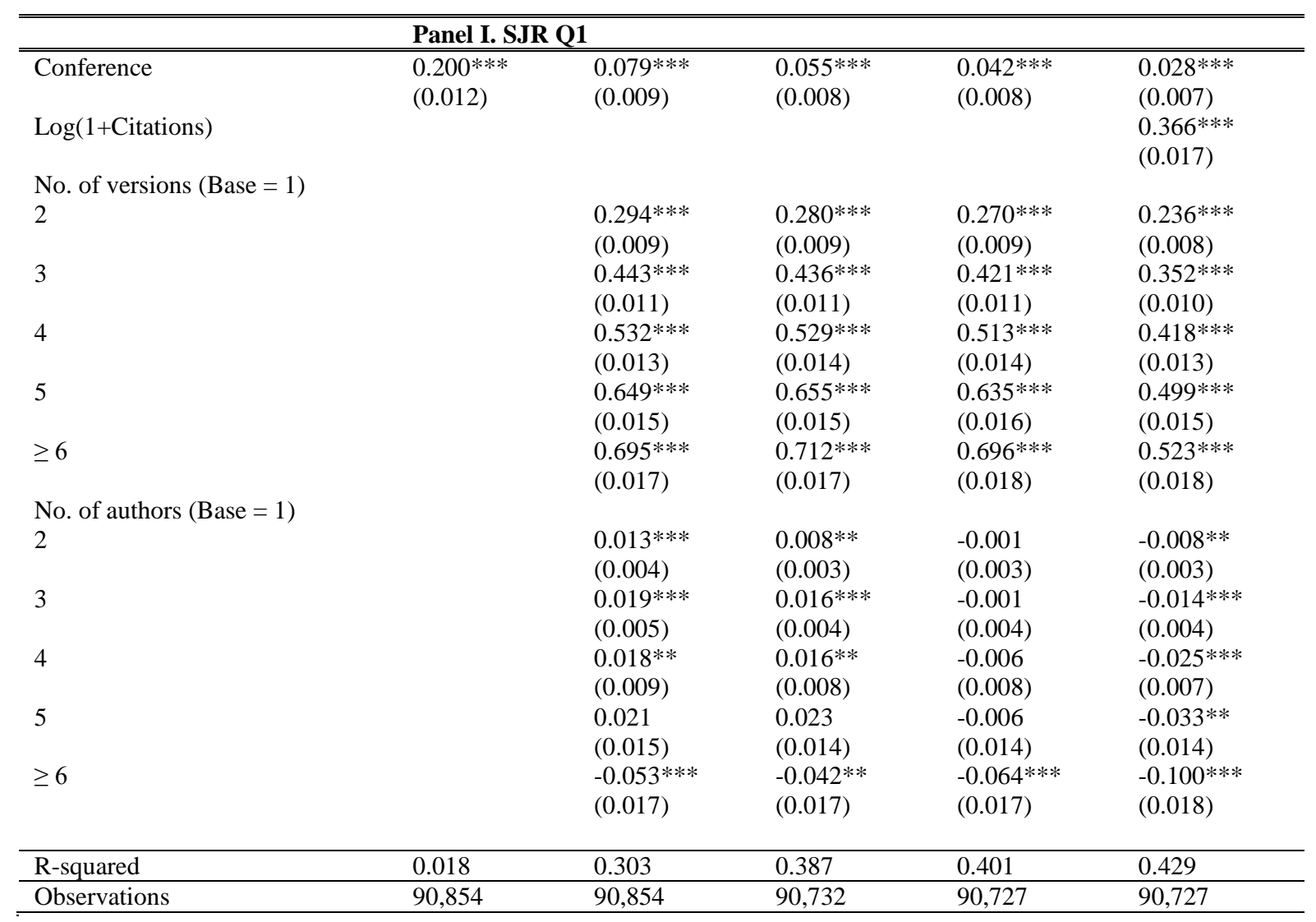

Notes: This table presents results for the link between conference presentation and the probability of being published in the ABS or SJR journals. Conference equals to one if the paper is presented in one of the conferences and zero otherwise. Citations is the average number of citations that the received monthly. No. of versions is the number of versions of the paper. No. of authors is the number of the paper's authors. Column 1 reports results for the estimation without control variables. Columns (2)-(5) report results when control variables are added. Panels A-I show results for publications in the ABS 1-4* journals and SJR Q4-Q1 journals, respectively. Standard errors are clustered by author and date of the first posting. *, **, and *** denote $10 \%, 5 \%$, and $1 \%$ significance level, respectively. 
Appendix Table A5. Conference presentation and publishing (using Scopus citations)

\begin{tabular}{|c|c|c|c|c|c|c|c|c|c|c|}
\hline & (1) & (2) & (3) & (4) & (5) & (6) & (7) & (8) & (9) & (10) \\
\hline & Any & ABS 1 & ABS 2 & ABS 3 & ABS 4 & ABS 4* & SJR Q4 & SJR Q3 & SJR Q2 & SJR Q1 \\
\hline \multirow[t]{2}{*}{ Conference } & 0.001 & -0.010 & $-0.029 * * *$ & -0.018 & $0.040 * * *$ & $0.021 *$ & $-0.052 * * *$ & 0.002 & -0.016 & $0.067 * * *$ \\
\hline & $(0.002)$ & $(0.008)$ & $(0.010)$ & $(0.016)$ & $(0.013)$ & $(0.011)$ & $(0.007)$ & $(0.004)$ & $(0.010)$ & $(0.012)$ \\
\hline \multirow[t]{2}{*}{$\log (1+$ Citations $)$} & $0.004 * * *$ & $-0.044 * * *$ & $-0.042 * * *$ & 0.002 & $0.017 * * *$ & $0.070 * * *$ & $-0.034 * * *$ & $-0.013 * * *$ & $-0.037 * * *$ & $0.088 * * *$ \\
\hline & $(0.001)$ & $(0.003)$ & $(0.003)$ & $(0.005)$ & $(0.003)$ & $(0.003)$ & $(0.003)$ & $(0.002)$ & $(0.003)$ & $(0.004)$ \\
\hline \multicolumn{11}{|c|}{ No. of versions (Base $=1$ ) } \\
\hline \multirow[t]{2}{*}{2} & 0.002 & $-0.123 * * *$ & 0.033 & $0.173 * * *$ & -0.029 & -0.034 & $-0.204 * * *$ & $0.032 * * *$ & $0.062 * *$ & $0.111 * *$ \\
\hline & $(0.012)$ & $(0.045)$ & $(0.043)$ & $(0.053)$ & $(0.047)$ & $(0.027)$ & $(0.051)$ & $(0.008)$ & $(0.027)$ & $(0.055)$ \\
\hline \multirow[t]{2}{*}{3} & 0.006 & $-0.143 * * *$ & 0.013 & $0.179 * * *$ & 0.003 & -0.031 & $-0.211 * * *$ & $0.023 * * *$ & $0.057 * *$ & $0.136 * *$ \\
\hline & $(0.012)$ & $(0.044)$ & $(0.043)$ & $(0.054)$ & $(0.048)$ & $(0.028)$ & $(0.051)$ & $(0.008)$ & $(0.028)$ & $(0.056)$ \\
\hline \multirow[t]{2}{*}{4} & 0.003 & $-0.147 * * *$ & -0.001 & $0.172 * * *$ & 0.011 & -0.027 & $-0.214 * * *$ & $0.021 * * *$ & 0.045 & $0.151 * * *$ \\
\hline & $(0.013)$ & $(0.045)$ & $(0.044)$ & $(0.053)$ & $(0.047)$ & $(0.029)$ & $(0.051)$ & $(0.008)$ & $(0.028)$ & $(0.056)$ \\
\hline \multirow[t]{2}{*}{5} & 0.011 & $-0.146^{* * *}$ & -0.012 & $0.133 * *$ & 0.041 & 0.003 & $-0.196 * * *$ & $0.020 * *$ & 0.005 & $0.183 * * *$ \\
\hline & $(0.012)$ & $(0.046)$ & $(0.044)$ & $(0.054)$ & $(0.051)$ & $(0.031)$ & $(0.052)$ & $(0.008)$ & $(0.028)$ & $(0.057)$ \\
\hline \multirow[t]{2}{*}{$\geq 6$} & 0.012 & $-0.158 * * *$ & -0.041 & $0.119 * *$ & 0.053 & 0.046 & $-0.230 * * *$ & $0.027 * * *$ & 0.019 & $0.196 * * *$ \\
\hline & $(0.013)$ & $(0.045)$ & $(0.044)$ & $(0.058)$ & $(0.052)$ & $(0.034)$ & $(0.051)$ & $(0.009)$ & $(0.027)$ & $(0.056)$ \\
\hline \multicolumn{11}{|c|}{ No. of authors $($ Base $=1)$} \\
\hline \multirow[t]{2}{*}{2} & -0.002 & $-0.017 *$ & -0.010 & 0.019 & 0.011 & 0.004 & $-0.035 * * *$ & 0.005 & -0.004 & $0.032 * *$ \\
\hline & $(0.003)$ & $(0.010)$ & $(0.012)$ & $(0.016)$ & $(0.011)$ & $(0.009)$ & $(0.011)$ & $(0.005)$ & $(0.011)$ & $(0.013)$ \\
\hline \multirow[t]{2}{*}{3} & -0.002 & $-0.022 * *$ & -0.017 & $0.037 * *$ & -0.010 & $0.021 * *$ & $-0.038 * * *$ & 0.006 & -0.004 & $0.034 * *$ \\
\hline & $(0.003)$ & $(0.011)$ & $(0.013)$ & $(0.017)$ & $(0.013)$ & $(0.010)$ & $(0.011)$ & $(0.005)$ & $(0.012)$ & $(0.014)$ \\
\hline \multirow[t]{2}{*}{4} & $-0.010^{*}$ & -0.021 & -0.023 & 0.029 & -0.005 & 0.021 & $-0.046 * * *$ & 0.004 & -0.010 & $0.043 * *$ \\
\hline & $(0.005)$ & $(0.013)$ & $(0.018)$ & $(0.023)$ & $(0.018)$ & $(0.015)$ & $(0.015)$ & $(0.006)$ & $(0.015)$ & $(0.019)$ \\
\hline \multirow[t]{2}{*}{5} & 0.006 & 0.024 & -0.036 & -0.001 & 0.003 & 0.027 & -0.035 & 0.017 & $0.048 *$ & -0.024 \\
\hline & $(0.005)$ & $(0.023)$ & $(0.024)$ & $(0.043)$ & $(0.032)$ & $(0.028)$ & $(0.028)$ & $(0.012)$ & $(0.029)$ & $(0.041)$ \\
\hline \multirow[t]{2}{*}{$\geq 6$} & 0.007 & 0.020 & -0.061 & $0.154 * *$ & -0.041 & -0.053 & 0.023 & -0.002 & -0.003 & -0.011 \\
\hline & $(0.006)$ & $(0.032)$ & $(0.048)$ & $(0.075)$ & $(0.064)$ & $(0.039)$ & $(0.050)$ & $(0.015)$ & $(0.042)$ & $(0.060)$ \\
\hline Author FE & Yes & Yes & Yes & Yes & Yes & Yes & Yes & Yes & Yes & Yes \\
\hline Post Date FE & Yes & Yes & Yes & Yes & Yes & Yes & Yes & Yes & Yes & Yes \\
\hline Observations & 17,286 & 17,286 & 17,286 & 17,286 & 17,286 & 17,286 & 17,286 & 17,286 & 17,286 & 17,286 \\
\hline R-squared & 0.233 & 0.319 & 0.349 & 0.290 & 0.324 & 0.480 & 0.296 & 0.260 & 0.309 & 0.394 \\
\hline
\end{tabular}

Notes: This table presents results for the link between conference presentation and the probability of being published in any journal (Column (1)), ABS 1-4* journals (Columns (2)-(6)), and SJR Q4-Q1 journals (Columns (7)-(10)). Conference equals to one if the paper is presented in one of the conferences and zero otherwise. Citations is the natural $\log$ of one plus the number of citations recorded in Scopus as of August 2020. No. of versions is the number of versions of the paper. No. of authors is the number of the paper's authors. Standard errors are clustered by author and date of the first posting. *, **, and *** denote $10 \%, 5 \%$, and $1 \%$ significance level, respectively. 
Appendix Table A6. Publication time (by SJR quartile)

\begin{tabular}{|c|c|c|c|c|}
\hline & \multicolumn{4}{|c|}{ Publication quality } \\
\hline & SJR Q4 & SJR Q3 & SJR Q2 & SJR Q1 \\
\hline & $(1)$ & $(2)$ & $(3)$ & $(4)$ \\
\hline Conference & $\begin{array}{l}6.141 \\
(5.756)\end{array}$ & $\begin{array}{l}-2.968 \\
(9.128)\end{array}$ & $\begin{array}{l}10.063 * * * \\
(2.231)\end{array}$ & $\begin{array}{l}5.496 * * * \\
(0.537)\end{array}$ \\
\hline $\log (1+$ Citations $)$ & $\begin{array}{l}-9.787 * * \\
(4.331)\end{array}$ & $\begin{array}{l}-34.340 \\
(31.589)\end{array}$ & $\begin{array}{l}-13.724 * * * \\
(4.686)\end{array}$ & $\begin{array}{l}-10.592 * * * \\
(0.705)\end{array}$ \\
\hline \multicolumn{5}{|c|}{ No. of versions (Base $=1$ ) } \\
\hline 2 & $\begin{array}{l}-33.349 * * * \\
(8.518)\end{array}$ & $\begin{array}{l}-49.700 * * * \\
(12.758)\end{array}$ & $\begin{array}{l}9.312 * \\
(5.165)\end{array}$ & $\begin{array}{l}3.610 \\
(4.162)\end{array}$ \\
\hline 3 & $\begin{array}{l}-34.251 \text { *** } \\
(8.527)\end{array}$ & $\begin{array}{l}-29.036 * * \\
(14.284)\end{array}$ & $\begin{array}{l}12.815^{* *} \\
(5.341)\end{array}$ & $\begin{array}{l}7.456^{*} \\
(4.246)\end{array}$ \\
\hline 4 & $\begin{array}{l}-27.945 * * * \\
(8.657)\end{array}$ & $\begin{array}{l}-24.266^{*} \\
(12.605)\end{array}$ & $\begin{array}{l}15.853 * * * \\
(5.493)\end{array}$ & $\begin{array}{l}10.977 * * * \\
(4.187)\end{array}$ \\
\hline 5 & $\begin{array}{l}-17.790^{*} \\
(9.343)\end{array}$ & $\begin{array}{l}-17.502 \\
(22.286)\end{array}$ & $\begin{array}{l}16.949 * * * \\
(6.096)\end{array}$ & $\begin{array}{l}13.203 * * * \\
(4.254)\end{array}$ \\
\hline$\geq 6$ & $\begin{array}{l}-12.260 \\
(9.773)\end{array}$ & $\begin{array}{l}-95.365 * * * \\
(23.733)\end{array}$ & $\begin{array}{l}26.051 * * * \\
(7.800)\end{array}$ & $\begin{array}{l}18.636 * * * \\
(4.484)\end{array}$ \\
\hline \multicolumn{5}{|c|}{ No. of authors $($ Base $=1)$} \\
\hline 2 & $\begin{array}{l}-0.143 \\
(2.518)\end{array}$ & $\begin{array}{l}13.481 * * \\
(5.425)\end{array}$ & $\begin{array}{l}4.151 * * \\
(2.049)\end{array}$ & $\begin{array}{l}2.861 * * * \\
(0.627)\end{array}$ \\
\hline 3 & $\begin{array}{l}2.350 \\
(2.538)\end{array}$ & $\begin{array}{l}8.091 \\
(6.718)\end{array}$ & $\begin{array}{l}4.496 * * \\
(2.191)\end{array}$ & $\begin{array}{l}3.867 * * * \\
(0.692)\end{array}$ \\
\hline 4 & $\begin{array}{l}3.364 \\
(3.855)\end{array}$ & $\begin{array}{l}11.047 \\
(12.636)\end{array}$ & $\begin{array}{l}3.852 \\
(3.209)\end{array}$ & $\begin{array}{l}5.786 * * * \\
(0.934)\end{array}$ \\
\hline 5 & $\begin{array}{l}-1.801 \\
(4.969)\end{array}$ & $\begin{array}{l}1.811 \\
(19.366)\end{array}$ & $\begin{array}{l}0.149 \\
(5.539)\end{array}$ & $\begin{array}{l}2.735 \\
(1.875)\end{array}$ \\
\hline$\geq 6$ & $\begin{array}{l}4.679 \\
(5.689)\end{array}$ & $\begin{array}{l}77.142 \\
(54.025)\end{array}$ & $\begin{array}{l}4.543 \\
(6.931)\end{array}$ & $\begin{array}{l}3.904^{*} \\
(2.078)\end{array}$ \\
\hline Observations & 2,148 & 133 & 2,129 & 17,174 \\
\hline R-squared & 0.617 & 0.967 & 0.555 & 0.415 \\
\hline
\end{tabular}

Notes: This table presents results for the link between conference presentation and the publication time which is duration (in months) between the first posting date and the date the paper appears in the journal. Column 1 reports results for publications in any journal. Columns (1)-(4) report results for publications in SJR Q4-Q1 journals, respectively. Conference equals to one if the paper is presented in one of the conferences and zero otherwise. Citations is the average number of citations that the paper received monthly. 
Appendix Table A7. Conference participation (by conference) and publication outcomes (by SJR quartile)

\begin{tabular}{|c|c|c|c|c|c|c|}
\hline Journal quality & Conference & (1) & (2) & (3) & (4) & (5) \\
\hline SJR Q4 & $\begin{array}{l}\text { AEA } \\
\text { EEA } \\
\text { RES }\end{array}$ & $\begin{array}{l}-0.019 * * * \\
(0.004) \\
-0.020 * * * \\
(0.004) \\
-0.018 * * * \\
(0.004)\end{array}$ & $\begin{array}{l}-0.039 * * * \\
(0.005) \\
-0.036 * * * \\
(0.004) \\
-0.029 * * * \\
(0.004)\end{array}$ & $\begin{array}{l}-0.030 * * * \\
(0.004) \\
-0.039 * * * \\
(0.004) \\
-0.032 * * * \\
(0.005)\end{array}$ & $\begin{array}{l}-0.036 * * * \\
(0.004) \\
-0.044 * * * \\
(0.004) \\
-0.037 * * * \\
(0.005)\end{array}$ & $\begin{array}{l}-0.032 * * * \\
(0.004) \\
-0.044 * * * \\
(0.004) \\
-0.037 * * * \\
(0.005)\end{array}$ \\
\hline SJR Q3 & $\begin{array}{l}\text { AEA } \\
\text { EEA } \\
\text { RES }\end{array}$ & $\begin{array}{l}-0.000 \\
(0.003) \\
0.005 * \\
(0.003) \\
-0.001 \\
(0.002)\end{array}$ & $\begin{array}{l}-0.003 \\
(0.003) \\
0.002 \\
(0.003) \\
-0.003 \\
(0.002)\end{array}$ & $\begin{array}{l}0.000 \\
(0.003) \\
0.002 \\
(0.003) \\
-0.004 * \\
(0.003)\end{array}$ & $\begin{array}{l}0.000 \\
(0.003) \\
0.001 \\
(0.003) \\
-0.005^{*} \\
(0.003)\end{array}$ & $\begin{array}{l}0.001 \\
(0.003) \\
0.001 \\
(0.003) \\
-0.005^{*} \\
(0.003)\end{array}$ \\
\hline SJR Q2 & $\begin{array}{l}\text { AEA } \\
\text { EEA } \\
\text { RES }\end{array}$ & $\begin{array}{l}-0.015 * * * \\
(0.005) \\
0.023^{* * *} \\
(0.006) \\
0.016^{*} \\
(0.009)\end{array}$ & $\begin{array}{l}-0.032 * * * \\
(0.005) \\
0.008 \\
(0.006) \\
0.005 \\
(0.009)\end{array}$ & $\begin{array}{l}-0.017 * * * \\
(0.005) \\
-0.001 \\
(0.006) \\
-0.013 \\
(0.009)\end{array}$ & $\begin{array}{l}-0.020 * * * \\
(0.005) \\
-0.003 \\
(0.006) \\
-0.014 \\
(0.009)\end{array}$ & $\begin{array}{l}-0.015 * * * \\
(0.005) \\
-0.003 \\
(0.006) \\
-0.013 \\
(0.009)\end{array}$ \\
\hline SJR Q1 & $\begin{array}{l}\text { AEA } \\
\text { EEA } \\
\text { RES }\end{array}$ & $\begin{array}{l}0.270 * * * \\
(0.019) \\
0.153 * * * \\
(0.013) \\
0.120 * * * \\
(0.020)\end{array}$ & $\begin{array}{l}0.129 * * * \\
(0.014) \\
0.047 * * * \\
(0.011) \\
0.045 * * * \\
(0.016)\end{array}$ & $\begin{array}{l}0.083 * * * \\
(0.013) \\
0.032 * * * \\
(0.010) \\
0.041 * * * \\
(0.015)\end{array}$ & $\begin{array}{l}0.066^{* * *} * \\
(0.012) \\
0.023 * * \\
(0.010) \\
0.030 * * \\
(0.015)\end{array}$ & $\begin{array}{l}0.029 * * \\
(0.011) \\
0.021 * * \\
(0.010) \\
0.026 * \\
(0.015)\end{array}$ \\
\hline $\begin{array}{l}\text { Author FE } \\
\text { Post Date FE } \\
\text { Controls } \\
\text { Control for citations } \\
\text { Observations }\end{array}$ & & $\begin{array}{l}\text { No } \\
\text { No } \\
\text { No } \\
\text { No } \\
90,854\end{array}$ & $\begin{array}{l}\text { No } \\
\text { No } \\
\text { Yes } \\
\text { No } \\
90,854\end{array}$ & $\begin{array}{l}\text { Yes } \\
\text { No } \\
\text { Yes } \\
\text { No } \\
90,732\end{array}$ & $\begin{array}{l}\text { Yes } \\
\text { Yes } \\
\text { Yes } \\
\text { No } \\
90,727\end{array}$ & $\begin{array}{l}\text { Yes } \\
\text { Yes } \\
\text { Yes } \\
\text { Yes } \\
90,727\end{array}$ \\
\hline
\end{tabular}

Notes: This table presents results for the link between conference presentation by conference and the probability of being published in the SJR Q4-Q1 journals. The reported coefficients are for AEA conference, EEA conference, and RES conference which equal to one if the paper is presented in the AEA, EEA, and RES conferences, respectively; and zero otherwise. Column 1 reports results for the estimation without control variables. Columns (2)-(5) report results when control variables are added. Standard errors are clustered by author and date of the first posting. $* * *$, and $* * *$ denote $10 \%, 5 \%$, and $1 \%$ significance level, respectively. 
Appendix Table A8. Conference participation and publication outcomes by SJR quartile and field

\begin{tabular}{|c|c|c|c|c|c|c|c|}
\hline & Any JEL & Micro Theory & Econometrics & Macro & Applied Micro & $\begin{array}{l}\text { Development } \\
\text { Environment } \\
\end{array}$ & Missing JEL \\
\hline Journal quality & $(1)$ & (2) & (3) & $(4)$ & $(5)$ & $(6)$ & $(7)$ \\
\hline SJR Q1 & $\begin{array}{l}-0.048 * * * \\
(0.003)\end{array}$ & $\begin{array}{l}-0.033 * * * \\
(0.007)\end{array}$ & $\begin{array}{l}-0.040 * * * \\
(0.006)\end{array}$ & $\begin{array}{l}-0.047 * * * \\
(0.005)\end{array}$ & $\begin{array}{l}-0.047 * * * \\
(0.004)\end{array}$ & $\begin{array}{l}-0.045 \text { *** } \\
(0.008)\end{array}$ & $\begin{array}{l}-0.016 * * \\
(0.007)\end{array}$ \\
\hline SJR Q2 & $\begin{array}{c}0.000 \\
(0.002)\end{array}$ & $\begin{array}{c}0.001 \\
(0.004)\end{array}$ & $\begin{array}{l}-0.001 \\
(0.002)\end{array}$ & $\begin{array}{c}0.001 \\
(0.003)\end{array}$ & $\begin{array}{c}0.000 \\
(0.003)\end{array}$ & $\begin{array}{l}-0.001 \\
(0.003)\end{array}$ & $\begin{array}{l}-0.000 \\
(0.004)\end{array}$ \\
\hline SJR Q3 & $\begin{array}{l}-0.014 * * * \\
(0.005)\end{array}$ & $\begin{array}{l}-0.022 * * \\
(0.009)\end{array}$ & $\begin{array}{l}-0.018 * * \\
(0.007)\end{array}$ & $\begin{array}{l}-0.020^{* * *} \\
(0.007)\end{array}$ & $\begin{array}{l}-0.006 \\
(0.007)\end{array}$ & $\begin{array}{l}-0.009 \\
(0.010)\end{array}$ & $\begin{array}{c}0.009 \\
(0.008)\end{array}$ \\
\hline SJR Q4 & $\begin{array}{l}0.026^{* * * *} \\
(0.008)\end{array}$ & $\begin{array}{l}-0.006 \\
(0.018)\end{array}$ & $\begin{array}{c}0.009 \\
(0.016)\end{array}$ & $\begin{array}{c}0.019 \\
(0.012)\end{array}$ & $\begin{array}{c}0.018 \\
(0.011)\end{array}$ & $\begin{array}{c}0.023 \\
(0.019)\end{array}$ & $\begin{array}{c}0.008 \\
(0.014)\end{array}$ \\
\hline Author FE & Yes & Yes & Yes & Yes & Yes & Yes & Yes \\
\hline Post Date FE & Yes & Yes & Yes & Yes & Yes & Yes & Yes \\
\hline Controls & Yes & Yes & Yes & Yes & Yes & Yes & Yes \\
\hline Control for citations & Yes & Yes & Yes & Yes & Yes & Yes & Yes \\
\hline Observations & 59,980 & 15,559 & 16,124 & 26,766 & 28,863 & 12,825 & 29,801 \\
\hline
\end{tabular}

Notes: This table presents results for the link between conference presentation and the probability of being published by SJR quartile and field. The reported coefficients are for Conference variable which equals to one if the paper is presented in one of the conferences and zero otherwise. Columns (1)-(7) reports results for the estimations for papers in any field, in the field of Micro Theory, Econometrics, Macroeconomics, Applied Microeconomics, Development and Environment Economics, and papers whose JEL codes are missing, respectively. Standard errors are clustered by author and date of the first posting. *, **, and *** denote $10 \%, 5 \%$, and $1 \%$ significance level, respectively. 
Appendix Table A9. Spill-over effect (by SJR quartile)

\begin{tabular}{|c|c|c|c|c|}
\hline \multirow{8}{*}{$\begin{array}{l}\text { Author FE } \\
\text { Post Date FE } \\
\text { Controls } \\
\text { Control for citations } \\
\text { Observations }\end{array}$} & \multicolumn{4}{|c|}{ Publication quality } \\
\hline & SJR Q4 & SJR Q3 & SJR Q2 & SJR Q1 \\
\hline & Yes & Yes & Yes & Yes \\
\hline & Yes & Yes & Yes & Yes \\
\hline & Yes & Yes & Yes & Yes \\
\hline & Yes & Yes & Yes & Yes \\
\hline & 90,727 & 90,727 & 90,727 & 90,727 \\
\hline & (1) & (2) & (3) & (4) \\
\hline \multicolumn{5}{|l|}{ Panel A: Any conference } \\
\hline Conference & $\begin{array}{l}-0.044 * * * \\
(0.003)\end{array}$ & $\begin{array}{l}-0.002 \\
(0.002)\end{array}$ & $\begin{array}{l}-0.011 * * \\
(0.005)\end{array}$ & $\begin{array}{l}0.029 * * * \\
(0.008)\end{array}$ \\
\hline Conf. $\times$ Session with Top $1 \%$ & $\begin{array}{l}0.005 \\
(0.006)\end{array}$ & $\begin{array}{l}0.013 \\
(0.009)\end{array}$ & $\begin{array}{l}-0.000 \\
(0.010)\end{array}$ & $\begin{array}{l}-0.011 \\
(0.023)\end{array}$ \\
\hline R-squared & 0.125 & 0.080 & 0.140 & 0.429 \\
\hline \multicolumn{5}{|l|}{ Panel B. AEA } \\
\hline Conference & $\begin{array}{l}-0.034 * * * \\
(0.004)\end{array}$ & $\begin{array}{l}-0.002 \\
(0.002)\end{array}$ & $\begin{array}{l}-0.020 * * * \\
(0.005)\end{array}$ & $\begin{array}{l}0.038 * * * \\
(0.013)\end{array}$ \\
\hline Conf.×Session with Top $1 \%$ & $\begin{array}{l}0.007 \\
(0.010)\end{array}$ & $\begin{array}{l}0.014 \\
(0.010)\end{array}$ & $\begin{array}{l}0.020 \\
(0.013)\end{array}$ & $\begin{array}{l}-0.035 \\
(0.032)\end{array}$ \\
\hline R-squared & 0.122 & 0.080 & 0.140 & 0.428 \\
\hline \multicolumn{5}{|l|}{ Panel C. EEA } \\
\hline Conference & $\begin{array}{l}-0.045^{* * * *} \\
(0.004)\end{array}$ & $\begin{array}{l}0.000 \\
(0.003)\end{array}$ & $\begin{array}{l}-0.002 \\
(0.006)\end{array}$ & $\begin{array}{l}0.020 * * \\
(0.010)\end{array}$ \\
\hline Conf. $\times$ Session with Top $1 \%$ & $\begin{array}{l}-0.007 \\
(0.011)\end{array}$ & $\begin{array}{l}0.015 \\
(0.021)\end{array}$ & $\begin{array}{l}-0.030^{*} \\
(0.018)\end{array}$ & $\begin{array}{l}0.039 \\
(0.042)\end{array}$ \\
\hline R-squared & 0.123 & 0.080 & 0.140 & 0.428 \\
\hline \multicolumn{5}{|l|}{ Panel D. RES } \\
\hline Conference & $\begin{array}{l}-0.041 * * * \\
(0.005)\end{array}$ & $\begin{array}{l}-0.005 \\
(0.003)\end{array}$ & $\begin{array}{l}-0.014 \\
(0.009)\end{array}$ & $\begin{array}{l}0.029 * \\
(0.015)\end{array}$ \\
\hline Conf. $\times$ Session with Top $1 \%$ & $\begin{array}{l}-0.003 \\
(0.009)\end{array}$ & $\begin{array}{l}-0.001 \\
(0.003)\end{array}$ & $\begin{array}{l}0.006 \\
(0.028)\end{array}$ & $\begin{array}{l}-0.027 \\
(0.060)\end{array}$ \\
\hline R-squared & 0.122 & 0.080 & 0.140 & 0.428 \\
\hline
\end{tabular}

Notes: This table presents results for the link between conference presentation and the probability of being published, controlling for the spill-over effect of having a star scholar in the session (specification 4.1). Columns (1)-(4) report results for publications in SJR Q4-Q1 journals, respectively. Conference equals to one if the paper is presented and zero otherwise. Session with Top 1\% equals to one if the paper is presented in the session of which any author of other papers has been in top one percent of the IDEAS/RePEc Top Economist ranking and zero otherwise. Standard errors are clustered by author and date of the first posting. *, **, and *** denote $10 \%$, $5 \%$, and $1 \%$ significance level, respectively. 
Appendix Table A10. Prominent author effect (by SJR quartile)

\begin{tabular}{|c|c|c|c|c|}
\hline \multirow{9}{*}{$\begin{array}{l}\text { Author FE } \\
\text { Post Date FE } \\
\text { Controls } \\
\text { Control for citations } \\
\text { Control for author ranking } \\
\text { Observations }\end{array}$} & \multicolumn{4}{|c|}{ Publication quality } \\
\hline & SJR Q4 & SJR Q3 & SJR Q2 & SJR Q1 \\
\hline & Yes & Yes & Yes & Yes \\
\hline & Yes & Yes & Yes & Yes \\
\hline & Yes & Yes & Yes & Yes \\
\hline & Yes & Yes & Yes & Yes \\
\hline & Yes & Yes & Yes & Yes \\
\hline & 90,727 & 90,727 & 90,727 & 90,727 \\
\hline & $(1)$ & (2) & (3) & (4) \\
\hline \multicolumn{5}{|l|}{ Panel A. Any conference } \\
\hline Conference & $\begin{array}{l}-0.045^{* * * *} \\
(0.003)\end{array}$ & $\begin{array}{l}-0.001 \\
(0.002)\end{array}$ & $\begin{array}{l}-0.011 * * \\
(0.005)\end{array}$ & $\begin{array}{l}0.024 * * * \\
(0.008)\end{array}$ \\
\hline Conf. $\times$ Paper with Top $1 \%$ & $\begin{array}{l}0.015^{*} \\
(0.009)\end{array}$ & $\begin{array}{l}0.005 \\
(0.007)\end{array}$ & $\begin{array}{l}-0.000 \\
(0.010)\end{array}$ & $\begin{array}{l}0.033 \\
(0.022)\end{array}$ \\
\hline R-squared & 0.125 & 0.080 & 0.140 & 0.429 \\
\hline \multicolumn{5}{|l|}{ Panel B. AEA } \\
\hline Conference & $\begin{array}{l}-0.036 * * * \\
(0.005)\end{array}$ & $\begin{array}{l}-0.002 \\
(0.002)\end{array}$ & $\begin{array}{l}-0.019 * * * \\
(0.005)\end{array}$ & $\begin{array}{l}0.031 * * \\
(0.013)\end{array}$ \\
\hline Conf. $\times$ Paper with Top $1 \%$ & $\begin{array}{l}0.017 * \\
(0.010) \\
\end{array}$ & $\begin{array}{l}0.015 \\
(0.010)\end{array}$ & $\begin{array}{l}0.018 \\
(0.012)\end{array}$ & $\begin{array}{l}-0.004 \\
(0.030) \\
\end{array}$ \\
\hline R-squared & 0.122 & 0.080 & 0.140 & 0.429 \\
\hline \multicolumn{5}{|l|}{ Panel C. EEA } \\
\hline Conference & $\begin{array}{l}-0.046^{* * * *} \\
(0.004)\end{array}$ & $\begin{array}{l}0.001 \\
(0.003)\end{array}$ & $\begin{array}{l}-0.002 \\
(0.006)\end{array}$ & $\begin{array}{l}0.016 \\
(0.010)\end{array}$ \\
\hline Conf. $\times$ Paper with Top $1 \%$ & $\begin{array}{l}0.006 \\
(0.015)\end{array}$ & $\begin{array}{l}0.003 \\
(0.014)\end{array}$ & $\begin{array}{l}-0.025 \\
(0.019)\end{array}$ & $\begin{array}{l}0.081 * * \\
(0.036)\end{array}$ \\
\hline R-squared & 0.123 & 0.080 & 0.140 & 0.429 \\
\hline \multicolumn{5}{|l|}{ Panel D. RES } \\
\hline Conference & $\begin{array}{l}-0.040 * * * \\
(0.006)\end{array}$ & $\begin{array}{l}-0.004 \\
(0.003)\end{array}$ & $\begin{array}{l}-0.012 \\
(0.009)\end{array}$ & $\begin{array}{l}0.026 \\
(0.016)\end{array}$ \\
\hline Conf. $\times$ Paper with Top $1 \%$ & $\begin{array}{l}-0.018 \\
(0.011)\end{array}$ & $\begin{array}{l}-0.005 \\
(0.004)\end{array}$ & $\begin{array}{l}-0.015 \\
(0.027)\end{array}$ & $\begin{array}{l}0.026 \\
(0.064)\end{array}$ \\
\hline R-squared & 0.122 & 0.080 & 0.140 & 0.429 \\
\hline
\end{tabular}

Notes: This table presents results for the link between conference presentation and the probability of being published, controlling for the effect of having a star scholar in the author team (specification 4.2). Columns (1)(4) report results for publications in SJR Q4-Q1 journals, respectively. Panels A-D report results for presentation in any conference, in AEA, EEA, and RES conferences, respectively. Conference equals to one if the paper is presented and zero otherwise. Paper with Top 1\% equals to one if at least one of the authors of the paper has been in top one percent of the IDEAS/RePEc Top Economist ranking and zero otherwise. Standard errors are clustered by author and date of the first posting. $* * *$, and $* * *$ denote $10 \%, 5 \%$, and $1 \%$ significance level, respectively. 
Appendix Table A11. Gender effect (by SJR quartile)

\begin{tabular}{|c|c|c|c|c|}
\hline \multirow[b]{3}{*}{ Journal quality } & \multicolumn{2}{|c|}{ Unmatched sample } & \multicolumn{2}{|c|}{ Matched sample } \\
\hline & Female & Male & Female & Male \\
\hline & (1) & $(2)$ & (3) & (4) \\
\hline SJR Q4 & $\begin{array}{l}-0.039 * * * \\
(0.005)\end{array}$ & $\begin{array}{l}-0.044 * * * \\
(0.004)\end{array}$ & $\begin{array}{l}-0.037 * * * \\
(0.005)\end{array}$ & $\begin{array}{l}-0.041 * * * \\
(0.005)\end{array}$ \\
\hline SJR Q3 & $\begin{array}{c}0.000 \\
(0.004)\end{array}$ & $\begin{array}{l}-0.000 \\
(0.002)\end{array}$ & $\begin{array}{c}0.003 \\
(0.005)\end{array}$ & $\begin{array}{l}-0.003 \\
(0.003)\end{array}$ \\
\hline SJR Q2 & $\begin{array}{l}-0.013 * \\
(0.007)\end{array}$ & $\begin{array}{l}-0.011^{* *} \\
(0.005)\end{array}$ & $\begin{array}{l}-0.017^{* *} \\
(0.009)\end{array}$ & $\begin{array}{l}-0.007 \\
(0.007)\end{array}$ \\
\hline SJR Q1 & $\begin{array}{c}0.000 \\
(0.014)\end{array}$ & $\begin{array}{l}0.033 * * * \\
(0.008)\end{array}$ & $\begin{array}{l}-0.004 \\
(0.016)\end{array}$ & $\begin{array}{l}0.023 * * \\
(0.009)\end{array}$ \\
\hline Author FE & Yes & Yes & Yes & Yes \\
\hline Post Date FE & Yes & Yes & Yes & Yes \\
\hline Controls & Yes & Yes & Yes & Yes \\
\hline Control for citations & Yes & Yes & Yes & Yes \\
\hline Observations & 11,448 & 79,263 & 7,220 & 28,830 \\
\hline
\end{tabular}

Notes: This table presents the comparison of the link between conference presentation and the probability of being published between female (Columns (1) and (3)) and male authors (Columns (2) and (4)). Columns (1)-(2) report results for unmatched samples. Columns (3)-(4) report results for matched samples. The reported coefficients are for Conference variable which equals to one if the paper is presented in one of the conferences and zero otherwise. $*$, **, and $* * *$ denote $10 \%, 5 \%$, and $1 \%$ significance level, respectively. 
Appendix Table A12. Conference participation and Scopus citations

\begin{tabular}{|c|c|c|c|c|}
\hline & $(1)$ & $(2)$ & (3) & $(4)$ \\
\hline Conference & $\begin{array}{l}0.178 * * * \\
(0.045)\end{array}$ & $\begin{array}{l}0.105 * * \\
(0.041)\end{array}$ & $\begin{array}{l}0.140 * * * \\
(0.035)\end{array}$ & $\begin{array}{l}0.193 * * * \\
(0.034)\end{array}$ \\
\hline \multicolumn{5}{|c|}{ No. of versions $($ Base $=1)$} \\
\hline 2 & & $\begin{array}{l}1.012 * * * \\
(0.106)\end{array}$ & $\begin{array}{l}0.965 * * * \\
(0.100)\end{array}$ & $\begin{array}{l}0.764 * * * \\
(0.106)\end{array}$ \\
\hline 3 & & $\begin{array}{l}1.213 * * * \\
(0.112)\end{array}$ & $\begin{array}{l}1.147 * * * \\
(0.104)\end{array}$ & $\begin{array}{l}0.931 * * * \\
(0.107)\end{array}$ \\
\hline 4 & & $\begin{array}{l}1.312 * * * \\
(0.113)\end{array}$ & $\begin{array}{l}1.216 * * * \\
(0.106)\end{array}$ & $\begin{array}{l}0.977 * * * \\
(0.109)\end{array}$ \\
\hline 5 & & $\begin{array}{l}1.526 * * * \\
(0.119)\end{array}$ & $\begin{array}{l}1.339 * * * \\
(0.111)\end{array}$ & $\begin{array}{l}1.105^{* * *} \\
(0.115)\end{array}$ \\
\hline 6 & & $\begin{array}{l}1.663^{* * * *} \\
(0.128)\end{array}$ & $\begin{array}{l}1.412 * * * \\
(0.114)\end{array}$ & $\begin{array}{l}1.182 * * * \\
(0.116)\end{array}$ \\
\hline \multicolumn{5}{|c|}{ No. of authors $($ Base $=1)$} \\
\hline 2 & & $\begin{array}{l}0.231 * * * \\
(0.042)\end{array}$ & $\begin{array}{l}0.112 * * * \\
(0.037)\end{array}$ & $\begin{array}{l}0.181 * * * \\
(0.036)\end{array}$ \\
\hline 3 & & $\begin{array}{l}0.404 * * * \\
(0.045)\end{array}$ & $\begin{array}{l}0.203 * * * \\
(0.042)\end{array}$ & $\begin{array}{l}0.334 * * * \\
(0.042)\end{array}$ \\
\hline 4 & & $\begin{array}{l}0.473 * * * \\
(0.066)\end{array}$ & $\begin{array}{l}0.243 * * * \\
(0.053)\end{array}$ & $\begin{array}{l}0.429 * * * \\
(0.051)\end{array}$ \\
\hline 5 & & $\begin{array}{l}0.834 * * * \\
(0.104)\end{array}$ & $\begin{array}{l}0.504 * * * \\
(0.086)\end{array}$ & $\begin{array}{l}0.671 * * * \\
(0.080)\end{array}$ \\
\hline 6 & & $\begin{array}{l}0.852 * * * \\
(0.253)\end{array}$ & $\begin{array}{l}0.844 * * * \\
(0.137)\end{array}$ & $\begin{array}{l}1.073 * * * \\
(0.149)\end{array}$ \\
\hline Author FE & No & No & Yes & Yes \\
\hline Post Date FE & No & No & No & Yes \\
\hline Observations & 18,230 & 18,230 & 17,300 & 17,286 \\
\hline R-squared & 0.002 & 0.050 & 0.478 & 0.518 \\
\hline
\end{tabular}

Notes: This table presents results for the link between conference presentation and the number of Scopus citations received by a paper (specification (5)). Conference equals to one if the paper is presented in one of the conferences and zero otherwise. Citations is the natural log of one plus the number of Scopus citations that the paper received as of August 2020. No. of versions is the number of versions of the paper. No. of authors is the number of the paper's authors. Standard errors are clustered by author and date of the first posting. *, **, and *** denote $10 \%$, $5 \%$, and $1 \%$ significance level, respectively. 
Appendix Table A13. Conference participation (by conference) and publication outcomes (by quality) - LASSO

\begin{tabular}{|c|c|c|c|c|c|c|c|c|c|c|}
\hline & Any & 1 & 2 & 3 & 4 & $4 *$ & SJR Q4 & SJR Q3 & SJR Q2 & SJR Q1 \\
\hline & (1) & (2) & (3) & (4) & $(5)$ & (6) & (7) & (8) & (9) & (10) \\
\hline Conference & 0.008 & -0.000 & & 0.001 & 0.014 & 0.011 & -0.025 & & & 0.041 \\
\hline $\log (1+$ Citations $)$ & 0.245 & -0.025 & -0.008 & 0.047 & 0.117 & 0.242 & -0.017 & -0.002 & -0.004 & 0.381 \\
\hline \multicolumn{11}{|c|}{ No. of versions (Base $=1$ ) } \\
\hline 2 & 0.390 & 0.046 & 0.073 & 0.157 & 0.046 & 0.001 & 0.061 & 0.010 & 0.047 & 0.213 \\
\hline 3 & 0.530 & 0.048 & 0.085 & 0.219 & 0.083 & 0.000 & 0.069 & 0.009 & 0.056 & 0.314 \\
\hline 4 & 0.589 & 0.045 & 0.065 & 0.230 & 0.109 & 0.005 & 0.063 & 0.006 & 0.050 & 0.358 \\
\hline 5 & 0.633 & 0.037 & 0.047 & 0.228 & 0.135 & 0.017 & 0.070 & 0.002 & 0.008 & 0.407 \\
\hline$\geq 6$ & 0.624 & 0.020 & 0.008 & 0.205 & 0.142 & 0.046 & 0.042 & 0.001 & 0.010 & 0.399 \\
\hline \multicolumn{11}{|c|}{ No. of authors $($ Base $=1)$} \\
\hline 2 & & & & & 0.002 & & -0.001 & & & \\
\hline 3 & & & & 0.001 & & 0.001 & & & & \\
\hline 4 & & & & & -0.000 & & & & & \\
\hline \multicolumn{11}{|l|}{5} \\
\hline$\geq 6$ & -0.003 & & & & -0.011 & -0.012 & 0.001 & & & -0.003 \\
\hline
\end{tabular}

Notes: This table presents results for the link between conference presentation and the probability of being published in any journal, in the ABS 1-4* journals, and in the SJR Q4-Q1 journals (Columns 1-10) using LASSO (Least Absolute Shrinkage and Selection Operator) method for estimation. The optimal penalty level is chosen based on the Extended Bayesian Information Criterion (EBIC). Conference equals to one if the paper is presented in one of the conferences and zero otherwise. Citations is the average number of citations that the received monthly. No. of versions is the number of versions of the paper. No. of authors is the number of the paper's authors. Author fixed effect is controlled for. Missing coefficient means the coefficient estimate is not selected into the model. 
Appendix Table A14. Presentation slots of papers authored by well-known vs lesser-known authors

\begin{tabular}{llllllll}
\hline \hline Conference & Top 1\% authors & Morning & $1^{\text {st }}$ day & $2^{\text {nd }}$ day & $3^{\text {rd }}$ day & $4^{\text {th }}$ day & $5^{\text {th }}$ day \\
\hline$(1)$ & $(2)$ & $(3)$ & $(4)$ & $(5)$ & $(6)$ & $(7)$ & $(8)$ \\
\hline AEA & No & 71.58 & 36.63 & 27.51 & 35.87 & & \\
& Yes & 71.29 & 33.80 & 36.92 & 29.29 & & \\
EEA & No & 9.48 & 15.35 & 21.71 & 24.83 & 25.27 & 12.85 \\
& Yes & 16.11 & 11.15 & 22.92 & 25.28 & 27.88 & 12.76 \\
\multirow{2}{*}{ RES } & No & 29.87 & 24.82 & 41.09 & 34.08 & & \\
& Yes & 31.50 & 25.20 & 39.63 & 35.17 & & \\
\hline \hline
\end{tabular}

Notes: This table presents the distribution of papers authored by well-known and less known authors by time slots of the presentations. A well-known author is the scholar who has been in the top $1 \%$ of the Top Economist ranking. A less-known author is the scholar who has never been in this ranking. 


\section{Appendix B: Journal quality rankings}

The quality of scientific journals can be evaluated using different metrics such as the number of works published or the significance of published works. Thus, there is no consensus across countries and institutions regarding journal quality rankings/indicators used for publication/research evaluation: some countries/institution create their own rankings while some others use the wellestablished rankings. ${ }^{25}$ In this section, we will provide a brief overview of three well-known journal quality rankings/indicators of journal quality namely the Journal Citation Reports (JCR), the SCIMAGO Journal and Country Rank (SJR), and the Academic Journal Guide by Chartered Association of Business Schools (ABS).

In the JCR ranking, ranks are based on journals' citation impact within their discipline. A journal's impact factor is a ratio between the current year citations to articles published in the previous two years and the total number of articles published in the previous two years. In each disciplinary category, journals are divided into four quartiles where Q1 is occupied by the most impactful journals, i.e., the highest quality journals. The impact factor of a journal is updated on yearly basis, thus, the journal's JSR ranking might vary over time.

The SJR impact index is developed based on the Google PageRank's algorithm which takes into account the "prestige" of citations, i.e., a citation from a journal with a higher SJR index receives more weight in calculating the final impact index. Similar to the JCR ranking, within each subject category, journals are divided into four quartiles where Q1 includes the most prestigious journals. It should be noted that despite the different methodologies, the SJR and JCR impact factors of journals are highly correlated (Sicilia et al., 2011; Brown and Gutman, 2017). Hence, these two rankings are widely used as alternative tools to evaluate research impact/quality in many academic/research institutions in the US, Europe (e.g., Germany, Portugal), and Asia (e.g., Singapore, Hongkong). ${ }^{26}$

Different from the above rankings, the ABS ranking only focuses on social science subjects; particularly business, management, and economics. Each journal included in this ranking has a rating of either $1,2,3,4$, or $4 *$ in which the $4 *$ journals are considered the highest quality ones. The ratings are based on (1) peer review, (2) citation statistics, and (3) editorial judgements. Given that the ABS is a UK-based ranking, it is mostly used by UK universities. That said, a growing number of

\footnotetext{
${ }^{25}$ https://editorresources.taylorandfrancis.com/understanding-research-metrics/journal-ranking-lists/ 26 See, for example, https://libguides.library.cityu.edu.hk/researchimpact/impact-of-journals; https://ucsd.libguides.com/ResearchImpact/JournalImpact; https://guides.library.cornell.edu/impact/journalimpact; $\quad$ https://guides.lib.umich.edu/c.php?g=282982\&p=3409184; $\quad$ https://www.umm.uniheidelberg.de/medical-faculty-mannheim/library/search-find/journals/journal-rankings/; https://libguides.nus.edu.sg/researchimpact/journal.
} 
business/management schools in other countries such as Ireland have been also used the ABS ranking as a guide to evaluate research. 